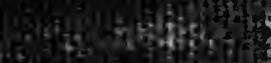

$$
\text { a }
$$

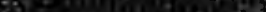

Fo

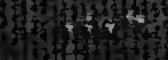

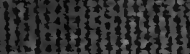

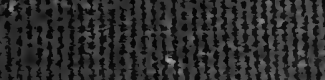
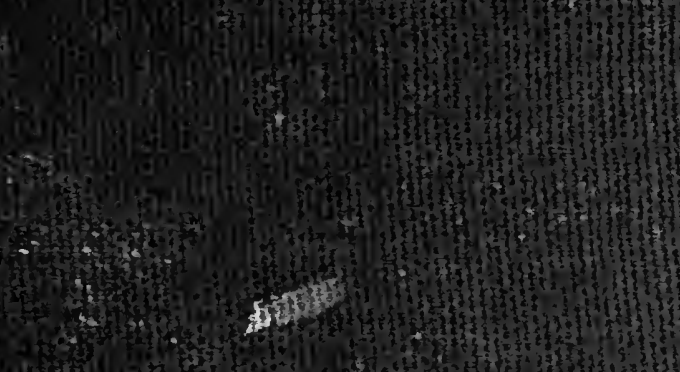

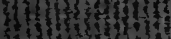

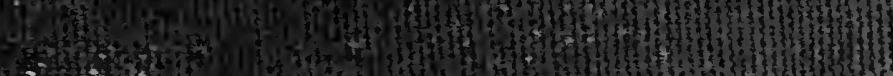

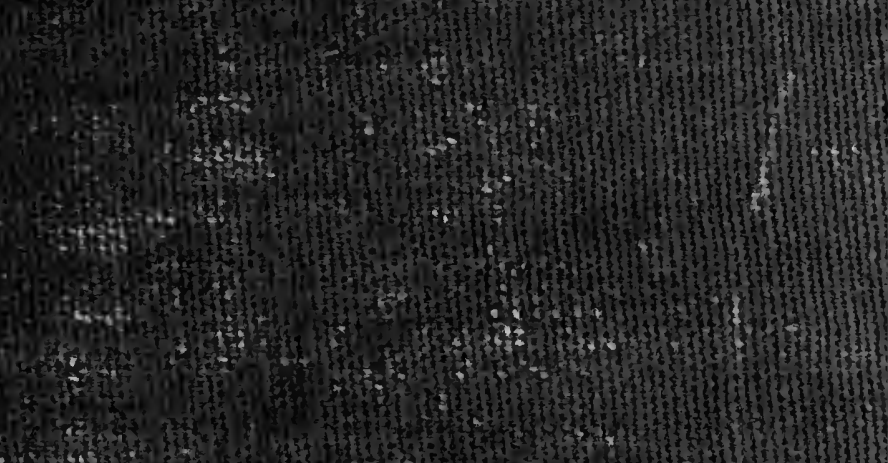
liforn.

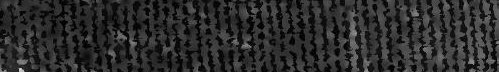

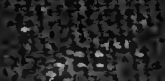
onal ity ald (39XY)

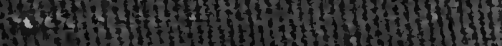

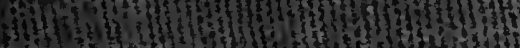
3. 4.t2 alst) 

le last date stamped below

$R J$
61
$D 41$

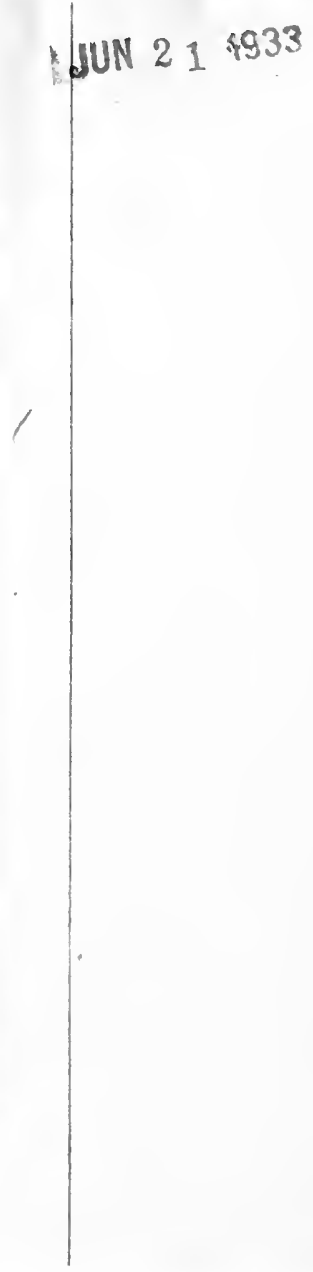


Digitized by the Internet Archive in 2007 with funding from Microsoft Corporation 




\section{THE HEALTHY BABY}




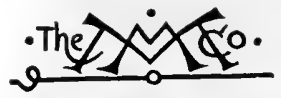

THE MACMILLAN COMPANY

NEW YORK - BOSTON - CHICAGO

DALLAS - SAN FRANCISCO

MACMILLAN \& CO., LiMited

LONDON - BOMBAY - CALCUTTA

MELBOURNE

THE MACMILLAN CO. OF CANADA, Ltd. TORONTO 


\section{THE HEALTHY BABY}

THE CARE AND FEEDING OF INFANTS IN SICKNESS AND IN HEALTH

BY

ROGER H. DENNETT, M.D.

INSTRUCTOR IN DISEASES OF CHILDREN IN THE NEW YORK POST-GRADUATE MEDICAL SCHOOL; ASSISTANT ATTENDING PHYSICIAN TO THE BABIES' WARDS IN THE NEW YORK POST-GRADUATE HOSPITAL; CHIEF OF CLINIC IN THE POST-GRADUATE DISPENSAKY FOR CHILDREN ; FELLOW OF THE NEW YORK ACADEMY OF MEDICINE

NTem 10utk THE MACMILLLAN COMPANY 1920 
Coptrieht, 1912,

BY THE MaCMILlaN COMPANY.

Set up and electrotyped. Published May, igiz.

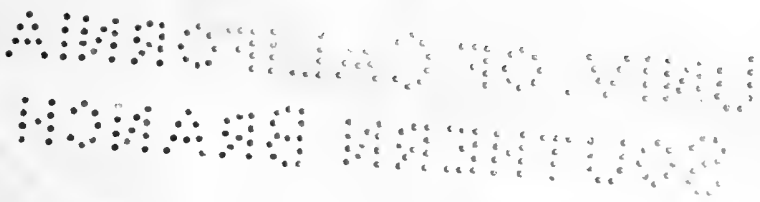

\section{$8+8$}

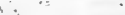

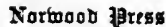

J.S. Cushing Co. - Berwick \& Smith Co. Norwood, Mass., U.S.A. 


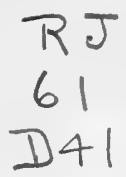

\section{Deotcation}

TO ALL CHILDREN AND ESPECIALLY

TO MY OWN CHILDREN

\section{ALICE, NANCY, AND SALLY}

WHO HAVE BEEN THE CHIEF INSPIRATION

IN MY STUDY OF CHILD WELFARE

THIS BOOK IS DEDICATED 


\section{.}




\section{PREFACE}

THE author's chief reason for writing this book was to make clear to the mother just how to do best the ordinary everyday things that every mother has to do for her child. $\mathrm{He}$ believes that there is a definite need for a book, which will describe in the minutest detail the daily care of the baby. The description or treatment of any but the simplest ailments has purposely been left out, because a book of this sort which attempts in any way to describe diseases, does more harm than it does good. A well-trained physician or a specialist in children's diseases finds it difficult enough at times to diagnose the different affections, and it only confuses the mother or nurse to describe the different diseases to her.

The chapter on feeding has purposely been cut down, and all complicated formulas omitted. Probably more harm has been done than can possibly be estimated, by giving to mothers sets of complicated formulas which she tries to 
use herself. She experiments first with one and then with another until she ruins her baby's digestion. I describe the simplest kinds of milk, water, and sugar mixtures, and if these do not agree with the baby, I would most emphatically recommend seeking the physician's help. . Feeding bottle babies is one of the most difficult things we have to deal with.

121 East 38th Street,

NEW YoRK. 


\section{CONTENTS}

PAGB

INTRODUCTORY $\quad$ - . . . . . . xiii

\section{PART I}

DEVELOPMENT AND THE BODILY FUNCTIONS

Developuent of Body AND Mind . . . . 3

- Sleep . . • • . . .

Crying . . . . . . . . . . . 17

APpetite . • . . . . . . . 20

VoMiting . . . . . . . . . 24

THE Bowels . . . . . . . . 28

\section{PART II}

HYGIENE AND TRAINING

C Clothing . . . . . . . . . . 41

¿ The Bath . . . . . . . . . 49

Fresh AIr . . . . . . . . 53

\& Exercise . . . . . . . . . 58

Training and Discipline • • • • . . 62

Daily Rodtine . . . . . . . 68

Habits . . . . . . . . . . 71 


\section{PAR'T III \\ COMMON AILMENTS}

THE Sick RoOM . . . . . . . 79

Contagious Diseases . . . . . . . 81

Fever . . . . . . . . . . 90

Colos and Covghs . . . . . . . . 92

Crour . . . . . . . . . . . 95

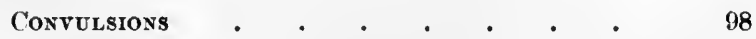

ACCIDENTS . . . . . . . . . 101

Bed-Wetting . . . . . . . $109^{\circ}$

WorMs . . . . . . . . . 113

The Nervous Child - . . . . . . . 115

\section{PART IV}

CARE OF THE SPECIAL ORGANS

The Throat

The Teeth . . . . . . . . . 124

The Eyes . . . . . . . . 130

The Ears . . . . . . . . 132

The SkIN . . . . . . . . . 134

The Hair . . . . . . . . . 137

The Genital Organs. . . . . . 139

\section{PART V}

FEEDING AND 1)IET

Breast Feeding. • . . . . . . 147

WeANING • • • • • • • • • 155 
PAGI

The Bottle and Nipples . . . . . . 162

MrLK • . . . . . . . • . 165

Mixing and Care of the Food . . . 169

The Composition and Strength of the Food 172

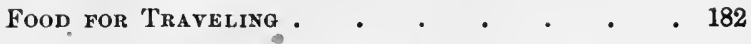

The Diet after The First Year • • • 183

Diet for Sick Children . • • • • 197

WATER . • • . • • • . . 201

\section{PART VI}

\section{IISTS AND TABLES}

List for Expectant Mother . . . . . 207

For the Baby's Basket . . . . . . 207

Clothes . . . • • • • . 208

Table of Height . . . . . . . 208

Table of Weight . • . • . . . 208

Number of Pulse Beats Per Minute . • 209

Number of Respirations per Mindte • . 209

Table of Poisons and Antidotes . . . 210

Mejorandum . $\quad . \quad$. . . . 213 



\section{INTRODUCTORY}

THE average mother has a keen sense of The Duties duty toward her children, and it is only her of Parentduty toward her children, and it is only her hood. lack of knowledge, when this duty is first thrust upon her, that prevents her from bringing up the baby in model fashion. In these days of artificial living, it requires constant watchfulness and hard work and devotion to carry the child through infancy and childhood in such a manner that he may reach adult life sound in body and in mind. The more normal the individual the better chance he has to succeed in later life. The vast majority of abnormalities start in the early years. The baby whose digestion is ruined by wrong feeding may grow up to be a dyspeptic adult, who can neither do his share of work in the world nor receive his share of pleasure out of it. The child whose adenoids are neglected not only may have colds and catarrh for the rest of his life, but he is less alert mentally and consequently backward in his studies. Lack of suc-

Success in Later Life dependent upon a Normal Start. 
cess in life is due, in many cases, to physical defects that might have been avoided by an intelligent bringing up.

The bowels, the skin, the hair, the teeth, the habits, and all the functions, therefore, should be carefully studied.

We should send our children out in life equipped with the right kind of body, as well as the right kind of mind. I realize fully that a mother has other duties than these toward her children. However, the mother who takes care of her own children will find it less work to do so in the proper modern way than did the mother of former generations, who carried the baby about in her arms while at work or rocked the cradle while she sewed. The mother who employs a nurse should devote some of her time to the baby and should supervise all its care. To do this, she must know how. It is bad policy to have a poor nurse and a good cook; if a choice must be made between the two, the nurse should have the superior intelligence.

There are constantly being brought to me children of all ages who are thin and flabby, or who perhaps cry a good deal, or have one or more signs of ill health which the mother either has not observed or, observing, has thought were 
either common to all babies, or peculiar to her Signs of own. It would, therefore, be well first to list Health. the things that denote good health, and later to consider each in detail. Every well child of any age should : -

(1) Show progressive development of body and mind.

(2) Gain constantly in weight, and have solid flesh and well-shaped bones.

(3) Have the proper amount of restful sleep.

(4) Cry but little.

(5) Have a good appetite.

(6) Have well-regulated bowels.

(7) Have no vomiting or gas.

(8) Have a clear skin and good color.

If the baby does not come up to this standard, we may know that something is wrong, and we must set ourselves the task of finding out what that thing is. It is much easier to prevent an illness than it is to cure one. With this fact in mind this book is written. 



\section{PART I}

\section{DEVELOPMENT AND THE BODILY FUNCTIONS}





\section{THE HEALTHY BABY}

THE CARE AND FEEDING OF INFANTS IN SICKNESS AND IN HEALTH

\section{DEVELOPMENT OF BODY AND MIND}

ThE gradual awakening of the various senses and the progressive development of the common acts and functions of life have been the same, generation after generation, since civilization began. Each baby is much like his predecessor, although we usually believe our baby to be a little bit superior to the average. Averages are hard to strike, but it is important to have a standard so that we may be warned early of any deviation. Importance of having a Normal Standard. from the normal. We can correct such deviations far more easily in the beginning. At the same time no "forcing" should be used to make baby come up to our standard, and the nervous mother should not be in a constant state of worry for fear her baby is backward or deficient.

The first three months of his life, baby doesn't notice much of anything. Loud 
noises disturb him, so we know that he hears. A strong light makes him blink, or close his eyes, so we know that he has some sight; in fact, often his eyes will follow a light the Natural De- second or third week. He is three or four velopment during the First Nine Months. months old before he discovers his hands and begins to play with them. About this time he learns to smile when we chuck him under the chin, or make clicking noises with our lips in the familiar manner in which we are apt to address him. He can say goo! goo! and make delightful little noises with his throat, which grandma declares are intended for her name. He holds his head erect at four months, and sits alone with a pillow at his back at six months; at this age also he knows his mother and is apt to dislike strangers. He holds things in his hands and puts them to his mouth, and now, most wonderful of all, the first tooth may appear. At eight or nine months he sits upon the floor alone and possibly learns to creep. Some babies never creep, however.

Up to this time there is not much danger of urging him too fast. Of course, it is not well to play with him too much nor to allow 
him to become excited. Mother, - and Father, too, - wants to enjoy him while he is so irresistible. However, he should not be made to show off and do tricks upon every The Danger occasion, and he should not be trotted out to of "Showing occasion, and he should not be trotted out to be played with and handed about for the Off." admiration of loving friends. He should not be taken to parties or calling, nor do unnecessary traveling.

When it comes to walking, he must bide his own time. He will walk when his bones and muscles are strong enough, and if he has been properly fed, we need not fear bowlegs or knock-knee when he starts to walk of his own accord, whatever the age. As a matter of fact, the age of walking is a very variable one. At nine or ten months baby first realizes that his feet are meant to stand upon, and if at a year he is able to walk with support, he is doing well. At eighteen months if he does not walk by himself, he may be considered backward and the cause should be looked into. Walking is, of course, a mental as well as physical process. Baby is bound to have some tumbles, but he learns to take them philosophi- 
cally. In order that his walking may be unhampered, his diapers should be discarded for drawers soon after he is a year old, for if he has been properly trained, he will not need them. The carriage of the body should be erect, and as the child grows older, faulty postures while standing or sitting should be guarded against.

When Baby

Learns to Talk.

The power of speech is baby's next acquisition. At a year he can say Mama and Papa. Gradually he adds a few more proper nouns to his vocabulary, then the names of familiar objects; laboriously he joins these with verbs, and finally, at two years, he has learned to express thoughts in simple language. Children who talk readily should not be stimulated too much.

Delayed Some children are very late in talking, parTalking. ticularly if they are not encouraged. They make signs or point to the object of their desires, and find it easier than learning to talk. This is pure indolence on their part and incidentally on the part of the mother. Adenoids are a frequent cause of delayed talking. If a child does not talk at two or two and a half years of age, deafness or men- 
tal deficiency should at least be considered as a possible cause of his backwardness.

Lisping, stuttering, and defective speech of all sorts, such as using one consonant for the Defective Speech. other, should be nipped in the bud. Such defects are overcome by constantly requiring the child to pronounce his words correctly. He is made to repeat the word each time he makes his mistake, which, of course, takes a lot of time and patience. I occasionally see children of four or five years of age who talk so badly that no one but the parents can understand what they say. Some children with defective speech need a special training, as well as an examination of the various organs of speech to make sure that these are not defective. In most of the children in whom I notice defective speech, I find that laziness is the reason for it.

The mental development of the child goes forward by leaps and bounds. Every day he learns something new, and his thoughts should be guided in the proper channels. He should be allowed all the independence of thought and action that is compatible with good discipline, in order that he may ac- 
Stimu- quire originality and initiative. It is most lating the

Child's

Mental Activity. difficult to find the mean between constant harassing and scolding and "don'ts," and spoiling the child by allowing him to have his own way in all things. Lest he become a laggard in the world, his time should always be occupied, particularly at four or five years of age when the simple entertainments of babyhood cease to interest him. For this reason, I approve of kindergarten for children of the proper age and robust health, provided it does not make them nervous or delicate. They should, however, be taught to entertain themselves some hours of the day.

Development of the Body.

While the mind has been developing, the body should have kept pace with it. Not only has the weight been steadily increasing, but the body has been lengthening out. It is of very little importance to keep track of the height, but a table will be appended for reference. The extremities should grow in proportion to the trunk and be well shaped. The head should be round and symmetrical. Any one-sidedness of the head usually denotes an inclination to soft bones. Especial care should be taken to lay the infant first on 
one side then upon the other. The fonta- The Fonnel, or bony opening in the top of the head, is worthy of the mother's observation. Widely open at birth, it begins to grow smaller during the end of the first year and is entirely closed at eighteen months or two years.

The teeth should come along on schedule time, be well formed, and not become carious. (See "Teeth.") The chest should be broad and symmetrical. The abdomen is naturally protuberant in early childhood, especially if the child is fat. It is firm and hard like the other muscles of the body. When the baby is sick, mothers often discover for the first time that the abdomen becomes hard while he is crying. It should be so, but the observation is made for the first time because she is worried. If the navel protrudes while the child is crying, it should be attended to at on se.

Baby has come into this world a very small bit of humanity. Every week he must grow The Abdomen. tanel.

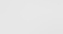


How much should the Baby Weigh?

How many times baby': mether has said to me, "Baby is not fat, but he is like his father in that." And then I explain that all well babies are fat. When baby is born, he weighs about seven pounds. He loses a few ounces the first few days and then he starts upon his journey. Each week he gains six ounces, sometimes more, sometimes less, until he is six months old, when he has doubled his birth weight; after that, he gains more slowly, say four ounces a week until, when he is a year old, he has trebled his birth weight. Then he slows down still more, gaining about five pounds each year until he is eight or nine years old. Of course, even well babies can't keep to the schedule all the time. If baby falls by the wayside and makes no gain for a week or two occasionally, but is otherwise well, do not worry about it - he is only imitating his pre acessors.

Fat Babies However, his flesh must be solid and his not al ways Healthy. muscles firm. Some fat babies are flabby because they have had food that has made them fat but has not built up the muscles and bones. These are never strong babies, and a serious illness is apt to go hard with 
them. Other babies have misshapen heads or chests, or large wrist bones, and these, too, are caused by wrong food.

Even a novice can readily see the reason Keeping for keeping watch of the baby's weight. It Track of is the chief indicator of his normal progress. It is not well to weigh the healthy baby more than once a week, lest we become worried unnecessarily. A chart or other record of weight may be kept, but we must avoid overfeeding just to make a good showing on the chart. The baby is stripped before his bath and before a feeding and put upon the scales. The best scales are the ordinary grocer's scales with the bar divided in ounces, along Scales to which slides the hanging weights, and provided with additional weights up to twentyfive pounds. There shculd be a flat platform at one end, upon which is placed the scoop that comes with the scales, or a basket made especially for weighing babies, and purchasable at any department or hardware store. The dial or spring scales, such as are ordinarily sold for weighing babies, are useless. When the baby kicks, the dial bobs about and makes it difficult to get an accurate reading. 
After the first year and especially during the second year, there should be a weighing once in two or three months to enable us to keep an eye on the nutrition.

\section{SLEEP}

The Early Months.
IT has been truly said that a baby's early life is made up of sleeping and eating. As soon as the excitement of his entrance into this world subsides, he promptly goes to sleep. When hunger awakens him, he takes his food and as soon as he has eaten enough, he goes to sleep again. This monotonous existence is interrupted usually twice a day, once when he has his bath and once when he indulges in a little exercise, say of an hour or so, which he takes in the form of crying, and to which he is entitled. Thus he sleeps twenty-two hours out of every twenty-four during the first two or three months. And "Shall we now comes the question, Shall we awaken Awaken him for his Food?" him for his food? The answer (with reservations) is "No." I am aware that authorities have long told us to awaken our babies every two hours to feed them, and I am also sure that this rule has caused many 
a pain and sleepless hour, and eventually a ruined digestion. The healthy, well-fed babe, when the food is right, awakens after three hours sleep. Occasionally he awakens in two and one half, or even two hours, when he should be persuaded to wait another hour, or half hour, as a matter of discipline in regularity. If this occurs too often, we may assume that his food is insufficient either in quantity or strength, and the remedy is to increase the quantity or strength. If this is impossible, as it sometimes is with the breast-fed child, the two-and-one-half or two-hour intervals should be adopted, but no healthy baby should be fed oftener than once in two hours. However, occasionally we see babies turn night into day by awakening at two- or three-hour intervals during the night and sleeping from four to six hours without eating in the daytime. These babies may be awakened for their food in the daytime at regular intervals, but more for the comfort of the mothers or nurses than for that of the baby.

After the third month, baby begins to take The Ques. more interest in life, and stays awake look- tion of 
ing at his hands or watching his neighbors a little longer each day, until at six months he sleeps twelve hours at night, from six to six, and has a two-hour nap both in the morning and in the afternoon. If he sleeps too late in the afternogn, he won't go to sleep promptly at six, as he should, so make the afternoon nap an early one, awaking him at three. During the first half of the second year we find he won't take two naps a day, or if he does, he won't sleep well at night, so we give up one or the other, preferably the afternoon nap. One nap a day is continued until the fourth or fifth year. The naps, especially during the early months, may be

Sleeping Out of Doors. taken out of doors in the baby carriage or on the piazza or even on the fire escape when this is the best we can afford. It seems unnecessary to say that sleeping out of doors is not harmful.

Amount of Sleep necessary for Growing Children.

And now we must be firm with the rule of to bed at six, for many temptations come up to prevent it. Twelve hours sleep is the right of every child until seven years of age, ten hours until ten or twelve years. Many a pale, washed-out looking child of this age 
owe his ill health to lack of sleep. However, the clder child usually regulates the amount of sleep himself if he has half a chance. Mothers who complain that their children sleep late in the morning allow them to stay up late at night. Oftentimes the child who awakens early in the morning has had too long a nap in the daytime. There is no excuse for any child arousing the entire household at four or five in the morni..g, if the hours are carefully regulated. Habit is an important factor in sleep. Baby mustn't be allowed to go to sleep with the nipple in his mouth. He should finish his nursing and then be put in his own bed, so that he may acquire the habit of going to sleep of his own accord. He should never be rocked to sleep, or sleep in a lighted room, or have any one remain with him while he is going to sleep. The mother should not form the habit of going into his room whenever he cries. I have known mothers whose custom Babies who Sleep it was to spend the whole evening listening Poorly. for a sound from the nursery. Baby cries and mother runs to him and stays with him until he goes to sleep again. This occurs 
more and more frequently until the child has become a restless sleeper and often gets so he awakens every hour or two throughout the night. The remedy is to stay out of the baby's room after he is once made comfortable for the night, and after we are sure that nothing is wrong. If he has already formed such a habit, we must let him "cry it out" for a few nights and he will soon unde'stand that he must sleep after he has been put to bed. Another bad habit is established when we tiptoe about the house and speak in whispers lest we wake the baby. It is far better for him to learn to sleep through the ordinary noises that legitimately exist in the household than it is to accustom him to absolute quiet, for then even a slight noise awakens him. At the same time the adult members of the family rarely enjoy a normal evening. Still another bad habit is established when baby is pushed about in the baby carriage in order to get him to sleep. This is, of course, the same as rocking him Every to sleep. Baby should sleep alone, in fact
Child should a child of any age ought to have a separate Sleep Alone. bed where it is possible. It is best to have a 
firm hair mattress and no pillow. In the early months he should be laid first upon one side then upon the other.

The windows should be wide open top Fresh Air at and bottom, winter and summer, after the Night. first few weeks, although it is well to avoid a direct draught. Warm night clothing, such as I will describe when I speak of "Clothing," is, of course, necessary.

At any age if the sleep is not restful and continuous, something is wrong and the physician should be consulted.

\section{CRYING}

CAN you tell what is the matter with baby when he cries? Usually a children's specialist can, but that is something I cannot impart to you. When you have heard him cry many times, you will know. There is the fretful cry of the baby who is discontented with his lot. He is wet, or he is hot, or unThe Meaning of the comfortably dressed, or hungry. There is Cry. the angry cry, the outburst of disappointment when he finds this world is not the pleasant place he thought it to be, and which is solaced by attention. There is the cry 
of pain, the unceasing cry which no amount of attention or distraction can alleviate. There is the hoarse cry of the child who has cried a great deal, or the throaty cry of the child suffering with some throat affection. There is the low moaning cry of the very sick child, which breaks your heart to hear. There is even the cry indicative of certain diseases, such as the "cephalic cry" of meningitis and other brain conditions, and the wild night cry with which the child with bone tuberculosis starts out of his sleep.

Normal Amount of Crying. lungs and muscles and helps the circulation. As David Harum says, "Some fleas is good
for a dog. It keeps him from broodin' on
bein' a dog." However, one or two hours
of crying a day is sufficient. When there is
much more than that, the cause should be As David Harum says, "Some fleas is good
for a dog. It keeps him from broodin' on
bein' a dog." However, one or two hours
of crying a day is sufficient. When there is
much more than that, the cause should be As David Harum says, "Some fleas is good
for a dog. It keeps him from broodin' on
bein' a dog." However, one or two hours
of crying a day is sufficient. When there is
much more than that, the cause should be As David Harum says, "Some fleas is good
for a dog. It keeps him from broodin' on
bein' a dog." However, one or two hours
of crying a day is sufficient. When there is
much more than that, the cause should be As David Harum says, "Some fleas is good
for a dog. It keeps him from broodin' on
bein' a dog." However, one or two hours
of crying a day is sufficient. When there is
much more than that, the cause should be investigated.

Hunger or Colic?

In the early months a certain amount of crying is good for a baby; it exercises his Perhaps the 
If the stools are a good yellow color, smooth and well digested, containing no mucus nor curds, and if there is no vomiting and no gas expelled, we may suspect that the trouble does not lie with the digestive tract. Hunger is more apt to cause crying just before the feeding is due, the length of time varying with the degree of hunger. A babe very much underfed may cry most of the time, because his hunger is never satisfied even immediately after a feeding.

Baby should not be allowed to get in the The habit of crying if he is well. Some mothers Habit of Crying have become so bound to routine that the $y$ do not change it as baby grows older, and Causes and Cures he cries more and more as the system appeals to him less and less. For instance, one mother had adopted the routine of putting her baby out of doors in the carriage early in the morning and of leaving him by himself, and going to him only when it was time to feed or change him. This was a very proper routine for the first months, but when he was seven months of age, she came to me to find out why he cried so much. It was, of course, because he was getting too old 
to sleep all day and all night, too. She was making a fussy baby of him through constant discontent and crying. Older children also form the habit of crying at the slightest provocation. They need tactful treatment to get them out of it. However, habitual crying is far more frequently due to errors in diet in a child of any age than to all the other causes put together. Next in the order of frequency comes the spoiled child, who needs different parents more than anything else.

Earache and the open safety pin are causes so much dwelt upon that even the father can make that diagnosis.

\section{APPETITE}

Poor BABY is a hungry creature. If he is not, Appetite in Infants.

something is wrong. Like a horse, he will always eat. If he awakens before his feeding time, his first thought is to eat. If he awakens at night, he cries until he is fed. When he is sick and fretful, he nurses still oftener (if you let him). In his early weeks it is the only form of recreation he has. It is good for baby to be hungry, but, as with the horse, our higher intelligence must, to a 
certain extent, regulate his feeding times and the food itself so that his appetite will remain good. If a horse gets into the oat bin, he eats until he is sick. If baby is allowed to eat whenever he cries, he eats until he is sick, finally loosing his appetite. When an infant refuses his bottle or the breast, we know (unless he has some definite illness) that we have been feeding him too often or too much, or that some element of the food is too strong; weaken the food or lengthen the intervals until he is hungry. Nothing will ruin baby's appetite or digestion more quickly than nursing three or four times during the night, and frequently breast-fed children are allowed to lie at the breast all night.

Infants who are taken acutely ill usually stop eating at once of their own accord. The Sick Babies' They show greater wisdom than does the mother who tries to force the child to eat when his stomach is in no condition to digest food. This voluntary starvation is the very best thing at the beginning of any illness, especially where there is fever. Sick children are often thirsty, as well as restless, 
so they sometimes nurse or drink milk to quench their thirst when their digestion will not take care of any nourishment.

Of course, some infants are too hungry. They cry as soon as the bottle or breast is taken away, and often keep it up until the next feeding. This is because the food is insufficient, or at any rate because there is something wrong with it. Many a mother has mistaken hunger for colic.

Loss of

Older children also should be hungry when Appetite in Older Children. it is time to eat. I think, perhaps, I have more difficulty with their appetites than I do with the babies', for we have to control both mother and child after infancy, while the baby always has to do as the mother wills. Sweets and eating between meals are the most frequent causes of lack of appetite in older children, and I am more and more firmly convinced that the minimum quantity of sweets is best for the child. Children with very poor appetites should be denied sweets altogether, for a time at least. Eating between meals is absolutely prohibited with the exception of certain fruits. Like the baby, the older child may 
have a poor appetite because his diet is wrong.

A hearty child has no right to be finical about his eating. He should eat whatever is put before him, and be glad to, provided it is the proper food. A certain amount of firmness on the part of the mother is all that is necessary. If he refuses the food he should eat, let him go hungry until the next meal. Why should we neglect to educate our children to eat the proper food and teach them such accomplishments as German and music?

Too much monotony in the food of course spoils the relish; the greediness with which a child will devour a different kind of bread Variety and Quantity of Food. is pathetic.

"Can a child eat too much sensible food?" is a question I sometimes hear. Occasionally I have seen children who had to have the amount of good food limited, but usually a child who eats too much in bulk has some element of the food in insufficient quantity.

Many mothers will be surprised to hear that a child may drink too much milk. If there is any one article of diet that is overestimated, it is milk. Most mothers are imbued 
with the idea that if their children will Value of drink milk, they are well fed. Milk is a good Milk. food, but, after the first year, must not be given to the exclusion of other foods. Time and time again I have children brought to me who do not eat because they drink one to two quarts of milk a day. It is often necessary to take away the milk altogether, especially during the second year, in order to get the child hungry enough to eat other things.

Diet both in infants and children is a subject which I will take up by itself.

\section{VOMITING}

Persistent Vomiting of Infants.

Medically there is a distinction between vomiting and regurgitation, but it is difficult to tell where one begins and the other leaves off. It is a fact, however, that a perfectly well baby overflows just after he has nursed, and this is supposed to be regurgitation. It is simply because he has taken a little more than his stomach can hold, and the surplus comes up. Children vomit very easily. This is a fortunate provision of nature, because they have not the discretion about 
eating that adults are supposed to have. However, nursing babies should not vomit much after the feeding, and it is particularly significant of ill health if the milk makes its appearance continuously or just before another feeding is due. Perhaps baby is nursing too often or too many times at night, or the milk comes too fast, or perhaps he is jostled about too much after nursing. When the stomach is full, baby should be kept quiet, for if he is trotted about or turned upside down, up comes the food. Tight bellybands are also a frequent cause of vomiting; in fact, any detail of baby's daily existence should be looked into when the vomiting is persistent. These things are as true of the bottle-fed baby as of the breast-fed. With the former, however, the food is the chief source of the trouble, when baby vomits habitually.

Sudden or acute vomiting in the previously healthy child means the beginning of almost

Sudden or Acute Vomiting. anything. All acute illnesses of childhood - pneumonia, scarlet fever, or what not may begin with vomiting. If I wanted to take a chance, however, I should say it was 
stomach upset - the child had overloaded his stomach or eaten some bad food, for this is the cause in the vast majority of children with acute vomiting. It is usually accompanied by fever, sometimes by diarrhea.

"Stomach Attacks" of Older Children.

When children have "stomach attacks" at intervals of a month or two, there will be found some error in their diet to account for it and that error should be sought and remedied. These attacks should not be considered unavoidable incidents in a child's life. How often do I hear a mother say, "John has been perfectly well all his life, but, of course, he has one of his vomiting spells every once in a while."

The treatment of acute vomiting is simple. Immediately stop all food, even the breast (and in older children, water also), where it is persistently rejected. Calomel is at once given in the method that I have described

Treatment of Acute Vomiting.

under "Diarrhea." Castor oil is not as good in cases of vomiting as calomel, because it is less apt to be retained and thus its effect is spoiled. However, if castor oil is given and retained, it acts more quickly. If it is 
vomited, the calomel should be started at once. Citrate of magnesia, as ordinarily put up by the druggist, is sweet and sirupy and should not be used in these particular cases. One level teaspoonful of good cooking soda in one glassful of water, to be sipped at intervals, is helpful in the vomiting of older children. If the child continues to vomit after twelve hours, he needs the physician's aid.

Bile in the vomitus (a watery fluid stained green or yellow) always inspires the mother with fear. It simply means that the food has all been cleared out of the stomach and that the vomiting has continued until the stomach has become irritable, the bile flowing back into the stomach. Not until the vomiting has ceased entirely for a number of hours and water is retained, should food be given. Bottle babies should first be started on a very weak food. Older children may have two or three tablespoonfuls of hot clear broth, free of fat, or bouillon, to begin with. Later, other foods are gradually added to the diet. Milk especially should be avoided for a few days. 


\section{THE BOWELS}

BABY's bowels have to be watched from the time he is a helpless infant until he is old enough to have a care of them himself. He must grow up with the knowledge that his bowels perform one of the most important functions of the body and it is a part of his training to learn to take care of them.

Normal Movements of the Breastfed Baby.

During the first three or four days the movements are black and sticky, two to four in number. Then, as the food begins to be taken and digested, they become yellow and more solid and should be one to four in number daily. At this time they occasionally remain scanty and even become green and thin for a week or so. This is because the milk is not sufficient to make good-sized solid stools, although the stools may be frequent. Usually the milk increases by the end of the second week, so there is no occasion to worry. And now the stools change according to the food baby is taking. If he is breast-fed, they should become light yellow, about the consistency of mush, and two to four a day. A few weeks later one a day will 
answer. I would caution mothers not to be too much worried about the number of the breast-fed baby's 'stools when he is sleeping well and everything else seems right, especially if he gains in weight.

The bottle-fed baby should be under the The care of the physician during the first weeks, Baby's as the great majority of sick babies owe their Stools.

ill health to the poor start they get in the early weeks. However, if properly fed, the bowels of the bottle-fed baby are not apt to move as often as those of the breast-fed child. One stool a day is sufficient, and even if there is only one stool in forty-eight hours, it is better to let them go that length of time rather than to irritate the bowels daily with cathartics and enemas and supposivories. The food can be changed gradually so that the bowels will move of their own accord every day. . The bottle-fed baby also has a larger and more bulky stool, lighter in color, and about the consistency of a firm ointment or cold cream, so that it holds its shape in the diaper. It should be smooth and uniform. Any curds (white lumps like cheese) or mucus (glistening, slimy, like phlegm) show that 
the food is not being well digested in the bowels, where most of the infant's digestion takes place. Usually this is a sign of diarrhea.

Training the Child to have Regular Habits.

When baby reaches the age of four months, if he is strong and well, we begin to train him to have stools at regular intervals. It is

- surprising how soon the little things learn to use the vessel. At stated times each day (once or twice, according to his previous habits) he is placed upon a small infant's chamber, which is comfortable if it exactly fits the buttocks. This may be held in the lap in order to support his back. He soon learns to grunt and strain whenever he is placed upon it, and the habit is quickly established. When he gets strong enough to sit up by himself, he must have a low comfortable chair which allows the feet to rest upon the floor. The chair should have a rubber ring which can be taken off and cleaned. This may be bought at any children's store. It is a most pernicious habit to allow the adult chamber to be used, because its large size tends to let the organs become displaced.

And finally, as he grows still older and has 
three meals a day, he must learn that he must go to stool at the same time each day (preferably right after breakfast) and stay there until his bowels have moved. In this way a habit is established which is carried through life.

Constipation has many causes. In breastfed children it is usually due to constipation of the mother or to the mother's diet or to Constipation in Breast-fed Infants. irregular nursing. These things we will consider under "Breast Feeding." If the constipation continues after mother's diet is corrected and her bowels regulated, it is far wiser to consult a physician than to try sweet oil and cream and various other expedients which require skilled supervision. It often happens, if oil is used, that it is just the wrong thing if the fault lies in a milk already too rich in fat.

The bottle-fed baby is constipated also because of his food. The most usual errors of diet are:-

Constipation in Bottle-fed Infants.

1. Too high a fat (when top milk or cream is used).

2. Food of insufficient quantity or strength (scanty stools). 
3. Not enough sugar.

4. Boiling the milk.

5. Weak, sickly babies are often constipated because they have not enough strength and muscular tone to have an evacuation.

Cathartics. One can readily see how wrong it is to give cathartics every day without remedying the cause, when the child's nutrition and growth may suffer from the error in diet which has caused the constipation. Having decided which of the above five causes gives rise to the constipation, changes in the food should be made accordingly. Temporarily, however, milk of magnesia may be used until the food is properly regulated, one teaspoonful one to six times a day in the bottle or just before the breast feeding. After six months of age, the fruit juices and raw scraped apple, such as I describe in the diet list, are useful.

Causes of Constipation in Older Children.
Older children are constipated because :1. They have not been taught to go regularly to stool, and they are too busy at play when they have the inclination to go.

2. The toilet arrangements are not comfortable. Often the feet hang dangling while 
they sit upon the adult water-closet, or the seat is too large.

3. During the second and third years particularly, too much milk is often given. It is sometimes necessary to take milk out of the diet entirely if the constipation stubbornly resists dietetic treatment.

4. The food may be too concentrated. The child has not learned to like vegetables or the coarser breads and cereals, which should be given in large quantities to constipated children. A diet list for constipated children will be given later.

5. Fruits are not given in sufficient quantities, for they are especially valuable additions to the diet. By this I do not mean a little orange juice at breakfast. Give the child all the fruit he will eat three times a day, preferably between meals, until the constipation is overcome.

6. There may rarely be some abnormal condition about the rectum, such as a fissure, hemorrhoids, polypus, or prolapse, which needs medical attention.

Massage of the abdomen is a very valuable Massage adjunct in the treatment of constipation; 
it consists in very gently stroking the abdomen with the tips of the fingers, first upward on the right side, then across from right to left in the upper part of the abdomen, then downward on the left side. This is followed by a general light and careful kneading of the whole abdomen. Do not use too much strength. Never massage the abdomen immediately after feeding.

Principal Causes of Diarrhea. fancy than almost any other illness. In the large cities, during the summer months, more babies die of diarrhea than of scarlet fever, diphtheria, typhoid fever, measles, and whooping cough combined. Diarrhea, therefore, should be treated in the beginning. In infancy there are but two principal causes of diarrhea-unclean milk and the wrong food.

Diarrhea from Unclean Milk.

Unclean milk may come from improperly managed dairies or from contamination in the home between the time it is delivered and the time it is consumed by the baby. Fortunately the best milk in the world may be had in New York City and in all of the large American cities where certified milk 
is available. It is delivered in a clean bottle packed in ice, and if kept cold and clean until the baby gets it, he will not be poisoned by it. Cleanliness, rapid cooling, and keeping it cool is the whole secret of good milk. This can be accomplished on the farm when certified milk is not within our reach. Babies' bottles and nipples and everything the milk comes in contact with should be kept scrupulously clean.

Improper feeding even of clean milk often Diarrhea results in diarrhea. Diarrhea and vomiting are conservative processes of nature which from Improper Feeding. the baby automatically performs, to get rid of that which our minds have been deficient in rejecting. Overfeeding is perhaps the most frequent kind of improper feeding. It is as fascinating as a game to watch the weight of a baby go up each week. Therefore we must have a care not to increase the strength of the food too fast in our anxiety to increase the weight. Too frequent feedings also cause diarrhea. During the hot weather a baby will not digest as much food as he will in the winter months. He should be kept hungry and perhaps it will be necessary to cut down 
the strength of the food while the weather is very hot. The baby will also be less inclined to have diarrhea if he is not too warmly clothed and if he has plenty of fresh air.

The The "second summer" is a most dreaded Dreaded "Second Summer." period in the minds of most mothers - and why? It is because baby has reached the age when he wants to eat everything he sees, and mother allows him to do so or doesn't take pains to prevent him, that he gets up a diarrhea. The second summer should be, however, and is the healthiest part of the child's life, provided his diet is right. To be sure he may be cutting some teeth at this time, but if he is kept cool and comfortable and is properly fed, he is not very liable to a diarrhea from teething. I must admit that he requires more care when he is cutting his teeth in the summer, and that there are children who have a tendency toward loose bowels when the teeth are coming through, but careful supervision will tend to avoid much difficulty.

Treatment of Acute Diarrhea.

All I have said has been in the way of prevention of diarrhea which is by far the most 
important side of the subject. What about the child who has actually started with diarrhea? The moment the disorder begins is the time to start treatment. Stop all milk or food of any kind at once. Even the breast should be discontinued for at least twelve hours in nursing babies. Give a cathartic, either castor oil op calomel $-\frac{1}{10}$ to $\frac{1}{4}$ grain every half hour until one to two grains is given, according to the age. Calomel is better when there is vomiting, and a large dose of castor oil is better than a small one. During the first few months a teaspoonful will be sufficient, but after that a tablespoonful is required to do the work well. If the castor oil is vomited, start the calomel.

Do not give anything else by mouth but water, and water should be limited or denied if there is much vomiting; otherwise, it should be given plentifully. If the child has much fever or if the diarrhea has not stopped in twelve to twenty-four hours, a physician's services will be required. Many a long illness has been prevented by this energetic treatment in the beginning. 



\section{PART II}

\section{HYGIENE AND TRAINING}




$$
56
$$




\section{CLOTHING}

There is one invariable rule in dressing The Sena baby - always make him comfortable. sibly

There is no more necessity of wrapping him Dressed Baby. round and round with pinning blankets than there is of binding his feet as the Japanese do: We have been hampered long enough in our dress by custom and tradition, but fortunately we are now dressing our babies in a sensible manner. When the baby is entirely dressed, he has on a belly-band, a shirt, a flannel skirt, a soft sheer underskirt, a simple dress or slip, socks, and diapers.

The belly-band serves ${ }^{\prime}$ wo purposes it supports the abdomen in the very young The Bellyband. infant and it protects the bowels from changes in temperature. Improperly used, it is a source of discomfort and even positive harm. As soon as the babe becomes very active, the pinned belly-band works up under the arms where it restricts the breathing rather than protects the abdomen. The bellyband should be made of an unhemmed strip of soft white flannel, eight inches wide and eighteen inches long, so that it goes around 
the abdomen once. It may be pinned firmly, but not too tightly, with five small safety pins. It is not necessary to sew it on the child as is the fad at the present time. It should be discarded at eight weeks of age (if the child is strong and well) and a loose knitted band with shoulder-straps substituted for it. The knitted band should be pinned to the diapers at the bottom. Three thicknesses are commonly sold, the medium silk and wool being the best. It should be worn throughout the first year.

The Baby's Shirt.

\section{cati} cate skin, should be of soft texture. The medium grade of silk and wool is preferable, or a cotton shirt may be used. It should fit the body closely enough to eliminate wrinkles, which are a source of discomfort in any article of baby's clothing. Heavy rough woolen underclothes are unnecessary and positively harmful at any age.

The The flannel skirt, which nowadays takes Flannel Skirt. the place of the uncomfortable pinning blanket, is made with straps which pin over the shoulders (one back and front for each shoulder). It should be made of soft white flannel 
and be twenty-six inches long. The white skirt which goes over this is not a necessity, but a luxury for dressy occasions. 'It should, of course, hang from the shoulders.

The dress, or slip, twenty-seven inches in length, should be simple, but no matter how The Dress, or "Slip." elaborate it is, it should have no lace about the neck to cause irritation of the skin. I have seen bad cases of eczema started in this way. The neck should not be tight and it is best tied with a tape in the back, rather than fastened with pins or buttons for the baby to lie upon. Sheer batiste or nainsook is the best material both for the underskirt and for the outer slip. The stockinette nightgowns are very nice and may be worn night and day in the early months, if we do not care to be dressy.

A jacket, as mentioned below, may be worn on cool days after the child is old enough to sit up. Socks are worn in winter, but never heavy woolen ones. They should be pinned to the diapers and not tied on.

The diaper problem is an important one, The especially in the city apartment where baby's $\begin{aligned} & \text { Diaper } \\ & \text { Problem. }\end{aligned}$ laundry has to be done up every day in a 
small space. Cheesecloth diapers are the nicest for the little baby. They are soft and easily dried. They are cut a yard square and hemmed. When folded cornerwise three times, making eight thicknesses, they are about the right size. The stork diaper may be used in addition to these where two diapers are necessary. These stork diapers are made of material which is like thick Turkish toweling, and they come in different sizes which are Rubber three-cornered in shape. They should not be Diaper. confused with the diapers made of a rubber sheeting which bears the same name. The latter should never be worn, since they cause irritation about the buttocks, as well as being a source of great discomfort. As the child gets older, the cotton bird's-eye diaper may be used together with the larger sized stork. The diapers should be changed as soon as the baby has wet them, always before a nursing, although it is not advisable to waken him just to change them. Soiled or wet diapers should be put immediately into a covered enamel pail, kept exclusively for that purpose, and washed out each morning. Under no circumstances should a diaper be 
used twice without washing. After the first year, diapers should be discarded for drawers and waists. Rompers should not be worn until baby has learned to keep himself dry in the daytime.

Blankets seem almost a part of the baby, Blankets. they are so numerous where he abides. While sleeping, the number of blankets necessary should be judged by the temperature of the room. When we have baby in our arms, one blanket is well in winter, but after he is old enough to sit up, the jacket should be substituted for it. Winding the blanket around him is unnecessary and uncomfortable even when he is out in his carriage. In fact I have seen temporary paralysis of the arm from pressure of the tightly wound blanket.

In putting on baby's clothes he should lie flat upon the nurse's lap, and the clothes should be drawn over the feet and not over the head. Baby's clothes should, of course, be changed throughout once each day at the time of his bath. During the first four months it is not necessary to change to night clothes at night, except for dressy babies

Changing the Baby's Clothes. 
who wear fancy gowns in the daytime. Night and day are very much alike to him. At four months short clothes may be worn. The one thing above all others that I have to talk to my patients the most about is overdressing. Not only are mothers apt to bundle up their babies too much, but their older children, as well. During the hot weather baby should be kept cool. On hot The days the flannel skirt and socks and even the Danger of Dressing Infants too Warmly. shirt should come off, provided the baby is strong and doing well. Any baby who perspires is dressed too warmly. This is the thing that governs me in dressing my babies. It is perfectly easy to slip on a flannel skirt when a cool day comes, for it does no harm to change the thickness of the clothing from day to day as the weather changes. Babies who are too warmly dressed do not digest their food as well and are apt to vomit or have loose bowels when the hot days come. Nor is it advisable to have too warm clothing in the house in the winter. Remember that the average house or steam-heated apartment is $70^{\circ}$ or even $80^{\circ}$ in temperature, which would be considered a warm day in summer. 
In older children especially is this error apt to occur. The average mother has such a fear of her child's catching cold that she gets the warmest, thickest underclothes she can How to Dress Older Children in Cold Weather. buy. The child is overheated in the house and then goes out with a skin which is moist and "coddled," so that it does not react to different temperatures, as it should and which is one of its chief functions. Probably more colds are acquired in this way than in any other, all through the mother's anxiety to prevent them. I never allow any thick woolen underclothes at all, winter or summer in this climate. -The girl has her flannel skirt, cotton underdrawers, waist, shirt, and stockings, and after she is too old to wear leggings out of doors, she may have lightweight underflannels coming to the ankles. The boy, after he has come to trousers, may wear balbriggan underdrawers and shirt, and knitted waists or suspenders to support the trousers. When they go out doors in cold weather, children should wear leggings and a warm coat. In fact they are far less apt to catch cold if we save the warm woolen things for out doors and dress them com- 
fortably in the house. Fur earlaps are pernicious things. They are worn on cold days and when taken off occasionally on a warm day, the ear, being unaccustomed to the change, is apt to suffer. I have repeatedly seen abscesses of the ear which I believe to have been contracted in this way. In winter it is well to have a bonnet or some protector for the ears for children under two years, but after that, a veil tied over the hat on cold days is sufficient. Even the thickness of the bonnet should not be changed from day to day.

Socks. Socks for older children are well enough in summer, but absolutely tabooed in winter. Some mothers have the idea that it "hardens" their children to let them go about in winter with no covering for the legs. It is not only a foolish idea, but a harmful one. Full-length stockings should, therefore, be worn except in the summer months.

shres. The shoes should be broad in the toe and always plenty long enough. Children's feet grow so fast that it is often a temptation to allow them to wear a perfectly good shoe even though it is a trifle short. Let us hope that 
there is another baby in the family who will come along soon to save them if one is economically inclined. Soft, thin shoes are best for the feet in the second year when baby is learning to walk. The present style of thick, hardy looking shoes should be reserved for the older child. Rubbers or overshoes should always be worn on damp or cold days, as the thin shoes are so easily penetrated by the cold or moisture. Wet feet may not do any harm, but they never do any good.

At night, since the nursery windows are to be wide open in the winter, the clothing

Night

Clothing should be warm. The infant has more blankets, and the older child an undershirt and outing flannel or woolen "Johnnie Bears" - one-piece suits with feet in them, the number of blankets varying with the temperature.

\section{THE BATH}

BABY's first full tub bath comes when he is about a week old (when the cord has come The Bathtub. off) and from that time on he should have one bath daily throughout childhood. The room should be warm, but not overheated, $75^{\circ}$ to $80^{\circ} \mathrm{F}$., and there should be no E 
draughts about. A metal or enameled bathtub is a necessity and it should be kept scrupulously clean. The folding rubber bathtubs are very hard to keep clean and I do not approve of them entirely. If one is used, it should be thoroughly cleaned, dried, and aired each day. I have seen a nurse put soiled diapers into the bathtub to soak, with the result that might be expected - infection of the baby's skin and a good crop of boils.

How to Wash the Baby.
The baby's head and face must first be washed and dried. The eyes, nose, ears, and genitals are then cleaned with a fresh piece of absorbent cotton dipped in a bowl of boracic acid and water, a teaspoonful to the pint. The mouth should be left alone, not only at the time of the bath, but at all times. One of the most pernicious practices of the present time is the constant scrubbing of the inside of the mouth. The mucous membrane or lining of the mouth is often injured in this way, and makes it far more liable to thrush and other infections instead of preventing them. The baby's mouth will take care of itself and be far better cleansed by its 
own saliva. The baby should be thoroughly soaped in the lap and then laid in the bathtub to wash the soap off, with the head supported. Under no circumstances is the sponge or washcloth to be used for little babies. A fresh clean piece of absorbent cotton is much better. Every baby should love the bath ; if there is any crying, it should be only when he comes out of it. After the bath, the baby is quickly dried with a clean, soft (possibly old) towel, but with very little rubbing, and the folds of the skin powdered.

The temperature of the bath is as follows: The TemThe first eight weeks, $100^{\circ} \mathrm{F}$; until six perature of the Bath. months, $98^{\circ} \mathrm{F}$.; after six months, $95^{\circ} \mathrm{F}$.; during the second year, $85^{\circ}$ to $80^{\circ} \mathrm{F}$. After the second year, at the end of the bath, a cold douche poured over the child at the temperature of the cold water faucet is stimulating, and keeps him from catching cold. A bath thermometer is a necessity. It should not be discarded after the first few months, as is the custom in most of the families with whom I come in contact. Any child who has been accustomed to warm or hot baths should have the temperature lowered a little each day 
until the proper temperature for his age is reached.

The Time of the Bath.

The time of the bath is not of vast importance. It should, however, come before eating. The infant is more apt to need it in the morning, and it is my custom to give a morning bath throughout the first year, and an evening bath after that time.

In all of these talks, I have in mind the well baby, but perhaps it would be best to say a word about the sickly baby's bath. Small, thin, emaciated babies often do not stand Certain the bath well. They, of course, are under Cases when

the Bath may be Omitted. the care of a physician, and he will recommend a sweet oil rub, or whatever is necessary to take the place of the bath. Children with eczema or other skin affections are often benefited by omitting the bath. However, I do not believe the bath should be omitted because the child has a cold or a little fever or any other illness too slight to require a physician's attendance. At such times a bath is often restful and quieting, and the child goes off to sleep for the night when he would otherwise have been fretful and restless. 


\section{FRESH AIR}

THE last generation feared fresh cold air and a draught as the present generation fears Draughts versus bacteria and the germs of disease. In both tion. generations we have gone too far, and as usual the pendulum has swung way beyond its intended turning point. Plenty of fresh air tends to get us into such good condition that we may resist or throw off colds and other illnesses caused by germs; at the same time overexposure and draughts I am sure will sometimes cause them. Some of our leading authorities still claim that draughts are not harmful, but I believe that when we are in the house, it is best to avoid them, provided it is possible to get a good supply of fresh air coming into the room all the time. If I had to choose between bad air and draughts, I would take the latter, but I do not think the choice is often necessary. In the summer a cool breeze does not seem to cause colds. One hour of bad air will do more harm than good air for the other twentythree will undo; therefore, keep the room well ventilated every moment of the day. 
How to get Fresh Air into the

House.

Proper Temperature of the Living Rooms.

It seems to me that it takes a great deal of thought to ventilate the individual house or apartment properly. If the rooms are large and open into each other, one or two windows in the proper place will furnish fresh air for the whole house. If we are dealing with a small apartment, we must select one room where the windows may be opened top and bottom and from which the fresh air may circulate without causing too much of a breeze, or draught. It is a well-known fact that open fireplaces are wonderfully good ventilators, but they are now considered a luxury, I am sorry to say. At any cost, keep the air good night and day.

The temperature of living rooms should be $65^{\circ}$ to $70^{\circ} \mathrm{F}$. A thermometer should hang in the rooms that are most frequented by the children, and should be placed at the height of their heads. Overheating is the commonest error in the city. In the country perhaps the most usual mistake is draughty rooms, floors, and cold halls. On the other hand air-tight rooms in which the same air is breathed over and over again without once changing is a common occurrence. 
The sleeping room should have one or more windows wide open top and bottom throughout the year. The bed should be as far away Ventilation of the Sleepfrom the windows as possible and in a corner out of the direct draught. If this is not possible, a blanket may be pinned around the crib, so that the winter winds will not blow directly upon the baby. It is sometimes hard to convince the mother that her child should sleep in an unheated room, but when she has once accustomed the baby to it, she soon sees what a beneficial effect it has upon him. He sleeps more quietly, learns to keep under the bed clothing, and does not catch cold nearly as easily. The room being cold, the night clothing should be warm, varying with the temperature (see "Clothing"). This does not, of course, apply to weak, sickly infants nor to those under six weeks of age. Of course in very cold climates the temperature of the sleeping rooin should be kept well above the freezing point.

It is my observation that city children get more fresh air than country children during Outdoor Airing. the first and second years. As is proper, the carefully brought up city child gets his airing 
at a stated time each morning and each afternoon. It is his routine that saves him, while the country child is not allowed to be out when the snow is deep or the weather inclement, and often is taken out only when convenient. Babies, beginning at six weeks, should be taken out for their airing once a day, and later two times. In mild weather or in warm climates they may be taken out at the age of two weeks, but usually not earlier than this. In winter the best time is when the sun is high; in summer, when it is coolest. The length of time for the airing depends upon the age of the child and the time that can be devoted to it by the mother or nurse. At six weeks, an hour a day is sufficient; at six months three or four hours is a necessity: after that the more the better.

The only contra-indications to going out are - extremely cold weather (below zero), rain or snow, and possibly sharp winds, unless a sheltered spot can be found. When

What to do when the Weather is Inclement. this outdoor airing is absolutely impossible, the baby should be dressed for the street and put in the carriage close by the widely open windows and in the sun. The sun should 
not be allowed to shine directly into the unprotected eyes, whether in or out of doors. In the city it is as necessary to have a carriage for the baby as it is to have a bed. Rainy days are hard on any child, but the older one is sure to miss his outing. Put on his hat and cloak and open all the windows in the nursery, and see how much pleasure it gives him, as well as rosy cheeks.

The delicate child often requires fresh air even more than the well child. The appetite The

Delicate is improved and the strength increased by good pure air. Sleep also is often induced by the airing. Many a sick child who will not sleep well in the house immediately sinks into a restful slumber as soon as he is put out in his carriage. Of course, there is no objection to sleeping out of doors in sickness or in health, provided the baby is properly dressed for it. Occasionally the mother of a sickly child will tell me that she cannot take the little one outdoors at all, because every time she does so he catches cold. That is the very reason he is sickly, and unless he is taken out every day and accustomed to the fresh air treatment he will always remain delicate. 
He should, therefore, be taken out in spite of his catching cold unless he has a fever.

Schocl- School children should have especial care rooms. paid to their supply of fresh air. It is always possible for the energetic parent to impress upon the proper authorities the beneficial effects of fresh air in the school. The modern public school buildings have splendid systems of ventilation, but private schools are often in dwelling houses that were not meant to hold many people, so the air supply must be carefully regulated by means of the proper window ventilators. School children should have their share of outdoor life, too, since this is often the period when sedentary habits are established.

\section{EXERCISE}

JusT as children automatically get the proper amount of sleep, if they are given half a chance, so will they of their own accord take the proper amount of exercise. It only remains for us not to restrain them. Of course, there are occasional exceptions to this rule.

The chief restraint that we are apt to place upon them during the early months is that 
of clothing. If this is loose enough to per- Freedom of mit of free movements of the arms and legs, Movement mit of free movements of the arms and legs, should baby will get exercise, especially when he cries. At the same time he should have half not be Restrained by Clothing. an hour night and morning when his diapers and socks are removed and he is laid upon First Year. the bed in a room of the proper temperature, free of draughts. There he kicks and plays to his heart's content and develops his muscles. When he has learned to creep and later to walk, if yoald seem as though he would Second Year. wear himself out, he keeps at it so constantly. There is no danger of this, however, if he is not overpersuaded and if he has the proper number of naps and sleeping hours.

After the second year, the baby carriage habit is a common restraint in the city. Baby The Baby Carriage Habit. has been wheeled about all through infancy and it is difficult to change to walking, but we will not make this mistake if we realize that he needs this exercise. On the other hand, long walks on the street to the point of fatigue are, of course, unnecessary and harmful. In tíe country a shovel and a dir's or sand pile will be sufficient incentive to exAfter the Second ercise. As a matter of fact country children 
usually get enough exercise from this age on, if you turn them out in the open and let them play from morning until night, except for the naps. The city child often stores away enough good health from his summer outing to last him throughout the winter.

After five years of age, the matter of exercise is occasionally a problem; for there are those children who have been kept too closely to the mother or nurse, or who have been brought up to fear dirt, or have a natural inclination to sedentary things, such as sewThe Child ing or reading. Every inducement in the who does' not Want to go Out. way of making outdoor life attractive should be offered. If this method is not successful in getting the child to like it, he should be compelled to go out. I am aware that the city mother may dread sending her children into the streets and parks, and the country mother may fear the contact with her neighbor's children, but if she has brought her children up to obey her and wish for her approval of their acts, she need not fear association with other children. At any rate, I would vote for the outdoor exercise in spite of risky associations. 
As the children get old enough, especially girls, it is well that they become interested in competitive outdoor games, and in this way pave the road to a lifelong fondness for exercise. Gymnasium work in the winter and the indoor sports are invaluable paths to good health in the cities.

The delicate child should have his exercise Exercise regulated for him. Most excellent work is now being done in calisthenics for delicate for the Delicate Child. children by those trained in this work. A child who tires easily usually has some particular cause for it.

Can the child get too much exercise? Can the Child get There certainly are active bcys and girls too much who enter so enthusiastically into their play Exercise? that they come into the house perhaps too tired to eat or sleep. This is due to excitement during play, especially when they are playing with children older than themselves. Here, as in almost every question of childwelfare, moderation is advisable, and such children should be restrained to a certain extent. 


\section{TRAINING AND DISCIPLINE}

LACK of discipline is an American weakness. You cannot imagine the humiliation with which I have heard foreign-born mothers of my charity patients say, "But he is like the American child, he does not mind."

The Keynote of Discipline.

A child's training begins during his first week, and unless he has learned the meaning of discipline at home, where it is kindly meant, it goes hard with him by the time he gets out into the world; for wherever he is, he muist stand the consequences of his acts. This is the keynote of discipline. A child's naughtiness is punisied because, if it is allowed to go on, he will not be happy himself and he will be the cause of unhappiness in others - just as in later life he will be rewarded at least with a happy conscience if he does right, or will be punished if he does wrong.

Too much Handling in Babyhood.
From the very first a baby who is picked up every time he cries recognizes the lack of discipline. He cries to attract attention it is about the only thing he knows how to do. He is held more and more each day until he ruins his health by lack of sleep and 
too much handling, and spoils the pleasure of his parents. I do not mean that he should never be taken up and held, for I believe parents should enjoy their babies, especially after they are old enough to take notice of their surroundings. But there is a happy medium; if we play with the baby a little before his feedings or during his afternoon recreation hour, he will become accustomed to being taken up and laid down as we wish, and it will never occur to him to expect it at any other time.

There are several particularly trying periods in a child's training. One of them is at eight or nine months when he is emphatically insistent upon having his own way. He has really just discovered that he is an individual with a will. He wants something on the table and grabs for it. Mother takes it away from him and he picks up the next thing as quick as a wink. Mother takes this away and the same performance is repeated until there is nothing left. Then he cries until mother gives back the desired object in order to keep him quiet. What mother should have done is to put up her finger and

Nine

Months of Age a "Trying" Period. 
say, "No." If after this he tries it again, as he is liable to do, his chair should be turned back to the table so that he may know his misbehavior has been punished. It is wonderful how soon he learns to "stop" when told to do so, for we are apt to underestimate his intelligence greatly. $X$

Anger and

Threats

have no

Part in Discipline.

Disciplining should always be done in as pleasant a manner as possible. Of course, every one knows that the spirit of anger is not part of discipline. Correction should also be done with a positiveness that leaves no doubt in the child's mind what his course is to be. Sternness is seldom necessary. Allow the child every liberty that comes within the limits of propriety; use few "don'ts," but when the word is once said, enforce it. Make him happy and enter into his pleasures as enthusiastically as you know how. But, when you tell him to do a thing let him mind without any hesitation. Do not speak but once. If he does not obey the first time, do something that will impress his mind with the fact that you meant what you said the first time you said it - let him understand that your word is law. The mother 
who threatens her children with punishment a dozen times to every once she administers it, is never obeyed. Her children know that she is apt to lie twelve times first, and, being natural optimists, they think of the thirteenth time when they will have to obey as in the far distant future.

As a child grows older, we must recognize his individuality. Some children are far more difficult to manage than others, but secretly I always have my doubts about the parents of a child who does not mind well. It requires not only good judgment, but a fondness for children, to attain good discipline in one's family. The rod is not popular at the present time, I know, but some children still need it.

The same kind of punishment repeated time and time again is often ineffectual in a child who is hard to manage. A child who is shut in the closet every time he is naughty soon learns to amuse himself there, even to the point of forgetting that he is being punished. If we can manage to show our scorn of his misdeeds in some unexpected way, it is far more apt to make an impression upon him. 
The Above all do not punish him too often. I

Danger of

Too Frequent Punishment. have the greatest sympathy for the child who is constantly in trouble. Try to make his happiness your object, and obedience a natural consequence of your wishes. An entirely different tack may be taken up when one kind of treatment has been tried and found wanting. I have known a child to improve wonderfully in his behavior when the parents have overlooked his misdeeds, and stopped all punishment for a while.

Teasing. Teasing has ruined the disposition of many a child. The parents, of course, will not be guilty of such conduct, but older children in the family, or an uncle or aunt, may make a child's life utterly miserable by constant teasing. I have seen a great strong brute of a man keep a child struggling hours for some object and almost allow him to get it over and over again, only to thwart the little fellow's purpose by sheer strength just as he has reached his goal.

Truthful- Truthfulness and honesty are not born in ness and Imaginaevery child, but it may always be acquired tion. if we take the trouble to teach it. In the first place never tell an untruth to a child 
yourself. If you make a practice of it, he is not to blame for acquiring the habit, too. Then never allow an untruth to be told by him without letting him see that you know it is not the truth. Do not make too much of it, but simply correct him in his statement, unless lying has become a fixed habit. I do not mean that you should doubt his word constantly, for that leads him to think you expect untruthfulness of him and he surely will not disappoint you if you do. Remember that there is a certain age when the child is very imaginative, and this tendency should be encouraged, for imagination is a very valuable trait if it is under proper control. In fact, I believe in imaginative stories being told to children, and imaginative events being described to them, both to encourage the trait and to enable them to distinguish between imagination and lying. For instance, if you tell him a tale about himself that is purely imaginative, he will say, "Is it a true story or a fooling one, mother?"

Asking questions is a much discussed sub- The ject which I will just touch upon. Answer Question a child's sensible questions so long as he is 
interested enough to listen to the answer and remember it afterward. The annoying habit of a child's asking one question after another without waiting for an answer is to be discouraged. Always answer truthfully and do not try to make him feel that you are infallible, for he will lose faith when he finds you are not.

Above all teach a child to be happy. Instill happiness into him by being happy in his presence. We sometimes hear a mother say, "The children are cross to-day," when it is because she has been in a bit of an ill humor herself. Things have not gone right and the children have caught the spirit of it immediately. Allow them every pleasure that will do them no harm, so that the spirit of joyousness will blossom within them and they will learn to be happy even in adversity.

\section{DAILY ROUTINE}

Beginning the Day Right.

DiD you ever go into a home where everything went off like clockwork, so that it seemed as though the household moved smoothly on of its own accord? Every event in the day has its time and place. Well, 
that is due to a good daily routine. Even such a model household as this is terribly upset when a new baby comes into it, but the executive mother, as soon as she is strong enough, will set the machinery going right again. The first thing she does is to plan out baby's daily routine. The feeding times must first be adjusted, for these come at definite intervals which divide the day into sections. When we have decided upon the length of time between feedings necessary for this particular baby, - two, two and one half, or three hours, and it is usually three hours (see "Feeding"), - we start the first feeding at a given time, say six o'clock in the morning, thus beginning the day right. This will give the nurse or mother time to dress, have her breakfast, give the baby a bath, and even make up the bottle-fed baby's feedings before nine o'clock, when the next feeding is due.

After the nine o'clock feeding, the baby is taken out for his airing and morning nap. The Day's Schedule.

If there is a yard or fire escape available for this part of the day's program, the mother has this interval free for other duties. At 
twelve comes another bottle, followed by the mother's luncheon and baby's afternoon nap and airing. At three there is another feeding, followed by an interval, during which baby has his recreation hour, lying on the bed or sitting on the floor at play by himself. During the hour before six he may be held in the lap or entertained, if one has the inclination, or if he gets restless and fussy by himself. After the six o'clock bottle, he goes to bed for the night and is not taken out of bed again until morning, except for his feedings. The mother or nurse then has her evenings free to do many things she wants to do. I have heard mothers say that they never realized there was a baby in the house after they adopted some routine of this sort. The routine has to be changed with changed conditions, but I have outlined this one which has proven very useful to many of my patients.

Necessity of Changing the Program as the Child Grows Older.

As the child grows older, the daily program has to be changed, the mother having meanwhile learned to develop the routine that serves her best. She should remember, however, that routine is meant to aid her in performing her duties in the easiest way as well 
as to bring up baby to be orderly and systematic. She must not become a slave to routine, so that the day's work is a drudge, for the best of rules are meant to break when the occasion demands it. For instance, when the child reaches the age when four meals a day are necessary, the mother very likely reads a diet list which prescribes breakfast at six, a lunch at eleven, dinner at two, and supper at six. Her own meals must come in between these hours, so that there is some meal being cooked in the household nearly all day long. How much simpler it is to have baby's breakfast and luncheon at the family's regular meal hours, with a bottle at 10 P.M., to make up the four feedings. In this way the mother makes a routine which is easiest for her and equally as good for the baby.

\section{HABITS}

As I have said, a child is a creature of habits, and so are we all. Let us begin with him early and make the habits good ones. Train him to do the right things from the start. The habit of regularity, the habit of cleanliness and the habit of happiness may 
be started, and are even best started, in infancy. The habit of the bodily functions, the habit of orderliness, the habit of obedience are developed as he grows older.

Cleanliness and Orderliness.

Habits of cleanliness are cultivated by constant watchfulness. There is no need of a child's covering himself with mud as soon as he has been dressed, nor of smearing himself with food as he eats. The older child develops habits of orderliness by being taught to hang up his clothes as they are taken off, and by putting his toys away when he is through with his play. $\mathrm{He}$ is taught to pick up after himself as he goes along, instead of leaving one grand clutter to be cleaned up after he has gone to bed.

Proper As to the bodily functions, if we keep his Training of the

Bodily Functions. diapers dry and clean in infancy, he learns to warn us by crying when he is wet and uncomfortable. If, as he grows older, we put him upon the chair at regular intervals, he learns to make the function of urination a voluntary one and under the control of the will. So, at eight months or thereabouts, put him on the chair every hour while he is awake and gradually lengthen these intervals 
until at a year he will reward you for your labor by keeping dry all day long. Take him up at night when you go to bed (giving him dry suppers) and he will form the habit of not wetting the bed as soon as he is old enough to have his ten o'clock nursing or bottle discontinued. The habit of the bowel functions I have spoken of under that heading.

There are bad habits that baby acquires himself, and there are bad habits which we The "Baby Comfort." deliberately bestow upon him. In infancy the most common of these is sucking. The use of the "Baby Comfort" or nipple is never a habit he picks up himself. It is taught him by his elders, who show little sense in compelling him to acquire a habit which is injurious. It is natural for the baby to get his food by sucking, but the continual sucking deforms the mouth and jaws and is the chief cause of protruding teeth in adults. That it also causes adenoids and enlarged tonsils I am firmly convinced. Finger sucking and sucking of the sheet and clothing the Finger Sucking. child learns himself, and it is still more injurious and more apt to be continued through 
the second and third years. Even sucking of the lips sometimes becomes a habit. These sucking habits require different treatment according to the age of the child and the form the habit has taken. Babies may be broken of finger sucking by putting on mittens or pinning the sleeves to the dress or bed clothes. Older children may wear celluloid gloves for a few nights. Sucking of the sheet or pillow case may be remedied by taking that article away from the child's bed altogether. The best way to treat any bad habit is to put a stop to it at its inception.

Some children cannot go to sleep without pulling the ear or twisting a curl of hair about the fingers. These habits are not as harmful as some others, but it is well to check them lest worse ones follow.

The Importance of Selfmastery.

Nail biting in itself does no harm except to disfigure the nails, but the very notion that a child gets, that he has a habit which he cannot stop, is harmful in itself. $\mathrm{He}$ should be persuaded to give it up by rewards, or otherwise, so that he may acquire a sense of self-mastery. This knowledge that he has himself in control is a wonderful trait to ac- 
quire, and if more children were taught it, fewer young men and women would fall by the wayside when more serious temptations present themselves. 


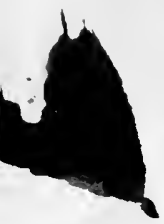




\section{PART III}

\section{COMMON AILMENTS}





\section{THE SICK ROOM}

We are not all situated so that the ideal Arrangesick room is a possibility. Apartment ment of the Sick Room. dwellers especially have to be content with as close an approach to it as is practical under the circumstances. It is, however, absolutely necessary to give up one room exclusively to the sick child at whatever sacrifice it requires - that is, if a prolonged sickness is anticipated. This should be the quietest, sunniest, airiest room in the house, even though you have to take a room which is not ordinarily used for a sleeping room. The chief consideration is the matter of airing. Under no circumstances should we select a room which cannot be aired while the patient lies in bed, and at the same time be well heated. It is not necessary to take down the pictures and hangings and take up the rugs, but this may be done if one wishes. It is best to have the bric-a-brac and knickknacks removed, and the table and bureau top swept clean of its usual complement of articles, so that the furniture may be used for medicines and other paraphernalia of sickness. . The bed should be so placed that 
the sun will not shine directly into the patient's eyes, and it should also be out of the direct line of a draught when the windows are open. This being impossible, a screen may be used.

The Sick Room Conduct.

The sick room conduct is of the greatest importance. All should be quiet and orderly and systematic. No visitors are allowed until permission has been granted by the physician. Engaging in prolonged conversation even in an undertone is very disturbing to the child. Never more than two persons are allowed in the room at the same time, and unless some particular duty relative to the treatment requires it, one is all that is necessary. If there is a trained nurse in attendance, do not hamper her with any interference. She can gain the child's confidence more quickly if she is given a few hours alone with him than she can if you are there. Where there is no nurse, one person should be responsible for all that goes on in the sick room. She should be relieved of her duties for her sleep, as she is not competent to attend to the patient properly when she is tired out for want of rest.

In contagious diseases, the person in attend- 
ance should not leave the room, but should In Case of have her bed there, or, better still, in an Contagion. adjoining room. Where two nurses are required, a second room is indispensable. All dishes should be kept separate and washed in the room if possible. All clothes, towels, and the nurse's outer clothing should be soaked in a solution of carbolic acid, one half ounce to a gallon of water, before they leave the room to be laundered. No visitors are allowed - even the family should not come into the room for fear of carrying the contagion about the house.

\section{CONTAGIOUS DISEASES}

Iт is odd that with the present popularity of medical lay articles, the writers have not shown more interest in teaching the public how to avoid the common contagious diseases. Such information would certainly be more helpful than the pages devoted to the problematical causes of infantile paralysis and other subjects which have not yet been settled among the members of the medical profession themselves.

In the first place, never expose the child 
Exposure to any contagious disease in order that he to any Contagious

Diseases to be may have it once and done with it. Even the so-called simple children's diseases, such as Avoided.

measles and whooping cough, have a death rate that is appalling. Nor should you allow politeness to stand in the way 'when there is any danger of your own child getting a contagious disease. This may sound like unnecessary advice, but I have known parents to say they could not offend their friends by refusing to see them when there was a contagious disease in the family from which the caller came. Never take your child into a household where there is any sickness whatever, for it may turn out to be a contagious illness no matter how it begins.

Each contagious disease has a special mode of invading your family and there is a special way of preventing its invasion; so I will take up the important considerations of each disease, one at a time.

Searlet Scarlet fever is among the most dreaded Fever. diseases of childhood, and rightly so. It is also one of the most contagious, but fortunately the danger of contagion is not so great during the early stages. I have known a 
child to sleep in the same bed with another child coming down with scarlet fever and not catch it. From this it is evident that we should remove the already exposed child away from the contagion as soon as we discover it, no matter how late that may be. In scarlet fever there is a chance, at least, that he has not contracted it from this one early exposure. However, the disease is caught early through the vomitus, and consequently it is safer to avoid a vomiting child in the streets, cars, and public places anywhere. Unfortunately scarlet fever is contagious for a long while after it has actually set in. As long as there is any peeling or discharge from the ears or nose, the danger of contagion is still present. Everything with which the scarlet fever patient has come in contact during his illness may be regarded as a source of contagion even months and years after the illness.

Measles, on the contrary, is just as con- Measles. tagious in its early stages, when the eyes and nose are running and four days before any eruption has appeared, as it is at the height of the disease. This is why the whole family 
is liable to come down with it when one member of the family brings it home. Unless the physician is called during this stage, the disease is not diagnosed until the eruption appears, when it is too late to prevent the rest of the family from getting it. This is also another reason why we should keep our children away from any one, especially another child, who has a cold in the head. I have had the misfortune to treat for measles ten children in different families who had all attended a birthday party at which was present a child who was in the catarrhal stage of measles, no eruption having made its appearance in the child when he went to the party. His mother thought he simply had a bad cold and let him go. It is needless to say that that mother was not popular in that particular set for a long while afterward.

Diphtheria. Diphtheria, I am happy to say, is one of the contagious diseases which the physician can prevent absolutely after the child has been exposed. An immunizing dose of diphtheria antitoxin will always make it a certainty that a child will not get this dreaded disease in spite of definite exposure to it. There are 
no dangers in giving antitoxin in its presentday perfection, no matter how delicate the child may be. Sometimes there is a slight discomfort following its use, but this may be disregarded when we consider what a dreadful disease this was before the days of antitoxin. A person may have diphtheria many times, in fact some people have the habit. I know a physician who has had it fourteen times.

Whooping cough is not so contagious as some of the other infections, but it is fully as

Whooping Cough. dangerous once it is acquired. It cannot be carried by the third person, and one exposure may not be enough to cause it. The person having it is a source of contagion as long as he has a paroxysmal cough, this period varying from six weeks to three months. The death rate from this so-called benign disease is as great in New York City as that from scarlet fever, diphtheria, and measles combined. Therefore, keep your child away from whooping cough, especially your baby, for it is most fatal among children under a year. It is well to keep children away from anybody who has a cough. Once acquired, 
do not become pessimistic and think whooping cough must "run its course." Your physician can do something to prevent the severity of the disease, and he can often shorten its duration. He can usually prevent the complications which are the dangerous phases of the disease.

Neither mumps, chicken pox, nor German measles is a dangerous disease if the child is well cared for during its run.

Smallpox. Smallpox may be absolutely prevented by vaccination, provided the vaccination takes properly and provided it is done often erough. I have no sympathy with anti-vaccinationists. They do not recognize the fact that before vaccination was compulsory, epidemics of smallpox swept over the country, leaving one third of the population dead and many others marked for life with the pits of this most dreaded of diseases. It was with the utmost satisfaction that the medical profession in recent years witnessed the deliberate exposure to smallpox of a prominent antivaccinationist of Boston. He had claimed that there was no danger to the unvaccinated from the disease. He acquired smallpox at 
the prescribed time and barely escaped with his life. Every healthy child should be vaccinated before he is six months of age. $\mathrm{He}$ should subsequently be vaccinated once Vaccination. in five years and when he is exposed to the disease. There are no dangers at the present time from vaccination if it is done properly and the wound kept clean until it has healed. Any serious trouble always comes from the lack of these precautions.

Colds and coughs, sore throats, and tonsilCoughs litis are certainly contagious. Keep your chiland Colds dren away from people who have any of these ailments. However, the better your child's hygiene and the better his general condition, the less liable is he to become infected if exposed to them. Kissing is an unfortunate custom of civilization, for it spreads disease, especially coughs and colds. It would hardly seem necessary for parents to be constantly on their guard to prevent the kissing of their children by friends and strangers, but such is the case. Public drinking cups are the cause of many illnesses and the common cup at school should never be allowed. (See "Colds.") 
The Mcs- Mosquitoes are the sole cause of malaria. quito and the Fly.

In malarial districts take the most rigid precautions to prevent mosquito bites. The much-abused house fly deserves his reputation. He is the carrier of typhoid fever, bowel troubles, possibly infantile paralysis, and other infections.

School Inspection.

Schools are the chief source of the principal contagious children's diseases, as the statistics show that these diseases are most rife during the school months and in children of the school age. In our large cities the public schools are well inspected medically. It is our duty to our children to demand proper medical supervision in the private school, also, before we place them in one.

Tubercu- Tuberculosis is a contagious disease. It losis, or Consump. has so long been considered an inherited tion. disease that the general public find it hard to get the old notion of transmission from parent to offspring out of their minds. To be sure the tendency may be inherited, that is, a poor and weakened constitution, but this may be overcome with comparative ease under the proper conditions. Children from a tuberculous family should have especial 
care paid to fresh air and diet from the moment they are born. They should be kept in robust health by fresh air night and day, and by having the diet a nourishing one. The vigilance of the parents should never be relaxed in either direction. On the other hand, exposure to tuberculosis should be avoided. By this I do not mean that children will acquire tuberculosis upon one exposure, but that they should not live with tuberculous people nor come in contact with them daily. For this reason it would be well if the general public looked upon tuberculosis as a contagious disease. Care should be taken that the nurse has no cough and has not been in contact with people suffering with tuberculosis.

I believe that many cases of tuberculosis in children come from living in houses or apartments where consumptives have formerly lived. When we realize how many families move into a house whose former occupants are not known to them, it is only to be wondered at that this disease is not spread even more than it is. I believe milk to be a source of tuberculosis in spite 
Milk as a of the fact that certain authorities have Cause of denied this mode of transmission. In no
Tuberculosis. other way can we explain some of the cases of tuberculosis in children. Therefore, all milk used in making infants' foods, as well as milk for older children, must be from tuberculin-tested cows. Since an infant so often depends entirely upon milk for his sustenance, this is more important in infancy than at any other age.

\section{FEVER}

How to Tell if a Child has Fever.

Children get fever very easily, so that this symptom has not so much significance in a child as in the adult. Fever often goes as quickly as it comes. It is usually easy to tell whether or not a child has fever by feeling ' of the body underneath the clothing and by his flushed face and glistening eyes. It does not seem necessary for mothers to have thermometers, for in my experience these have been a cause of worry without being of any particular benefit. The untrained observer is not able to judge correctly the significance of the different degrees of fever. A high fever often serves to make the mother un- 
necessarily nervous when there is no cause for alarm, and a low temperature may occur in a child who is dangerously ill. It is enough, therefore, for her to know that there is a fever, and this knowledge she may gain by her sense of touch.

With the onset of fever it is usually safe to administer a cathartic, stop food, and give an hat to do in Case of Fever. alcohol friction bath in the following manner : The clothing is entirely removed and a dry sheet or blanket wrapped around the child. One part is exposed, say an arm or the chest, and wet with equal parts water and alcohol. This is then rubbed briskly but lightly with the hand until it has dried. It is moistened again and the same process repeated, the whole body being gone over back and front in this way. A half hour is allowed for the entire bath. Do not dry with a towel or cloth. It is the cooling during evaporation, together with the friction, which brings the blood to the surface, that takes down the fever.

Plenty of water to drink may be allowed if there is not excessive vomiting. In fact cold water helps to take down the fever and 
dilute any poisonous products within the body.

If the mother has not controlled the fever within twelve hours, or at least made sure of the cause of it so that she knows she can control it, she should not take the responsibility of treating the child further herself.

\section{COLDS AND COUGHS}

How to

Prevent Culds.

"Hardening" Process.

The best way to treat colds is to prevent them. There is no necessity of a child's having a cold most of the time, even though he is exposed to the infection through adults who have colds. His physical condition should be so healthy that he resists the infection when he is exposed to it (for colds are contagious), and he should never acquire

The a cold of his own accord. This physical condition involves the so-called process of "hardening." It means fresh air every hour of the day, winter and summer. It means avoiding overexposure, direct draughts, and wet unprotected feet. It means getting the skin to react promptly and properly to different changes of temperature by correct clothing and by cold baths. It means the 
right diet and proper, sufficient nourishment. It means plenty of sleep and an orderly routine of existence. It means that the child must be free from adenoids and enlarged tonsils (abnormalities which I have discussed under their respective headings). If it is worth while to prevent our children from having colds, then we must work, and work intelligently, to do all these things right.

There is no doubt about it that the warm steam-heated apartment, with the dry air Other Necessary which steam heat gives, dries out the mucous Precautions. membrane or lining of the nose and air passages so that they are susceptible to infection and colds. I would recommend placing a jar of water on every radiator so that the air may be moistened somewhat to prevent this error in artificial heating. I would also recommend, where steam heat is used, that the twelve to fourteen hours of sleep should take place in an unheated room, no matter how cold the weather may be. Turn off the radiator as soon as the child is in bed and open the windows, the child bcing warmly clad for the night. If you have done all 
these things and done them right, your child will not have continual colds, as I have proved to my satisfaction over and over again.

Colds due to Change in Climate. part of the country to another, he may not be able to throw off the new variety of contagious colds that are rampant in the new climate, even though he is in good enough physical condition to resist those infections where he has come from. This is because he has formed a resistance (or acquired immunity) from the bacteria in his own country but is overwhelmed by the new variety of germs in the next place he goes to. He has not become acclimated.

The Treatment of a Cold.

A cold once acquired needs to be handled properly. I cannot give you any one treatment for all kinds of colds, for there is none such. I would, however, advise against overdressing the child and the use of flannel about his chest and throat. I would most certainly not omit the bath. I would be still more persistent about the child's having his full supply of fresh air. In good weather I would not keep him in the house for a cold, unless he has a fever. 
Sore throats are dangerous things to dally with, for it is very difficult for any one unSore Throat. skilled in throat examinations to tell the difference between tonsillitis and diphtheria.

Coughs are often due to the same causes as colds. There are, however, other causes which we must consider. Errors in diet are Coughs Their Causes and Significance particularly liable to cause coughs, as are adenoids and enlarged tonsils. I have children under my care that develop a wheezy cough whenever they overeat or "stuff," or when they eat certain articles of food which have been prohibited. A chronic cough should never be allowed to go on, and a child who has many coughs throughout the winter should have a thorough overhauling to find. the cause. Tuberculosis is always lying in wait for the child with the chronic cough, particularly after an acute illness, such as pneumonia, measles, whooping cough, and other children's diseases.

\section{CROUP}

Croup is a spasmodic contraction of the larynx or air passage which may occur during the course of any ordinary cold. Some 
Croup - children, and even all the children in certain

Its Causes

and Symptoms. families, are prone to have croup whenever they have a cold, while others never have it. The child perhaps has had a cold through the day and goes to bed in a fairly comfortable condition. Suddenly he awakens and sits up gasping for breath. The breathing is slow, noisy, and labored, and he is in great distress. There may or may not be a sharp, distinctive, brassy, barking cough. The excitement which the condition causes in those about him only increases his symptoms. Untreated, this condition continues three or four hours, when his fatigue causes the spasm to relax and he goes off to sleep. If it lasts longer than this, our suspicions should be aroused that we are not dealing with ordinary croup, but with diphtheria, or some more dangerous condition. This is also true of "croup" developing in the daytime. A child never dies of uncomplicated spasmodic croup, so even in his distress we should be consoled with the fact that he is in no danger, provided the diagnosis is correct. The next day the cold may be as it was the day before, and again after he has gone to bed the brassy 
cough develops and the same distressing scene takes place.

The treatment during the attack consists How to of the following measures:

(1) Wring out $\begin{gathered}\text { Treat } \\ \text { Croup. }\end{gathered}$ dry in cold water $\left(60^{\circ} \mathrm{F}\right.$.) a soft cloth folded into at least six thicknesses. Place this quickly about the neck from ear to ear, underneath the chin. Cover with a piece of oiled silk or thick waxed paper, which is held on by a handkerchief tied about the neck. Change this every half hour until the croup has subsided, when it should be discontinued. (2) Cover the bed or crib with a sheet and set the croup kettle going with the spout underneath the sheet. (A steaming teakettle kept boiling by an alcohol lamp or gas stove may be rigged where a croup kettle is not at hand, care being taken not to set fire to the bed clothing.) This may be continued for hours or until the noisy breathing has subsided, even after the child has gone to sleep. (3) If the breathing is extreme, or if the above measures are not effective, or if the croup is caused by indigestion, administer one to two teaspoonfuls of sirup of ipecac, which will produce 
vomiting and cause the child to relax at once.

Suitable medicinal measures should be instituted through the day to prevent a recurrence of the attack the next night, and proper treatment begun to prevent further attacks.

\section{CONVULSIONS}

One Convulsion Leads to Another.

BABIES and young children have convulsions when anything is wrong just as the adult has a chill or a severe headache. The oldfashioned mother used to think that her baby was entitled to so many convulsions anyway, and she was therefore very little disturbed when he had one. This was very wrong because even one convulsion, especially if it is prolonged, may do permanent harm. Besides that, one convulsion predisposes to another, and the more of them a baby has the more he is liable to have. Epilepsy is thus started in this way. Some children are far more liable to convulsions than others and have them on the slightest provocation. Unless the child has some definite disease of the brain, convulsions can be controlled by proper treatment so that he won't have 
any more, provided the treatment is begun before too many have occurred.

The vast majority of convulsions are caused by something the child has taken into his stomach, by indigestion, or by incorrect diet. By simply changing the diet, I have many times put a stop to convulsions in children who have had them in increasing numbers for over a year. Other causes are: the beginning of an acute illness, irritation about the genitals, intestinal parasites (worms), adenoids and enlarged tonsils, inflammation within the ear, slight injuries to the head, teething (exceptionally, and only when the process is abnormal), rickets, and poor nutrition of any sort. Slight attacks called "petit mal" are precursors of convulsions, and children having them should be treated "Petit Mal." before they develop into real ones. In these attacks the child stops suddenly and stares straight ahead without moving a muscle. This lasts from a few seconds to a minute, and then he comes to with a start and acts as if nothing had happened. In the more severe kind, the whole body becomes stiff and rigid for a minute and then it is over. 
The Treatment of Convulsions.

When a child is suddenly seized with a convulsion, all is confusion and we are unprepared to do anything for him. It is well, therefore, to have some orderly method of procedure which we may institute at once. (1) Loosen the clothing, but do not take it off except the shoes and stockings.

Place the child upon a bed or table with his legs hanging over the edge from the knees down. (3) Put his feet and lower legs into a pail of hot water to which has been added one tablespoonful of powdered mustard, if it is at hand. If there is no mustard, use hot water alone. Be very careful that it is not hot enough to burn. (4) Put an ice cap to the head; lacking an ice cap, use plenty of cracked ice done up in a towel. (5) Give an enema of warm soapsuds. Repeat, if it is not retained. (6) As soon as the child is able to swallow, give a large dose of castor oil. By this time the physician, who has probably been hastily summoned, will arrive and he can give any medical treatment required to prevent a recurrence of the convulsion.

I do not approve of the full hot bath in 
unskilled hands because it is apt to cause Possible harm when hastily done. I have seen children get bad burns from such baths, and I Hot Bath. have seen them catch cold from being put into the bath with their clothing on and allowed to lie around in the wet clothing afterward. It is usually very difficult to take the clothing off while the child is in the convulsion.

Older children have a towel or spoon handle put between the teeth so that the tongue will not be bitten. Allow the child to go to sleep as soon as possible after the attack. After a child has had more than one convulsion, no matter how long the interval between them, take him to a physician so that the cause may be discovered, and treatment instituted to prevent further attacks.

\section{ACCIDENTS}

MANY mothers are not within reach of the doctor when accidents occur. Consequently Emergency Supplies.

it is well, especially when starting out on a summer vacation, to be prepared for a few of the most common emergencies. The first thing is to lay in store the following list of 
necessary supplies: A five-yard package of sterile gauze; half a dozen sterile gauze bandages, assorted widths; a pound of absorbent cotton; a bottle of corrosive sublimate tablets, $7 \frac{1}{2}$ grains each; a bottle of creolin.

Cuts or

Open Wounds.

In the case of cuts or open wounds of any sort, first stop the hemorrhage where it is excessive; second, prevent infection or blood poisoning by keeping the wound clean. Hemorrhages can usually be stopped by using a piece of sterile gauze held firmly over the bleeding spot or bound tightly over the cut with a bandage. In bad bleeding of the extremities, a tourniquet made of a rope or strip of cloth is twisted tightly about the extremity between the wound and the body until the bleeding has stopped. Where there is little bleeding, the most important thing is to prevent infection. This is done by. soaking the wound for half an hour in a hot antiseptic solution (one corrosive sublimate tablet or one teaspoonful of creolin to a quart of water). A piece of sterile gauze wet with the antiseptic solution is then placed upon the wound, and after bandaging, is left un- 
disturbed until the wound has healed; or, if gaping open, until the physician can give it further care.

If the skin is unbroken, bruises require Bruises. no special treatment except, perhaps, where they are very extensive, - in which event, ice is immediately applied and the injured part allowed to rest for a time.

Fractures or broken bones are worthy of Fractures our notice here only to call attention to the ${ }_{B}^{\text {or Broken }}$ fact that often in infancy and in childhood they seem to cause comparatively little pain. For this reason, after a child has had a fall, he soon gets over the original hurt and makes no fuss except perhaps when he is undressed, taken up, or handled. If we watch him closely, we will see that he doesn't move the arm or the leg or whatever part is affected. I have had children brought to me three or four days after the accident and I have found that they had a broken collar bone or a broken arm which had gone unnoticed for that length of time.

Nosebleeds, if habitual, are caused usually Nosebleeds. either by adenoids or by ulcerations on the inside of the nose. Both of these conditions 
should receive their appropriate treatment in order to stop them permanently. The treatment at the time of the nosebleed consists in keeping the child quiet in the upright position, unless he is faint, putting a piece of ice to the back of the neck, and holding the nose firmly between the thumb and forefinger. The latter is done on the chance that the bleeding is caused by an ulceration on the septum of the nose. Blowing the nose is prohibited until all chance of a return of the hemorrhage has gone.

Foreign Bodies in the Ear or

Nose.

Foreign bodies, such as beans or pebbles, in the ear or nose should not be too vigorously sought for by the untrained attendant, as sometimes this serves only to poke them farther in or to break them into bits so that the physician has a good deal of difficulty in removing them when it comes his turn to try and get them out. We should also remember that there is no urgent hurry about removing them as they may remain there a number of hours without causing serious harm. However, if there is no physician available, a small steel hairpin may be straightened out and a small hook made of it 
by bending one end over sharply ( $\frac{1}{4}$ inch). This is then passed up the nose flat against the septum or inner wall and after the hook has passed by the foreign body, it is turned outward, so that it will catch upon the top of the offending particle, and pulled gently down. The same process may be used in the ear, but it is more difficult, and I would not advise it except in case of absolute necessity.

Foreign bodies in the throat, too, are often not so urgent as they at first seem. As long

Foreign Bodies in the Throat. as the child is breathing all right and is not blue in the face, do not do anything to make matters worse. It is marvelous the size of object a child can get into his throat without a great deal of discomfort. I recall the case of a child six months old who had swallowed a silver dollar. His mother was sure he had swallowed it because she had seen it go into his mouth, and had poked at it with a pair of scissors as it was going down. When I got there, the child was in far better condition than the mother, and breathing more regularly. I put in my finger and pulled out a plum, in the form of a silver dollar, that had lodged behind the palate - where she had 
poked it, I presume. In case the breathing is hard and the child is choking, grab him by the legs and hold him upside down while some one pounds him on the back. If he does not cough the object up and is still blue in the face, put your finger as far back-in the throat as you can reach and try to dislodge it.

When Children often swallow such things as Children Sivallow "Things." open safety pins, screws, and coins without its doing them any harm. In due time these objects travel through the stomach and bowels into the world again. Do not administer cathartics, but give the child plenty of coarse food - oatmeal; potatoes, and bran biscuits. In these days of the X-ray machine, it is best to take the child to your doctor, who will locate the foreign body and make sure it is not in a place where it will do harm.

Something in the Eye.
Foreign bodies in the eye, if they have not penetrated any part of the eyeball, are best removed by pulling the lid away from the eyeball with the finger so that the tears will flow and wash the particle away. Never rub the eye. When the eye ball is penetrated, 
you cannot take the child to an oculist too quickly.

There are three degrees of burns. The Burns. first is simply a reddening or inflamed condition of the skin; the second destroys the first layer of the skin, causing blisters; and the third injures the flesh itself. For the reddening or simple inflammation all that is necessary is to relieve the pain, and this may be done by covering the burned part with sweet oil and limewater, equal parts of each. If this is not at hand, sweet oil alone, or even lard or vaseline may be used. A burn of the second degree should be treated just like an open wound, because when the blister breaks, infection, or blood poisoning, may set in if it is not kept perfectly clean. For this reason, it should be entirely covered with a piece of gauze soaked in a weak antiseptic solution, such as I have described in "Open Wounds." It should then be left alone until seen by a physician. Burns of the third degree, where the flesh is actually destroyed, should be treated in the same way. These are apt to be much more serious and will in all probability leave a scar. 
Poisons. Children more often take poisons of various kinds than do adults. As prevention is better than a cure, all poisonous substances and medicines should be kept out of the reach of the child, and not be left where he may get them. Disregarding this rule has caused many a mother regret to the end of her life. Most medicines, if taken in excessive quantities, are poisonous. We should always bear this in mind.

As soon as it is discovered that the child has taken poison, send for the doctor at once, telling him, if possible, what poison has been taken so that he may come prepared for the emergency. It is always well to remember that an antidote for the poison is often printed upon the bottle in which the poison came. This saves time in looking up the treatment. A general principle which it is safe to follow is to make the child vomit at once. Whatever the poison, the sooner it comes up the less harm it will do. If the antidote is known, it may be given before the emetic which is to produce the vomiting, and in some instances repeated after the vomiting. The best emetics are those which are always at 
hand in every household. Mustard flour; two teaspoonsful to a glass of water, usually starts vomiting at once. As soon as it is swallowed, the finger is stuck down the throat to cause gagging, so that the child will not retain the mustard long enough to burn the stomach. Another good way to produce vomiting is to give a glassful of strong soapsuds. Sometimes just sticking the finger into the throat after giving a glass of warm water will produce the desired result. Sirup or wine of ipecac, one to two teaspoonsful, is the best emetic of all, but it is not always at hand. A list of antidotes for the various poisons is appended in the back of this book.

\section{BED-WETTING}

There are many causes of bed-wetting, and it is always well, first, to find the cause Causes of Bedwetting. before trying to treat the child for this condition. A small percentage of the children who have this unfortunate failing have some organic error back of it. The principal disturbances of this sort are adenoids, enlarged tonsils, and irritation about the genitals, incorrect diet, constipation, and pin- 
worms. Although it is necessary to make sure that the bed-wetting child has none of these things, such cases are far in the minority. The vast majority are caused by lack of training in early years. When the child is eight or nine months of age, he should be trained to use the vessel instead of remaining wet. In this way he learns to make the act a voluntary one under the control of his will. It is a lot of work to put the child on the vessel every hour throughout the day, but in the end it saves a lot of trouble. It is surprising how soon children with the help of this training will learn to use the chair. At the end of the first year he will reward his mother by remaining dry all the time. At eighteen months of age, the ten o'clock nursing is usually stopped. This gives the baby a chance to remain dry during the night. If he is taken up when the mother goes to bed, and possibly once more during the night for the first few weeks, he soon learns to keep dry all night long. By two years of age, he should stop wetting the bed altogether.

The Cure of Bedwetting.

How about the older child who has already established the habit of bed-wetting? We 
should first make sure that he has none of the organic troubles of which I have spoken. Probably it will be necessary to have him examined by a physician in order to be assured that everything is all right. This attended to, we should proceed in the following manner: (1) Begin with him just as though he were a little baby and put him on the chair once an hour throughout the day in order to get the bladder functions under the control of the will. This is kept up for about two weeks, and then we may lengthen the intervals to an hour and one half for two weeks more. After that, the intervals are increased gradually until he is made to pass his urine once in three hours throughout the day. This is a matter of training and should be rigidly followed for the effect that it has at night. Regardless of the fact that the child may already have good control in the daytime, it teaches him to pass his urine at will. (2) At first he should be taken up three times each night, later twice, then once, and finally not at all after ten o'clock. It is usually advisable to take every child up at nine or ten o'clock at 
Importance of Diet in Bedwetting.

night, until five or six years of age.

(3) No liquids should be allowed after 4 P.M. The supper should be absolutely dry, since soups and milk and such things are just as bad as water. This is a great hardship, but it is absolutely necessary.

(4) The supper should be a light one, consisting of bread, toast or crackers, with apple sauce or cut fruit, or the little child occasionally may have cereal with butter, to break up the monotony of the diet. The diet throughout the day should be, of course, a sensible one. (5) No tea nor coffee is allowed. They are stimulants that no child should have, but are especially harmful for bed-wetting children.

(6) Finally, if this treatment is not successful in breaking up the habit, medicinal measures are necessary, and the physician should be consulted.

Do not Punish Bedwetting Children.
A child should never be punished for bedwetting. Most children dislike the habit as much as the parents do, and it is punishment enough for them to wake up wet each morning. The younger the child, the more easy it is to overcome this habit of bed-wetting, and if such treatment is started soon after 
the second year, the habit can usually be controlled very easily in a few weeks. After five years of age, it may take months to effect a cure. Children who suddenly acquire the habit of bed-wetting in later childhood always have some organic cause which should be attended to at once. Usually this is some disease of the urinary tract.

Wetting the clothes in the daytime is a still more uncomfortable habit, and it, too, is most often caused by lack of proper training. The same treatment should be used for this condition.

\section{WORMS}

There was a time when every mother symptoms thought that her child had worms whenever of Worms. he was not in his usual good health, and the doctor laughed at the idea. Now we know that many children do have worms, especially country children and those who drink well water in the summer. Of course, a great many children who have all the symptoms of worms (grit their teeth at night, have a foul breath, and an irritation about the nose which causes them to pick at it, or even have convulsions), simply have indigestion. Any 
irritation about the rectum, if unexplained otherwise, is especially significant of pinworms. The general health of children with worms may or may not be poor. Often, however, they are pale and listless or nervous and irritable. The appetite may be poor, and it is rarely as ravenous as some parents expect it to be. It is not a bad practice to

How to Tell whether or not a Child has Worms.

watch the stools of these children. The only way we can make sure whether or not the child has worms is to see them in the stools or have the stools examined for the eggs. There are three common varieties: pinworms, which look like short bits of white thread; roundworms, which are two to six inches long and look like earthworms; and tapeworms, the latter come away in flat segments like a piece of ordinary tape.

Once it is determined a child has worms of any sort, it is useless to dally with a little worm medicine; instead, a regular course of treatment must be instituted, lasting over a number of days or even weeks. This involves diet, as well as medicine, and is too complicated for a work of this sort. 


\section{THE NERVOUS CHILD}

There is no doubt that some children are much more nervous than others. They either come from nervous families and naturally have a nervous disposition, or are made nervous by their surroundings and treatment. Such children must, of course, have different treatment from the placid easy-going child who is never upset by anything. And what do we mean by a nervous child? In the first place, one who is easily upset by a slight cause, or one who is easily frightened, or perhaps a child who cries a great deal on slight provocation. Some children show their nervousness by being afraid of things that ought not to cause fear, and others show their nervousness by having various pains and imaginary ills, just as the hypochondriac adult does. The twitching of a group of muscles is another way that the child has of showing his nervous make-up. These motions are called habit spasms or tics. They are so common that they hardly need de. scription. The child who continually blinks his eyes or shrugs his shoulders or makes any

Different Ways of Showing Nervousness.
Tartalang and Habit Ípasms. 
peculiar motion of the body does it more and more often until it has become such a fixed habit that he can only overcome it with great difficulty. Some children even have a nervous cough or rasping of the throat which becomes more and more a habit. It is very important to overcome these things in their beginning because if this is not done, the child grows up to be a nervous adult and has hysteria and various other neurotic tendencies all his life.

The unfortunate part of the whole subject is that the nervous child usually comes by his affection honestly; that is, he inherits a nervous disposition from one or both of his parents, and at the same time being constantly associ-

The ated with them, he is surrounded by nervous Influence of Nervous Surroundings. influences. For that reason I have occasionally found it necessary in some of the worst cases, to separate the child from the nervous mother. This may be done by sending the child away to stay with some relative, always being careful to select one who is not nervous herself. In other cases, a nurse may be found who is not of a nervous or excitable disposition. This will answer the purpose 
very well if she is allowed to have full control 'of the child. In still other cases, a mother, once she understands the cause of the child's condition, can be brought to look upon it in a sensible manner, and overcome it herself.

It is impossible to give any one plan of Treatment treatment for all nervous children, because of Nervous each case is different, and each child must be Children. handled with the utmost common sense and tact. There is one rule which applies to all, and that is for those who surround the child never to become excited themselves. Some children can be broken of their nervousness by severe and strict discipline, while others must be humored to a certain extent. They should never be allowed to listen to a recital of their own nervous symptoms, and they should not continually be told that they are nervous. In fact, it is sometimes best to overlook the nervous symptoms altogether. They should be allowed to play with other children of their own age, and not kept by themselves, as is often done. Sometimes in the younger children the nervous symptoms disappear when the child starts to school. 
In the older children of the school age, the nervousness may be aggravated by hard study or indoor life. Occasionally, a complete change of surroundings is beneficial. This change of surroundings is far more effective with children than with adults, because children forget more easily. Their curiosity stimulates them to new things more quickly, and old ties are soon cut off.

Many nervous children do not get enough sleep. Sometimes they sleep poorly because of the nervousness and sometimes it is because their daily routine is not a proper one. At the same time, the lack of sleep makes them still more nervous. The diet, also, has a great deal to do with causing such a condition. The strictest diet must be established and maintained. The child who has more or less indigestion, or who does not take plenty of good nourishing food, could only be expected to be nervous. 


\section{PART IV}

CARE OF THE SPECIAL ORGANS 


\section{THE THROAT}

The throat, unlike the eyes, ears, and teeth, The Value is an organ that needs no special local treat- of Throat ment in health. In fact, the use of sprays tion. and applications in the healthy nose and throat is to be deprecated. The healthy throat depends upon the general condition of the child and his mode of life. It is a good practice, however, to accustom the child to a throat examination after he is old enough to understand that it will do him no harm. When he is ill, he then submits to the examination without being upset by it, which sometimes makes a great deal of difference in the outcome of the illness. It is also well for the mother to become familiar with the appearance of the normal throat, so that she may recognize early any acute affection there.

Adenoids and enlarged tonsils are the two chief chronic conditions of the throat that are Adenoids and Enlarged common in children. Adenoids consist of a Tonsils. grapelike mass of tissue which grows back of the palate in the passage that leads from the throat to the nose through which the air must pass when the mouth is shut. They 
may be large and completely fill the passage, or they may be smaller so that some air may pass by them. Tonsils are normally in the throat. They are harmful when they are much enlarged or ragged, or are the cause of frequent illnesses.

Cause of Adenoids and

Tonsils.

We often hear the question asked, "Why do so many children have adenoids and tonsils nowadays? They used to be unheard of." There are two answers to this question. The first is that we live under different conditions than we formerly did. Apartment-house life, steam-heated houses, richer foods, more coddling, and the constant use of nipples or baby comforts, have brought about this condition. The second reason is that children did have them, but they were unrecognized at that time.

Why Adenoids and Enlarged Tonsils should be removed.

Many an adult carries about with him to-day physical abnormalities which are the result of untreated adenoids and tonsils. Deafness for life is one of them. A deformed narrow jaw and prominent nose with the characteristic open fish mouth is another. How many people do we see in the course of a year who have grown up with 
this typical facial expression, when they might have been beautiful to look upon if their throats had been properly attended to in childhood? Upon the question of tonsils the writer feels very strongly, for through his childhood he had three or four attacks of tonsillitis a year which still leave a lasting impression upon his mind and which would have been eliminated had his throat received proper treatment. The tonsils are also the seat of entrance of many other infections besides tonsillitis.

Breathing with the mouth open night cr day, snoring at night, restless sleeping, poor Symptoms of Adenoids. nutrition and debility, loss of appetite, nervousness, bed-wetting, impaired hearing, as shown by lack of attention, backwardness in school, seeming stupidity, nosebleed, defective speech, a nasal voice, and frequent colds, - all are symptoms of adenoids.

The only treatment that is of any avail is to remove them. It is sometimes wonderful the immediate improvement following this Removal the only Effective Treatment procedure. As to the age at which this may be done, I would most emphatically say that there is no age limit. I have seen 
babies four months old who have never done well because of the obstructed breathing during nursing and sleep. The removal of the adenoids caused them to show improvement at once, so that they took the first good nursing of their lives a half hour later, and got fat and strong without delay.

" Do .Another question that is frequently asked Adenoids is, "Do adenoids return?" They sometimes do grow again, but that is no argument against their removal. A child is developing every day of his life, and if the operation gives him only a year, in which he is free of this obstacle to his proper development, just so much is gained. They may be removed again if necessary, but fortunately this is not a common occurrence.

\section{THE TEETH}

THE first tooth is awaited with the greatest interest, and let us hope that this interest in those useful and beautifying organs of mastication will not abate as the novelty

When the Teeth should Appear. ceases to be entertaining.

The two lower central teeth come first, at six or eight months; the four upper central 
teeth two months later; within the next two months the two other lower teeth appear on either side of their fellows. Taking count, therefore, we have the eight central teeth at a year or a little later. At fourteen to sixteen months come the four double teeth, and at a year and a half the eye and stomach teeth come along to fill in the space that intervenes. There are then sixteen teeth, the full complement with which the child may chew hard food. We may not expect the four other double teeth until two and one half years, when our baby has all the temporary masticators, twenty in number.

We should not worry too much if the teeth do not come along upon schedule time. The breast-fed child is far more apt to have

Delay or Irregularity in Teething. his teeth early and easily, than is the bottlefed baby, and the children of certain families are prone to early teething, while others get theirs late. Any marked delay or great irregularity of teething may be caused by errors in diet or by nutritional abnormalities. Extreme delay in teething should be looked into, as rickets and other nutritional diseases are particularly apt to cause it. 
Teething a

Natural

Process, not to be Dreaded.

Teething during the summer is often dreaded by the mother, but if her child is properly nourished and well cared for, she need not fear any great amount of disturbance. We are apt to lay everything to teething because it is easier to explain an illness in that way than it is to look into the real cause. We must remember that teething is a natural process, as normal as the development of the bones or muscles or any other part of the body ; it is so easy to say a child has this or that "because he is teething." I have had the privilege of observing a great many children during the teething period and it is in the great minority of my cases that I see much disturbance from this cause. This is not invariably true, however. Perhaps a few days' discomfort is experienced and the tooth comes through. However, when the gums are red and swollen and the child is irritable or even sick from the discomfort, we should help the eruption of the tooth by rubbing the inflamed gums with a rough towel. Such a procedure is usually welcomed by the uncomfortable baby and may bring a tooth through far sooner than 
it would otherwise have come. Lancing of the gums is occasionally necessary, but when it is done too early, a scar is left which is far harder for the tooth to penetrate than it would have been if we had not meddled.

The eruption of the second teeth gives very The little discomfort, which is sufficient proof in my opinion of the theory that the first teeth should come through without much trouble. The molars or back teeth are the first to appear at five or six years of age, before any of the first or temporary teeth have come out. At seven years comes the ugly stage when the front teeth drop out, but the space is soon filled by the permanent teeth. At nine to ten years the temporary double teeth give place to the permanent double teeth, the bicuspids. At twelve years the canines, or pointed teeth, take the place of the temporary ones, and at twelve to fourteen years the next double teeth, or second molars, appear behind those that came at six years. Finally, when the child is a child no longer, - at eighteen to twentyfive years of age, - the wisdom tecth come

Appearance of the Second Teeth. 
along to make.up the full set of thirty-two teeth.

The Care

of the Teeth.

The care of the teeth begins as soon as the first one comes through. The softest toothbrush it is possible to get, baby size, is purchased, and the teeth brushed night and morning. Later the brushing is best done after each meal. Tooth powder should not be used, but a mild antiseptic like glycothymoline is added to the water. The teeth are brushed up and down, as well as from side to side. Pay as much attention tu brushing the child's gums as you do the teeth, as it keeps them in good condition. It is not necessary to pass a thread between the teeth if their contour is good, because nature has made their shape so perfect as to allow no food to collect there. But if they are irregular or have once started to decay, it is of the greatest necessity to use the thread after each meal.

Causes of Decayed Teeth.
The causes of decayed teeth are three in number : errors in diet, lack of proper cleaning, and disuse, by which I mean the absence of hard chewable food in the diet. The diet should be nourishing and contain the proper 
proportions of meat, eggs, vegetables, fruits, starches, and fats. There should be no eating between meals and a minimum amount of sweets should be taken. Cereals and soft, mushy food should not be given to the exclusion of hard food. Bread toasted in the oven, zwieback, hard crackers, are an important part of the dietary, and they should be chewed without moistening so the child can harden his teeth by long chewing. Dogs naturally have exceptionally hard teeth because long use in chewing up bones has made them so. Nature usually arises to the demands put upon it, and I believe the present generation has bad teeth as much from this lack of use as from any other cause. This is not a theory, but a fact that $I$ have put into practice with remarkable results.

When there is a decayed spot, it should be The filled at once. The teeth should thereafter Importance of Dentistry. be inspected once or twice a year by a dentist. The temporary teeth should not be extracted before their time unless it is absolutely impossible to fill them. Remember that the six-year-old molars are permanent teeth and take special care of them. 
Brittle teeth are sometimes caused by adenoids. Protruding teeth are most often caused by finger sucking. Irregularity of the second teeth should be attended to by the dentist.

\section{THE EYES}

Care of the Eyes during the First Year.

physician, who puts antiseptics into them to prevent any infection that they may get during the baby's introduction into the world. After that, the nurse washes them out each morning with a clean piece of cotton soaked in a fresh solution of boracic acid, one level teaspoonful to a cup of boiled water. This is kept up during the first year. Any discharge from the eyes should not be tampered with by the mother or nurse. The physician's attention should be called to the condition at once. The vast majority of blind people owe their misfortune to neglect at this time.

Danger from a Strong Light.

Baby, like the moth, seems to be fascinated by a strong light, so he should not be laid where he can stare at one when he is small, nor should the sun be allowed to shine directly into the unprotected eyes. I am not sure 
but that this is one factor in the causation of weak eyesight in the children of the present generation.

The next period at which the eyes are called to our attention is at the time the child starts to school. I think it would be a splendid practice if every child had a Age. thorough eye examination by a competent oculist before he began his school life. Any defects of sight would then be discovered and proper treatment instituted at once. Many children appear stupid in school because they cannot see the blackboard, their eyesight being deficient. Headaches are frequently caused by defective vision.

I am sorry to say that not enough attention is paid to the proper lighting of schoolrooms. The light should come in through the windows behind the children so that it shines over their shoulders on to the desk instead of striking them directly in the eyes.

The child who is cross-eyed or has any Defective noticeable defect should consult the oculist Eyesight. early, for during early childhood glasses may remedy a defect which will require an operation later on. 


\section{THE EARS}

Washing THE ears should be washed daily with the Ears.

boric acid and water. The best thing for this purpose is a small piece of cotton wound about a toothpick. One should never try to wash far into the ear, or put any small object like a hairpin into it to take out the wax or for any other purpose. The ears should not be bundled too much and the thickness of the bonnet, if worn, should not change from day to day. (See "Clothing.")

To Prevent Protruding Ears.

Protruding ears, or ears which are doubled over from lying upon them, should be attended to in infancy if we care anything about the child's appearance in later life. When the child is too young to turn over of his own accord, we should see that the ear is flat when he is laid down. Later, when he becomes more active, prominent ears should be kept back tight to the head by a skeleton bonnet made of tape which comes over the ears and ties under the chin. These may be bought at any children's furnishing store.

Defective hearing is first shown by the child's becoming inattentive. I recall the 
case of a child three and one half years old Causes and who had been irritable and unlike himself for three weeks, although he had seemed otherSymptoms of Defective Hearing. wise in good health. His mother noticed that he did not mind and sometimes did not pay any attention to her when he was spoken to. Upon being brought to me, I found that he had an inflammation of both eardrums and the hearing was very much impaired by the process. The proper treatment soon remedied the condition. Adenoids are the most frequent cause of impaired hearing in children.

An acute inflammation or abscess of the ear, if untreated, may leave a child with Earache and Absces of the Ear. poor hearing or even entirely deaf. Any symptoms referable to the ear or any discharge from the ear should be attended to at once. Children are very prone to such trouble with the ear. It usually begins with earache, which in the infant is not always easy to diagnose. It is often accompanied by such severe pain that the child gets no sleep at all. He cries night and day until the abscess breaks or until it is lanced. When this pain is not present and the child has 
fever, loss of appetite and restlessness, nothing but an examination of the ear will locate the trouble. Putting the hand to the ear is not a sign of earache in very young babies, as most mothers think it is. In fact, a child under three years cannot locate pain very accurately.

Best The best treatment for earache is a hot Treatment for Earache.

irrigation with two quarts of water from a fountain syringe. This is followed by the application of the hot-water bag until the physician takes charge.

\section{THE SKIN}

Keeping IT is a wonder to me that the baby's skin the Skin in Good does not suffer more often than it does when Condition. we consider that he is wet a certain amount of the time in spite of all the care we may give him. The child's skin certainly is delicate and needs a great deal of care to keep it in good condition. Bathing and the use of castile soap upon the healthy skin keeps it in good condition. The soap should be thoroughly washed off in the bath and a generous application of toilet powder (especially in the folds of his fat little body) 
made after the bath and every time we have occasion to dry him. During the hot weather this is more necessary than ever. Strong brown soap used in the washing of diapers and other clothing which comes in contact with skin often causes trouble.

The girl's complexion should be carefully attended to, for what is more delightful than The Girl's Complexion the clear healthy skin of the young! The cold bleak winds of the northern climate make chapping a frequent occurrence, which leaves in its wake a rough coarse skin. Daily applications of cold cream both morning and night will not only give the child comfort, but insure a good complexion as she grows older. Any pimples are usually caused by overeating or some error in diet. This should not be allowed to go on, as the young girl may be marked for life by neglect of pimples when they first appear.

There is one thing that I never offer an Eruptions. opinion upon until I have seen it and studied it myself - and that is an eruption upon the skin. The eruptive diseases may do so much harm that it is not well to take a chance. It is so easy for the mother to say she thinks 
it is only a stomach rash or prickly heat. She does not forgive herself easily when she finds out later that it is scarlet fever. Eruptions are often difficult for the welltrained physician to diagnose, so the mother should not expect to become proficient in distinguishing the different varieties herself. My one warning would be not to let any acute eruption go undiagnosed.

\section{Chronic}

Chronic eruptions, too, should not be alEruptions. lowed to go on. For instance, an eczema which starts in a fold of the skin may spread over the whole body and be a very difficult thing to treat after it has become so extensive, or even after it has become chronic over a small area. A child with eczema should not have a full bath, because soap and water are very harmful to the inflamed skin, particularly the soap. The diet is usually at the bottom of the trouble in some way, even in the breast-fed baby.

Prickly Prickly heat is due to too much clothing or Heat. rough things coming next the skin, which, of course, involves over heating. Dress the baby as coolly as possible and put sodium bicarbonate (cooking soda) into the bath, 
a tablespoonful to the gallon of water. Powder the body thoroughly many times a day with talcum powder which has boracic acid added to it, say a couple of teaspoonfuls to the usual one-ounce box of powder.

\section{THE HAIR}

GIRLS especially are dependent upon the hair for attractiveness in later life, and since we wish to start our children off with all the physical perfections possible, it is well to devote a certain amount of attention to this "crowning glory."

After the hair has come thick upon the The head, it is not well to wet it every day at Shampoo. the bath time. One shampoo a week is sufficient, and if the hair is dry and brittle, once in two weeks is often enough. Castile soap is best for the shampoo, as some of the stronger soaps, while they remove the oil, tend to make the hair break off.

"Shall I cut my girl's hair?" is frequently asked me. If the hair is very thin, it does

Effect of Cutting the Hair. sometimes make it thicker to cut it; but frequent cutting does often spoil the natural curl in later life. While I do not believe in 
sacrificing comfort and health for beauty, I must admit I admire beauty; comfort can be attained by cutting the back hair a few inches so that the neck will not be too warm. The discomfort from a heated head, moreover, is not very great.

Frequent Brushing is Beneficial.

Frequent brushing of the hair tends to make it healthy and vigorous. Taking the snarls out with a comb is ruinous, for it breaks off and pulls out so much that the hair soon looks thin and scraggly. Long hair never need interfere with the sleep as we are sometimes told if it is properly braided and tied out of the way at bedtime.

Milk During the first year, the scalp is often Crust in the Scalp.

covered with a coating which is called milk crust. This is a great source of discomfort to the child, and a worry to the mother. It should receive energetic treatment as soon as it is noticed. Stop washing the scalp altogether, for I believe that it is often caused by excessive cleanliness in this direction. The crust should be softened by rubbing in a generous supply of cold cream. After it is all loosened in this way, a soft piece of linen covered with cold cream is used 
to remove the crust. Then a fresh application of cold cream is applied and repeated two or three times a day. Each morning clean away any of the crust that has accumulated. If there is much hair, it should be cut close to the scalp. After the condition is cured, be careful not to wash the head too often.

\section{THE GENITAL ORGANS}

A GREAT deal of care is necessary in keeping the genital organs of the girl baby free from any irritation. Any inflammatory condition which begins here, not only causes discomfort, but occasionally spreads upward to the bladder and kidneys, thus resulting in a more or less serious condition. The vagina should be carefully washed, at the time of the bath, with boracic acid and a clean piece of cotton. For this purpose never use the washcloth, or the soap and water which is used for the bath. It is also necessary to wash the vagina toward the rectum, so that it will not become contaminated with the matter from the stool. Care should also be taken that the clothing, especially after the girl has become old enough to wear drawers, is not too tight, so

Care of the Girl's Genitals. 
that these parts will be chafed. Occasionally adhesions are found between the lips of the orifice, where they are joined together above. These are apt to cause the so-called "reflex symptoms," such as restlessness, nervousness, frequent passing of urine, and even convulsions. Any symptoms of this sort call for an examination by the physician, who will separate the adhesions. If at any time the parts look red and irritated, the cause should be looked into, and the proper treatment instituted at once. A frequent cause of such irritation is pinworms, and when they are present, there is apt to be an itching about the rectum as well. If there is any discharge at any time, it should be attended to at once.

The Boy's The genital organs of boys do not as a Foreskin. rule need so much attention, although it has been more or less of a fad in recent years to regard circumcision as a routine necessity. I believe that the matter has been very much overdone. Every boy is born with the prepuce adherent or glued together, but this does not as a rule interfere with the proper flow of the urine. I do 
not believe that nature could go so far astray as to make this condition almost universal if it were a harmful one, and I therefore advise no interference unless symptoms arise which require it. Such symptoms are frcquent urination, fretfulness, or any sign of irritation about the orifice. Sometimes the foreskin is so long that a drop of urine remains in the canal after urination, and this often means that a circumcision is necessary. This, however, is not a common occurrence. At the end of the first year it is well to free the adhesions, so that the foreskin can be drawn back easily. After this has been done, it is necessary to wash the parts thoroughly with a boracic acid solution each day at the time of the bath, and keep them clean the same as you would any other part of the body. The older boys particularly need this care, as any lack of cleanliness permits the retention of the secretions which are apt to form behind the foreskin, and may cause an inflammatory condition, bed-wetting, or even masturbation. The latter is a subject which I have not dealt with in this book 
because I think the physician should be consulted frankly and unhesitatingly if the occasion arises.

Un- The subject of undescended testicles is descended Testicles.

one which should be touched upon here. If one or both of the testicles cannot be felt in the scrotum, the probability is that they are either in the canal which leads from the abdomen, or they are in the abdomen itself. If they do not cause any pain in such a position, no treatment is necessary during the first year, but after that the physician should be consulted, and the condition remedied by operative procedures if necessary. If there is pain, the matter should receive immediate attention.

Retention of Urine.

A condition which seems to give the mother a great deal of worry is that of retention of urine. The mother thinks the child does not pass the urine often enough, or perhaps none at all is passed for twelve or even twenty-four hours. This is most apt to occur during an illness of some sort, and it is most frequently due to the small amount of liquids that the child has taken. Naturally when the child does not take the usual amount of 
milk or water, there cannot be as much urine eliminated by the kidneys, so that it should not be a real cause of worry. Usually it is not necessary to do anything, but after twelve hours, if no urine has been passed, hot cloths may be placed over the region of the bladder. Probably in one out of a hundred cases that I see where this condition is complained of, there is something the matter other than this, and then the physician should be called. 



\section{PART V}

\section{FEEDING AND DIET}





\section{BREAST FEEDING}

The mother's milk is the only food that, Every was ever meant for a baby during his first. year, and any other food is at best a poor substitute. I look upon the breast milk as Mother should Nurse her Baby if Possible.

a true elixir of life. If we knew how to make it and were able to distribute it in its purity, just as it flows from the mother's breast, we could save thousands upon thousands of babies' lives each year. Can you imagine a mother so indifferent to her child's health and life as deliberately to throw away this precious fluid? I am happy to say that I have seen but few. Most of the mothers I meet are glad and anxious to nurse their babies. It is usually lack of knowledge which leads them to loss of this milk. During the first two or three days there does not seem to be much of anything in the breasts, but if we observe carefully we will find that there is a thin watery fluid there. This is all the nourishment the baby requires at this time. Do not give him water (either sweetened or plain), or milk, or anything else. These things give him colic, and when his stomach is full he will not take hold of the nipples. Put him 
to the breast once in four hours whether there seems to be anything there or not.

The Baby's

Health dependent upon the Mother's.

The young mother should first of all guard her own good health for the sake of the baby, if not for herself. She should keep good hours and get plenty of sleep. She should not change her habits too much (if they have been good ones). If she has been accustomed to much walking or other outdoor life, she should not give it up. If she has been used to playing golf or riding, or going about socially, or doing housework, she should not suddenly change her mode of life unless, as I say, if it is for the better. A certain amount of exercise helps the milk in quantity and quality. If the mother has not been accustomed to exercise before the baby was born, she should begin to take a little each day afterward, gradually increasing the amount of exercise, perhaps by walking a little farther each day, but always being careful to stop just short of the point where she gets tired. Fatigue should be avoided. A woman who has led an active society life is apt to become discontented if she gives it up entirely. She should, therefore, not be persuaded to eschew 
it altogether. The sleep is apt to be broken by the night nursings so that a nap in the daytime is advisable. At any rate see that the proper amount of sleep is taken.

Nervous, neurotic mothers are not good nurses. The slightest distress upsets them, spoils the milk for the time being, and makes Nervous Mothers not Good Nurses. the baby sick. Nursing mothers who are so constituted should try to overcome the tendency and make every effort to lead a quiet, placid life. Fortunately, the more or less athletic mother of the present generation is a far better nurse than was the Jane Austen type of the past generation, and I believe she is the salvation of her race.

The nursing mother's diet is the one thing that seems oftenest to go wrong. Every The Mother's one she meets tells her of some article of food Diet. she should not eat, until, if she obeys all the advice she receives, the poor mother has little left in her dietary which she dares to eat. Each part of the country, too, has different notions about foods that are injurious to mother and child. In one place it is fish, in another fresh vegetables or sour things or sweets. My advice to the nursing mother is 
to avoid all excesses in eating, and, that being done, to eat the food to which she has been accustomed before the baby was born, if it gives her no indigestion. Fish occasionally, and plenty of meat are good milk makers, and fresh green vegetables are a necessity where there is a tendency to constipation. The bowels of the breast-fed baby depend upon the condition of the mother's bowels, as does his general nutrition. Every nursing mother should have at least one good evacuation each day. Usually, unless she is habitually constipated, plenty of fruits and vegetables will remedy any deficiency in this direction. Sour things are harmless except when eaten in excessive quantities. Certain mothers, like all of us, do have idiosyncrasies of digestion, and when they find that any particular article of food disagrees repeatedly with them or with the baby, it should be stopped. The diet should, however, be a general one, avoiding monotony and including the various kinds of food. It should also be a generous one, since the mother has two bodies to nourish instead of one. Three meals a day may be sufficient, 
but many women feel the need of a little lunch in the middle of the morning and in the afternoon. If this does not take the appetite away from the regular meals, it is a very good thing.

Milk may be drunk between the meals or with them, except where it is taken to the exclusion of, or spoils the appetite for other food, or where it disagrees with the stomach or causes constipation. When milk is well borne, however, it is a great help in increasing a deficient milk supply. Cornmeal and oatmeal gruels are also valuable for this purpose if taken in sufficient quantities, but not to the exclusion of other foods. Plenty of liquids should be taken, but these, too, should not be overdone. I have known mothers who have taken two quarts of tea a day because they were told to drink a lot of liquids. The tea made them nervous and tied up the bowels so that the milk supply was ruined. Alcoholic beverages are usually not necessary and occasionally do harm to the baby. If the mother is accustomed to a moderate amount of wine or malt liquors, it may also agree with the baby, but she should watch for

Milk and Other Liquids for Nursing Mothers. 
any signs of colic in her offspring and give up the beverage altogether if it seems to be disagreeing with him. Occasionally when we are sure the breast milk is deficient, a glass of ale or porter with the meals will increase the milk supply.

The Breastfed Baby may have "a Bottle or Two."

The question often comes up, "Is it advisable to give the baby a bottle or two so that the mother may get a rest or possibly a little recreation from her constant and arduous duties as mother and wet nurse?" I believe it is. In the first place, the mother, if she so desires, has some rights to a few hours of freedom from her baby each day. In the second place, it is well to accustom the baby to taking his food from the bottle in case an occasion should arise where it is impossible to feed the baby from the breast. This should be done with the advice of a physician, lest we give a food that is not good for the baby.

Care of the Breasts and Nipples.

The breasts and nipples themselves should be well cared for. The nipples should never be touched or handled until the hands have been scrubbed with soap and a nailbrush. The penalty of disobedience of this rule may 
be an abscess of the breast. During the first weeks especially the nipples are unaccustomed to the constant moistening and pulling which the baby gives them. The skin is apt to become soft and tender, and when in this condition the breasts are easily infected by the nurse or mother who also handles the stools of the baby. After each nursing, the nipples are washed with a solution of boracic acid and boiled water, one teaspoonful to the pint. They are then thoroughly dried and a large piece of sterile gauze laid over the nipples so that they will not come in contact with the clothing. Corsets should be worn which are either high enough to support the whole breast and taken off while nursing, or low enough so that the breasts are not rubbed and irritated by the upper edge.

When a nipple becomes so tender that nursing is very painful or when there is a Use of the Nipple crack or fissure in it, the child's mouth should not be allowed to touch it at all. Instead the nipple shield is used. The best kind is made of glass with a rubber nipple on the end of it. The sore nipple should not be moistened with the boracic acid solution, 
but instead it should be kept continuously covered with zinc oxide ointment; with this treatment (if begun at the start) the nipple will be healed in a few days and the nipple shield can be discarded.

How often should the Nursings Come?

The quality and quantity of the milk, as well as the condition of the breast, depends also upon the manner and the frequency of nursing. When the child's mouth is put to the nipple, the breast is stimulated to activity by this natural act. For this reason a breast does not secrete as much milk when the breast pump or nipple shield is used, and ii either is used for any length of time, it may spoil the milk supply altogether. In the same way a child that is put to the breast every time he cries, not only upsets his own digestion but spoils the milk. The intervals should be regulated, therefore, as soon after birth as it is possible to do so. The question of how often the nursings should come depends upon the size, strength, and age of the baby and upon the quality and quantity of the milk. This is often a question which the physician must decide, but in general a small weak baby should be nursed every two hours from 
6 A.M. until 10 P.M., with one feeding at 2 A.M., making ten nursings in twenty-four hours. A strong fat baby may from birth be nursed every three hours from 6 A.M. to 9 P.M., which with the 2 A.M. feeding makes seven in twenty-four hours. At three months of age the baby should, if he has gained in weight properly, even though he was small at the start, be put upon the three hour nursing schedule. At four months, if he is a normal well child, he should not be nursed at all between 9 P.M. and 6 A.M. This gives him six feedings in twenty-four hours, which is sufficient throughout the first year.

\section{WEANING}

BY weaning I mean, of course, both dis- When carding the breast for the bottle or for a Freast general diet, and discarding the bottle for a general diet. Substituting the bottle for the should be Stopped. breast is, perhaps, the most important part of this subject, because it is done so frequently during the first year when there is no necessity of taking such a radical and often disastrous step. When it is necessary to stop the breast, however, it should be done without 
any hesitation. There are certain definite indications for such a procedure and they are as follows: (1) Excessive vomiting accompanied by loss of weight, or by stationary weight extending over a period of two weeks or more. (2) A bad diarrhea which cannot be remedied while the baby is breastfed, and accompanied by loss of weight or by stationary weight extending over a period of two weeks or more. Loose bowels alone, especially when there is a progressive gain in weight and the proper general development, is not an indication for discontinuing the breast. (3) Progressive loss of weight or stationary weight extending over a period of three weeks or more while the digestion seems normal. (In all of these conditions every effort should be made to overcome them while the child remains on the breast. It is also important that these things do not arise from an acute illness of the baby aside from that due to a poor milk supply.)

A serious disease of the mother.

Baby's Weight is Best Guide in Weaning.

In my discussion of breast-feeding it may appear as though I thought that all mothers could nurse their babies if they so desired. 
I wish that this were so, but it is not. And when shall we know that the baby is not getting sufficient nourishment from the breast? First of all, from the weight. When a breastfed baby ceases to gain in weight, we look about for a reason. Is he fed at regular intervals? Is he vomiting? Has he any intestinal indigestion, as shown by bad stools? Is the mother's diet a correct one, are her bowels in good condition, and is she paying the proper attention to all the details of the baby's daily routine, including nursing at regular intervals? These things we regulate to the best of our ability and still the baby does not gain in weight. Even then we stick to the elixir of life, the breast milk, and add to this a few bottles of the properly modified milk each day to see if we may remedy the conditions and get a gain in weight and good stools and no vomiting. After a faithful trial of all these things, we bravely step forward and defy nature, or rather the present artificial mode of living, and take up the task of nourishing this baby with as much faith in our success as our experience will allow. It requires a great deal of 
experience to acquire sufficient confidence in one's self to step in and assume the rôle of nature. Therefore, I would advise mothers and nurses to go slowly without medical advice. After many years' experience in infant feeding, I still find cases that require the utmost resourcefulness to enable me to make some of my babies do well on the bottle.

Milk may

Appear

Insufficient

the First Few Weeks.

The first few weeks after the baby is born, it may appear as though the breast milk was insufficient, but we must not be too easily discouraged. It is a trying period and conditions are never at their best. The mother has endured the hardships of the labor and she is in bed at least convalescing, if not ill. Where there is any question of discontinuing the breast at this time, we should wait until the mother is up and about and living her normal natural life again before we decide to start upon the bottle. Often the milk supply increases at once when the getting-up time comes. Of course, if there is a continuous loss in weight after the usual loss of the first three days, this waiting policy should not be adopted. In fact, continuous loss of weight at any period of the baby's life is 
sufficient reason either to stop the breast or add supplementary bottle feedings. The same may be said of stationary weight extending over a period of two to four weeks.

I would not give the impression that all mothers are able to furnish sufficient nourishment for their babies throughout the first year, for many seem to do well until the latter half of this period, when the milk supply gives out in spite of all we can do.

There are certain conditions arising in the mother when it is necessary to discontinue the breast, for we should have some con-

When the Nursing Mother gets Sick. sideration of her welfare. Any acute illness with fever is apt to spoil the milk supply for a time, as well as to be an extra drain upon the mother's strength, so that it is well to stop the breast while it lasts. If the illness is short, the breast feeding may be resumed upon its abatement. Throughout such an illness the breasts should be pumped out with the breast pump at regular intervals, usually once in three hours. This is to prevent the breasts from drying up while the mother is too sick for the baby to nurse her. A chronic disorder of any consequence is an indication for giving 
up the breast permanently. Tuberculosis, kidney disease, anæmia, epilepsy, grave mental disorders, progressive loss of weight in the mother, and pregnancy all point toward a discontinuance of the breast feedings. The return of menstruation is usually not accompanied by any alteration in the milk supply. It may occasionally give rise to a slight disturbance in the baby's digestion for a day or two, but unless there is a decided and permanent change for the worse in the baby, the breast should not be discontinued on this account.

Teaching the Baby to Use the

Bottle.

When we have finally decided that the baby must be weaned from the breast, our troubles are not over by any means, for we must then select the proper food and we have got to teach the baby to take his nourishment from the bottle. The bottle and nipple should always be used in a child under ten months of age if the breast is given up altogether, for he cannot at this age get sufficient nourishment from the cup or spoon. If he has already learned to take the bottle during his breast-fed days, as I have suggested, the task is easy. But if he stub- 
bornly resists all our efforts to give him sustenance in this artificial manner, a struggle is ahead of us. I am often obliged to get a trained nurse for these trying days until he has learned to take the bottle. However, if one is persistent and will not give in to the little fellow, allowing no nourishment in any other way for one or two days, he soon learns. The hole in the nipple should be very large so that the milk will run into his mouth without much sucking until he has learned to work for it.

After ten months or a year it is far easier The Proper to wean the baby, because if he has done well Age to Wean the up to this time and is strong and well, he may Breast-fed take milk out of the cup, eat cereals and other Baby. soft foods. In fact, as a matter of education, it is well to teach the child to drink out of a cup or eat cereals or stale bread while he is still doing well on the breast, say at nine months, so he will take to it kindly when the time comes to wean him. It is extremely rare to find a mother who can nurse her baby after the first year. Mothers often do it, but children who are nursed too long cease to gain in weight, their muscles become flabby, 
and they soon begin to suffer from rickets, anæmia or some other form of malnutrition. Some of the worst cases of poor nourishment I see in children over a year are due to nursing during the second year.

When to Wean the Bottle-fed

Baby.

When should a child be weaned from the bottle? Like the breast-fed baby, he should begin to receive some food from the cup or a spoon at about nine months, if he is up to the standard in weight and health. At a year he can get one whole feeding in this way and consequently one less bottle feeding. At fourteen months he can get sufficient nourishment with three feedings from the bottle and two meals of soft food. At sixteen months, three meals a day and one bottle at 10 P.M. will suffice. At eighteen to twenty months, the ten-o'clock bottle is stopped and baby is weaned.

\section{THE BOTTLE AND NIPPLES}

The Selection and the Care of Bottles.

THE first thing that concerns us when we find we have a bottle baby on our hands is the selection and care of the bottles and nipples themselves. The best bottles are those that are round and cylindrical and 
have a narrow neck for the attachment of the nipple. The one important requirement is that they have no corners on the inside, being rounded both at the bottom and at the top where the neck begins. This shape of the inside of the bottle enables us to clean it thoroughly. An improvised medicine bottle should never be used, as it is absolutely impossible to clean out the corners. It is best to get as many bottles as there are feedings in twenty-four hours. Also buy a wire bottle rack to hold them when the food is made up for the day. As soon as the baby has taken his feeding, wash out the bottle with soap or washing powder, using a longhandled bottle brush to get it scrupulously clean. Then rinse the soap out with hot water, and put into the bottle a heaping teaspoonful of borax. Some warm water is now poured in and the bottle is vigorously shaken until all the borax is dissolved. It is then filled brimming full of water and allowed to stand full of this strong borax solution until the next morning, when the feedings are made up for the day. If each bottle is treated in this way, we have in the 
morning the whole lot perfectly clean and ready to be filled with the day's feedings as soon as the borax solution has been poured out and the bottles rinsed once with clear 'water. With this method it is unnecessary to boil the bottles each day and it is a great saving of time and trouble. The bottles should never be allowed to stand unclean or filled with plain cold water or even with cooking soda in them, for borax is the stronger and better antiseptic to use.

The Kind of Nipples and how to care for Them.
The nipples are important, too. For the little baby we should see that the nipple is not too large or too long. Frequently, a long nipple will gag him and cause him to vomit up the whole feeding just as he has nearly finished it. It is often a very difficult task to get nipples with the right sized holes. If the baby gets the food too fast, it may cause colic or indigestion or vomiting, so we should select a nipple with one hole in it which will be small enough so that the feeding cannot be taken in less than twenty minutes. It is well to have two or three nipples on hand. When new, they should be boiled once. As soon as the feeding is 
taken, the nipple should be filled with borax and held under the faucet while it is being rubbed between the thumb and fingers. It is then placed in a cup of water containing one heaping teaspoonful of borax. The nipples need not be boiled out after the first lay, nor need they be turned inside out when nleaned

\section{MILK}

Fresh cow's milk, properly modified, is the inly food for the bottle baby. Nothing else will take its place. But we should endeavor What is meant by "Good Milk" to get good milk. By good milk I mean, in the first place, milk from cows that are free of tuberculosis, - tuberculin-tested cows. The cows should have plenty of air space. The hay should not be stored directly above them where the dust may sift down upon the milker, nor should the cows be hayed just before milking, for the same reason. The walls of the cow house should be whitewashed two or three times a year. The manure should be stored outside the barn. The floors are best made of cement and washed with a hose, but, of course, this is often impossible for the average farmer. 
He can, however, sweep the floor each day, sprinkling it first. The cows should be kept clean, the flanks and bag wiped off with a moist cloth before milking. The milker's hands should be washed before milking (it will do them no harm after his day's work). He can slip on a clean duster for this part of the day's work. The milking pails should be clean. The milk is rapidly cooled after milking to at least $45^{\circ} \mathrm{F}$. and put in quart bottles that have been boiled or sterilized and tightly covered. The bottled milk should then be kept cool until the milk is consumed.

The Danger from Bacteria.

There is, of course, a reason for all this seeming nonsense. Milk is a splendid food for germs, as well as for babies. If the milk is dirty to start with, it is swarming with bacteria. If it is allowed to remain warm, these bacteria multiply enormously, so that after a few hours there are as many as five or six million in a cubic centimeter or a quarter of a teaspoonful. This is what makes milk sour quickly. The products of these bacteria are what cause the vast majority of bowel troubles in infants during the summer, and they also cause so-called 
milk poisoning. Of course, all bacteria are not harmful. To any one who says that the method of producing good milk just described is not practicable, I will answer that the progressive farmer has proven to the contrary. It is to his credit that each day he sends thousands of quarts of perfect milk into New York City and many other cities in this country. This milk has to come up to the standard of the County Medical Society before it is accepted as "certified milk." It is subjected to repeated examinations for bacteria and rejected if the bacteria are found in excess of a stated number. From a financial standpoint it is a paying proposition, as such milk sells for from 15 to 20 cents a quart. It is also worth this extra price to the baby.

Pasteurized and boiled milk have been much discussed in the press. By pasteurizing we mean heating the milk to $150^{\circ}-175^{\circ} \mathrm{F}$.

Pasteurizing and boiling Milk. This kills most of the bacteria, but it gives us a false sense of security, since the milk will soon become as bad as ever if it is not put in clean containers and kept cold just the same as any other milk. When milk is boiled, it is brought to the temperature of 
$212^{\circ} \mathrm{F}$. This, of course, changes the taste of the milk and destroys still more bacteria, but not all of them. A child who takes nothing but boiled milk for a prolonged period of time receives no fresh food and is liable to get scurvy, just as the sailor does who eats no fresh food. Therefore, boiled milk should not be used for any length of time if good clean milk can be had, and if one can depend upon the intelligence of the person making up the baby's food. At times, however, these conditions are not right and it is best to use boiled milk through the summer months. The tendency to scurvy may then be overcome by giving the baby the juice of half an orange once or twice a day, according to his age, unless he has a diarrhea. Boiled milk is also used temporarily in suitable cases to make the food more digestible. For this reason, I usually advise boiling the new-born bahy's milk for the first two or three weeks, and also the milk of babies who have digestive disturbances.

Milk from One Cow or Herd?

Milk from one cow has its disadvantages, because if that cow eats something wrong or gets chased by a dog or what not, the milk 
is made temporarily indigestible for the baby. On the other hand, the milk from the whole herd would be far less liable to such accidents, and it would be more uniform from day to day. I would, therefore, prefer milk from the herd, if the dairy is well conducted.

\section{MIXING AND CARE OF THE FOOD}

IT is far better for the baby and easier for the mother if she takes a certain time each morning to make up the food for the day. She then does not have to think of it again until the next morning. All the utensils for mixing the food are kept in a place by themselves and are not used for any other purpose. The person whose duty it is to make the food should be responsible for their condition and keep them clean, not trusting to any one else. These utensils are not many. A cheap measuring glass, or graduate, holding sixteen ounces and divided into ounces, is a time-saving device, which it is well to have. A wide-necked pitcher that pours well and holds two quarts, a glass funnel which does not fit too tightly into the neck of the nursing bottles, a tablespoon, regula- 
tion size, a new enamel saucepan for boiling the water or gruel or food, and a one-quart preserving jar to put the gruel or boiled water away in until it is cold. If gruel is used to dilute the milk, it may be made the night before so that it will be ice cold before it is added to the milk.

The First, the bottles, one for each feeding Bottles. throughout the day, are attended to. They are all clean and standing full of borax water from the day before. The bottle rack is held over the sink, and the bottles, one at a time, are placed in it upside down to empty the borax water. They are then turned right side up in the rack and filled with hot water to rinse out the borax and again placed upside down to drain and cool while the food is being mixed.

Mixing the Food for the Day.

The fresh unopened bottle of milk is then poured into the pitcher so that the cream will be mixed in thoroughly, and then poured back again into the bottle in which it came. Measure the proper amount of milk in the graduate and pour it into the pitcher. Measure out the proper amount of ice-cold water or gruel and pour it into the pitcher. Meas- 
MIXING AND CARE OF THE FOOD 171

ure the sugar with the tablespoon and add to the food. If level tablespoonfuls are ordered, level each with a knife, heaping tablespoonfuls mean all you cān get upon the tablespoon. Stir until the sugar is dissolved and the food is done. Using the funnel, pour into each bottle the amount baby is to have at each feeding. Stop up the bottles with clean absorbent cotton and put the rack, full, in the ice chest, directly on the ice if possible; wash up the utensils and put them away for the following day.

And now, when the feeding time comes, all we have to do is place one of these bottles in Temperaa pan of hot water, or in an alcohol bottle ture of the Food. heater, and the milk is not contaminated by handling. The food should be just body temperature when it is fed. It is just as bad to have it too hot as it is to have it too cold. The temperature should be tested by pouring a few drops upon the forearm and never by putting the nipple in one's own mouth, or touching the finger to the food itself. In winter it is well to have a woolen bag or knitted cover, which just fits the bottle, to hold the heat in during the twenty minutes while the baby is feeding. 


\section{THE COMPOSITION AND STRENGTH OF THE FOOD}

A Radical The days of complicated formulas for Departure from Old Methods of Feeding.

babies' foods are over. Well babies do not need top milks and creams, whey, limewater, and the various foods that we have formerly used. Such foods should be reserved for sick babies who are under the physician's care. This is a great departure from the methods that we have used for the last fifteen or twenty years, but I speak with the authority of experience. Plain cow's milk (with its cream all stirred in) to which is added water and sugar, answers all the requirements of a good food until the baby is seven or eight months of age, when barley or oatmeal gruels may be used instead of the water. Plain milk mixed with water is easier to digest than cream or top milks, and nourishes the baby as well or better. The water is added so that the food will not be too concentrated for the digestion, as well as to give the proper amount of bulk and furnish the required quantity of liquids that the child needs in twenty-four hours. 
COMPOSITION AND STRENGTH OF FOOD 173

The sugar is added solely for its nutri- The Sugar. tional value and for its laxative action upon the bowels, and not at all for the taste. Sugar is very concentrated nourishment and is therefore one of the most important ingredients of the food. One ounce of sugar supplies as much nourishment as six ounces of milk. Sugar also is usually the most difficult part of the food to digest. If too much of it is given, it may cause either diarrhea or vomiting; while if too little is given, the child will not gain in weight. Milk sugar, which has been so extensively used in the past, should never be used where there is any digestive disturbance. It is not as easily digested as either cane sugar (ordinary table sugar) or malt sugar. The latter is the best of all the sugars, especially for young babies and for those with a weak digestion. The malt sugar that I have always used is Mead's Dextri-Maltose. It is nothing less than marvelous to see a baby (as I have in innumerable cases) who has never done well when fed on other mixtures, thrive and gain at once on the simple milk and water mixtures when Dextri-Maltose is used. 
The important considerations, then, in deciding upon a well baby's food are threefold: the amount of milk, the amount of sugar, and the amount of water to be added to make up the proper bulk and concentration. The quantities of these ingredients depend

How to upon the baby's weight and age. The gauge the

Proper Amount of Milk.

amount of actual cow's milk a given baby needs in twenty-four hours to sustain life and make a proper gain in weight is twice the number of ounces of milk as he weighs in pounds, provided he can digest one and one half ounces of sugar in his total daily quantity of food.

The Enough water is added to make the proper Amount of Water.

amount of food (the total quantity in twentyfour hours), which amount is determined, of course, by the quantity at each feeding and the number of feedings in twenty-four hours. The general rule for the quantity of food at each feeding is 1 to $1 \frac{1}{2}$ ounces more than the number of months of the baby's age ; at four months give 5 or $5 \frac{1}{2}$ ounces at a feeding; at six months, 7 ounces, etc. The rule for the number of feedings in twenty-four hours is as follows: the first three months, 10 feedings; the fourth month, 8 feedings; 
COMPOSITION AND STRENGTH OF FOOD 175

the fifth month 7 feedings; after that, 6 feedings. To illustrate: a child three months of age who weighs 12 pounds should receive and digest 24 ounces of cow's milk in twentyfour hours. To this must be added the proper amount of water to make up the bulk, and $1 \frac{1}{2}$ ounces of sugar. Therefore, if this baby were able to take $4 \frac{1}{2}$ ounces of food every $2 \frac{1}{2}$ hours, -8 feedings in twenty-four hours, - he would receive 36 ounces of food in twenty-four hours, 24 ounces of which is milk, 12 ounces of water, and $1 \frac{1}{2}$ ounces of sugar.

The table on the opposite page gives an approximate scheme for feeding babies of different weights and ages. It is not intended for babies with digestive disturbances, nor will it invariably suit every well baby.

The question of how often a bottle baby is to be fed is not always an easy one to decide. In general the small baby, or one under three months of age, should be fed every. two hours from 6 A.M. until 10 P.M. with one feeding at 2 A.M., making in all ten feedings in twentyfour hours. At three months (during the fourth month), the baby may be fed every two

Number of Daily Feed ings for Bottle-fed Baby. 
TABULATED SCHEME FOR FFEDING'

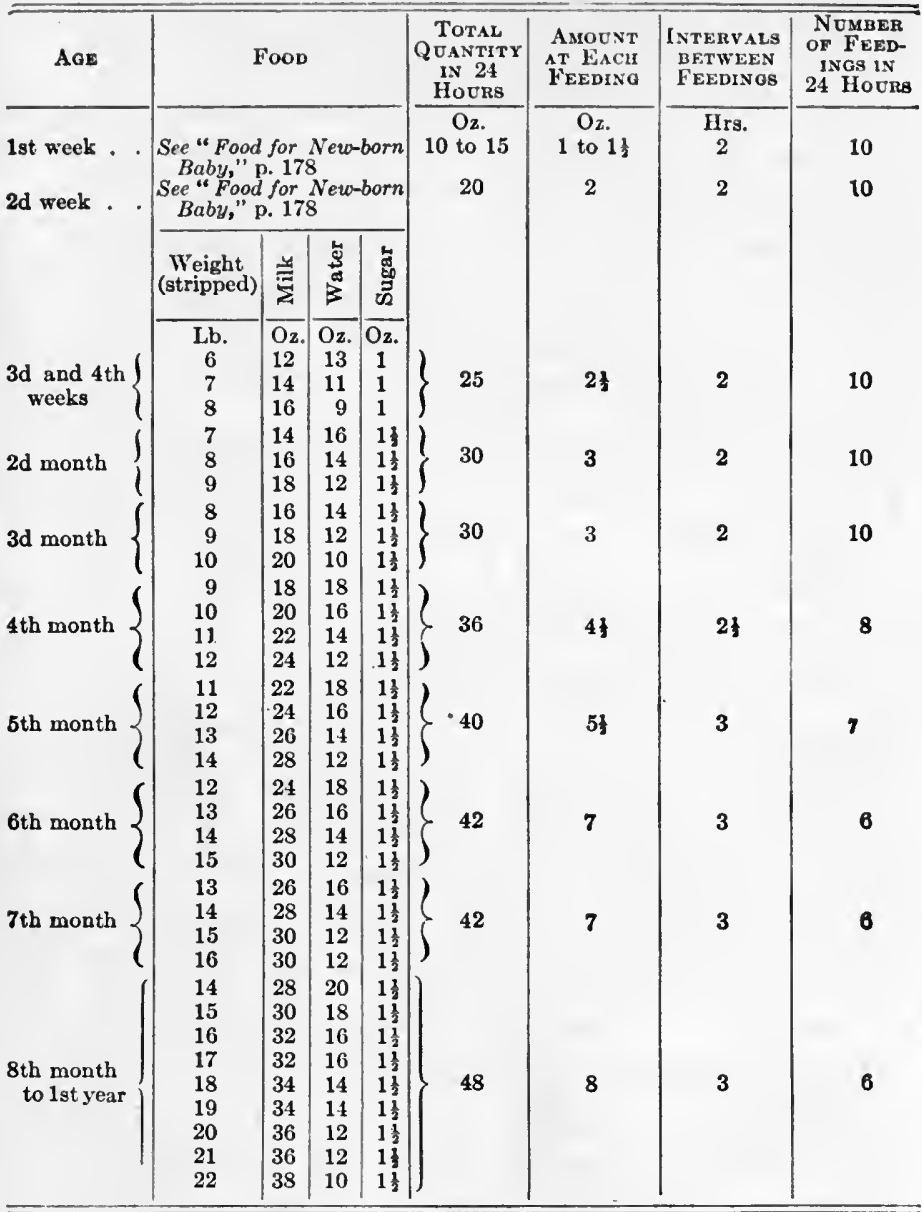

Under "Interval between feedings" is meant from 6 A.M. to 10 P.M.

One night feeding at 2 A.M. is allowed until five months of age.

Two level tablespoonfuls of cane sugar (leveled with a knife) make an ounce. Two rounding tablespoonfuls of Dextri-Maltose make an ounce. 
COMPOSITION AND STRENGTH OF FOOD 177

and one half hours from 6 A.M. to 9 P.M., with one feeding at 2 A.M., giving eight feedings in twenty-four hours. At four months (during the fifth month), the feedings come three hours apart from 6 A.M. to 9 P.M., with one feeding at 2 A.M., making seven feedings in twenty-four hours. After five months of age, six feedings in twenty-four hours are sufficient. In other words, the night feeding is omitted at five months, and the baby is fed every three hours from 6 A.M. to 9 P.M. From then on throughout the bottle period, the number of feedings and the intervals between them remain unchanged. However, I have fed many fat, robust babies from birth at three-hour intervals during the day with one feeding at 2 A.M., making seven feedings in twenty-four hours. These three-hour intervals, of course, make the care of the baby much easier. If the baby is weak and under weight, two-hour intervals are advisable at any age up to six months, provided the food is of the proper strength.

As to the quantity the baby shall get at Quantity each feeding, I can only give rules for the at Each well baby. Those who have not been up to 
the standard of weight and development, and those who are actually sick, need expert advice, and I would not assume the responsibility of generalizing for them. The well baby will take one half to one ounce at a feeding during the first week. During the second week he is usually able to take care of two ounces; during the third and fourth weeks, he may take two and one half ounces; and during the second month, three ounces at a feeding. After that, he can take one to one and one half ounces more than the number of months of his age up to eight ounces. It is never necessary to give the bottle baby more than eight ounces at a feeding. I would emphasize the fact that these rules apply only to well babies of normal weight and development for their age. Much harm is done by the novice trying to feed sick babies. After many years of practice, I still feel that the feeding of sick babies is a matter of judgment based upon a large experience.

Food for the Newborn Baby.

Đuring the first week a baby's digestion will not stand enough food to make him gain and we should not expect. it of the bottlefed baby. Therefore the rules given above 
COMPOSITION AND STRENGTH OF FOOD 179

do not apply to him. Occasionally it is necessary to feed a baby on the bottle from the start, through illness of the mother or because there is absolutely no breast milk. In starting his food, make it very weak at first and work up a little each day, until by the middle or end of the second week the food is strong enough to make him gain. On the second or third day make the twenty-four-hour quantity of food with three ounces of milk and twelve of water (boiled) - no sugar. The next day give him four ounces of milk, twelve ounces of water, one teaspoonful of sugar; the next day five ounces of milk, twelve ounces of water; and so on. Each day increase the food by adding one more ounce of milk until by the tenth or fourteenth day the baby is getting food of the proper strength for his weight. In the meantime the sugar should be gradually increased also, one teaspoonful at a time, until one or one and one half ounces are given in the total twentyfour-hour quantity of food. It is usually best to add one more level teaspoonful every other day. For the first few weeks, it is well to bring the milk and water rapidly to an active 
boil, stirring vigorously so that a scum will not form upon the top. This boiling makes the milk more digestible, but should not be continued for more than a month or so. The sugar is not added until the food is boiled and taken off the stove.

Food for

Babies who have not done well.

The gradual increasing of the food, as described in the paragraph above, also holds good in babies of any age who are fed by this system of feeding for the first time, or those who have not done well on other foods, although it is not necessary to make the food so weak at the start for older babies, and it may be increased more rapidly. It is usually well to begin older babies with one third milk and two thirds water, boiled after mixing. No sugar is added to the food until the stools appear well digested and-vomiting has ceased or improved greatly. When the baby's digestion improves, as shown by the vomiting and stools, the strength of the milk should be increased by adding one or two ounces more of milk, and one or two ounces less of water each day, until he is getting milk of the proper strength for his age and weight. The sugar is also begun at the same time, 
COMPOSITION AND STRENGTH OF FOOD 181

adding at first only one teaspoonful and increasing it each day, a teaspoonful or two at a time, until one and one half ounces are given in the total twenty-four-hour amount. Rei. cmber a child may not gain who is overfed. Ile is also apt to have diarrhea and vomiting. Remember, also, that sugar will cause diarrhea, undigested stools, or vomiting, and that some babies will stand more of it than others. That is why it is best to stop all sugar temporarily when these symptoms appear. The food should be boiled also, as described in the paragraph above.

Proprietary or patent foods are not necessary for any baby. I believe that there is Patent Foods Unnecessary. no virtue in the foods themselves, and any babies that I have ever seen who have done well on the proprietary foods have done so on account of the sugar or carbohydrate in the food and on account of the cow's milk which the mother adds to it. There is no mysterious lifegiving property about them. Most of them are made up of starches and the various kinds of sugars and some of them have dried milk or egg added. 


\section{FOOD FOR TRAVELING}

BABIEs really should not travel at all, but they often have to. However, the necessity should be very great to take a bottle-fed child on a long journey, especially if he has had any difficulty with his feedings. Each spring, particularly, I am busy instructing mothers how to prepare the food for a longer or shorter journey. If it is practicable, a traveling ice box with a wicker cover may be carried and good milk carefully prepared will last forty-eight hours in this, the ice being replenished constantly. Where this is not advisable, the food, after it is made, but before the sugar is added, is boiled for at least ten minutes. It is then put into preserving jars which have been boiled with the cover and rubber, and which are still piping hot when the boiling food is added, and the jars are sealed. This will last fortyeight hours, if cooled immediately and kept cold throughout the journey. The WalkerGordon Milk Laboratories make a specialty of putting up milk for traveling. The milk is prepared all ready for the baby to take 
in any strength or combination desired, and will last throughout a journey of six or seven days.

For any prolonged journey where fresh milk cannot be procured, unsweetened condensed milk is the best food. Remember that condensed milk is only twice as strong as fresh cow's milk and therefore make the food up accordingly, adding the proper amount of sugar and water. Remember, also, that it will not keep much longer than fresh milk once the can is opened. When it is given over any extended period of time, give the baby orange juice each day to add the fresh element to his diet. Condensed milk is not a good diet for a baby, and I would not put myself on record as indorsing it, but there are occasions when it is useful, and this is one of them.

\section{DIET AFTER THE FIRST YEAR}

The second year is the most difficult feeding period of childhood. All children in their

Three Classes of Children. second year may be divided into three classes: Those who won't eat anything; those who eat everything they shouldn't; and those who 
have their diet regulated for them at the cost of much patience, care, and thought on the mother's part. It is for you to choose under which class your baby will come, for it is within your power to regulate his diet and lead him toward a life of bodily health and happiness. Help him to form a taste for the proper kind of food and he will enjoy eating things that are good for him as much as he will those that are injurious.

Do not tempt the Child with Things he should not Eat.

A child that does not want to eat solid food at this age is generally overfed with milk, or perhaps he is allowed to nibble on crackers, or bread, or cake all day long, or perhaps have a drink of milk whenever he is thirsty. Eating between meals is not permissible. A child who eats things he shouldn't is taught to do so by giving him a taste of this or a taste of that from the table where he is allowed to eat with the family. I think it is only fair to the child not to set before him things which he is not allowed to eat. If he comes to the table with the adults, they should themselves forego some of the pleasures of the palate. A good compromise is to allow the child to come to the table for breakfast and luncheon, 
which may be simple meals such as he can eat, and to give him his supper by himself at 5 or 5.30 o'clock.

After the first year, we may divide the The feeding of children into two periods, which, of Weaning course, gradually merge one into the other. These are the weaning period, from nine or ten months to eighteen or twenty months; and the period of from eighteen months to two years, when three meals a day are sufficient. The weaning period begins when we first begin to feed baby from a cup or spoon in order to teach him to eat, and it lasts until he has all his teeth, which is usually at cighteen months. At nine or ten months baby is given a drink of milk from the cup once a The Baby First Less day before a nursing. A little later we try in Eating. a well-cooked cereal with some milk upon it, but no sugar, just to teach him to eat cereals. Still later we vary his training by giving him a piece of dry bread crust or crackers or zwieback, just before a nursing time, so he may learn to eat solids. It is very important that the child should learn to drink milk at this time, because if he does not he may dislike it all his life. It should be offered to him 
day after day until he has acquired a taste for it.

When introducing a new food into the diet, begin with very small quantities, just a taste at first and gradually increase the amount. If any new article of diet seems to disagree, it is usually well to persist in giving it in small amounts. It is well to remember that the stools are colored at times by the vegetables that are given. For instance, it is not at all uncommon to see the green spinach in the stools nor the yellow of carrots. This is no contraindication to giving these vegetables.

Diet One Year to Fourteen Months.

By the time he is a year old he has perfected himself enough in the art of eating to enable him to get a whole meal without the aid of the bottle or breast, which meal consists of a cereal and drink of milk from the cup with a piece of hard bread in his hand to chew upon. He is at this time fed every three hours from 6 A.M. to 9 P.M., and therefore gets five bottles or breast feedings in twenty-four hours and one meal, as above described. It does not make any particular difference what time this meal comes, but 
it usually takes the place of either the 9 o'clock or 12 o'clock bottle.

At fourteen months he can get two meals a day in addition to the three feedings from the Diet at Fourteen bottle, cup, or breast. The schedule for the Months. day is as follows :-

7 A.M., cereal, milk, toast.

11 A.M., eight ounces of undiluted milk from the bottle or cup, or a breast feeding.

2 P.M., baked potato with butter or milk upon it, a cup of milk, bread.

6 P.M., eight ounces of undiluted milk from the bottle or cup, or a breast feeding.

10 P.M., eight ounces of undiluted milk from the bottle or cup, or a breast feeding.

Rarely at this age, does the breast furnish milk in the proper quality and quantity for the feedings given at 11 A.M. and 6 and 10 P.M. If the breast milk supply is good, these three feedings may be given from the breast; otherwise, milk from the cup takes its place.

At fifteen months we give a meal made up of one vegetable, mashed fine, besides the baked potato. The vegetables contain iron,

Diet

Fifteen to Eighteen Months. which baby needs very much at this age. We 
also introduce eggs into his diet. He is now, at fifteen months, getting four feedings in twenty-four hours, three of which he may take at the family mealtimes, with eight ounces of undiluted milk at 10 P.M. His schedule for the day is then as follows:

7 or 8 A.M. Breakfast: cereal, bread, cup of milk.

12 or 1 P.M. Dinner: an egg, potato, one other vegetable, bread, dessert of fruit.

5 or 6 P.M. Supper: milk, bread.

10 P.M. Eight ounces of undiluted milk from the bottle or cup.

Raw fruits in the middle of the morning and afternoon help to shorten the intervals between meals when the child is unaccustomed to going so long without eating. He may have a scraped raw apple, an orange, pear, or peach between any or all of his feedings, according to the condition of the bowels.

Diet At eighteen months of age all the teeth

Eighteen Months to Two Years.

have come through and meat is added to the dietary. Occasionally it is a little later than eighteen months, but I am generalizing. And now three meals a day are all that are necessary since the meat supplies more concen- 
trated nourishment, and the 10 P.M. feeding is omitted. The menu for the day is :-

7 or 8 A.m: Breakfast: cereal, egg, bread or toast.

12 or 1 P.M. Dinner: meat, potatoes, one vegetable, dessert of cut fruit or sponge cake.

5 or 6 P.M. Supper: bread toasted hard in the oven, cup of milk, or, instead of the milk, fruits cut up raw or cooked, or plain broth may be given with the bread.

The supper is usually the milk meal, but it may be varied occasionally for the sake of eliminating monotony. Some children never tire of the milk at this meal, so that it is not necessary to make this change. The milk should be given at least five or six times a week.

There is really no reason why a child should have a diet that differs from the one that I Children. have given until he reaches adult life, with the exception of desserts, which I will mention later. This diet really contains all the necessary kinds of food, and allows considerable latitude, so that it is really sufficient, as far as that is concerned, for the adult. It should 
not differ from this one under any circumstances, until the school age is reached. When the child starts going to school, however, it may not be practicable to continue with the hearty meal at noon and the light supper. At the same time I believe that this is still the best plan if it is possible to carry it out. When the hearty meal must be given at night, the child should not go to bed for at least two hours afterward. It is also important that meat should not be given more than once a day until after the tenth or twelfth year. This makes the noon meal rather a slim one unless special care is given to it. Milk, custards, junkets, and hearty desserts made with milk and eggs often help to make the luncheon a nourishing one, so that the active child shall not go from early morning until a late dinner without sufficient nourishment.

Kinds of Bread to Give.

Bread should never be given when it is fresh or soft. It should be stale enough to crumble. It is best cut in squares and put into the oven until it is brown and hard all the way through. Do not give it this way all the time, for the monotony soon sickens the 
child of it. Vary the kinds of bread with white bread, whole wheat bread, graham bread, rye bread, and bran biscuits. Crackers are also a good addition to the starchy foods. Hard-tack, soda crackers, oatmeal crackers, graham crackers, egg biscuit, rice and arrowroot wafers, with an occasional sweetened cracker for dessert at supper, are allowable. Never give hot bread, hot muffins, doughnuts, griddlecakes, or waffles.

Cereals are good for the child, but one cereal meal a day is enough, and that is best at in the Diet. breakfast. Cereals may be cooked in milk or water. They should always be well cooked; one to three hours, according to the coarseness of the grain. Undercooked cereals are the source of much stomach disturbance. It is therefore well to cook them the night before, as they are apt to be underdone when hastily cooked for breakfast. Cream of wheat, rolled oats, wheatina, farina, gritz, cornmeal mush, rice and hominy, are all healthful. Teach the child to eat them without sugar, but with plenty of milk and some cream, and he will like them just as well as though they were sweetened. In the 
first place, sweetened food at the morning meal is apt to take away the appetite for the rest of the meal, and in the second place it is well to teach the child to like the cereals for their own taste. The so-called ready cooked cereals should be reserved for children over two years of age.

Vegetables supply the Necessary Iron.
Vegetables are a necessity in the diet because of the fresh element they supply and on account of the iron they contain. Babies are born with enough iron stored in the liver to last them during the first year, for a minimum amount is supplied in the breast milk and cow's milk. So we begin early with the vegetables. Potatoes must be well cooked, either boiled, baked, or mashed, but never fried or scalloped. One other vegetable once each day at the hearty midday meal must be prepared. Peas, string beans, spinach, carrots, asparagus tips, beets, wellcooked winter squash, and boiled parsnips, are all suitable vegetables. Children should not be allowed cabbage, cauliflower, onions, shelled beans, tomatoes, lettuce, celery, turnips, or sweet potatoes until after the third or fourth year. The vegetables should always 
be cooked until they are soft, and mashed fine with a fork.

Meat is given sparingly at first. A tablespoonful of rare beef scraped with a fork is thoroughly mixed into the potato for the first week or two, after the eighteenth month. The quantity is gradually increased and the variety extended during the next month or two. The meat should always be cooked rare and not boiled, except chicken. It should be cut up very fine and mixed with the potato during the second and third years. The meats a child may eat are : beef - roast, broiled, or chopped Hamburger fashion; lamb - roast or chops ; chicken-roast, broiled, or boiled; veal - roast or broiled; fish-boiled; bacon-cooked dry and eaten in the fingers at two and one half years. Never give pork, ham, sausage, liver, tripe, or thickened gravies.

Eggs should be given boiled, coddled, Eggs. dropped in water, and, after two and one half years, hard boiled. The whites should be soft and jellylike instead of tough and leathery. In order to do this, put them into cold water, and place them upon the stove until the water comes to a boil, and then set them 
aside in the water for a few minutes. It sometimes takes many trials to get them just right, but a little practice soon teaches the beginner. Eggs should never be fried. Many mothers think their children cannot eat eggs, but this is rarely true. If the egg is not well borne, give a teaspoonful each morning until that much is well taken and gradually increase to larger amounts.

Soups not Important.

Soups I have not said very much about because I do not believe they are an important article of food. Thickened meat soups are indigestible. Clear broths and beef tea are mostly water and are given only to vary the diet, stimulate the appetite, and act as a vehicle in which bread and crackers may be eaten.

Simple Desserts are not given until the second year. Deserts recommended. Then they should be simple puddings sweetened, such as, bread pudding, rice pudding, blancmange, gelatine puddings, farina, ice cream, soft and hard custards, sponge cake and lady fingers dry or with whipped cream, angel cake, sweetened crackers, and fruits raw or cooked. No other cake or pastry is allowed until after the child is twelve years 
old. Butter, lard, or suet cooked into any food is indigestible, and that is why the usual pastry, rich cake, and cookies are ruinous to the digestion.

Children seem to crave sweets, but I am not one of those who believe that this craving

Craving for Sweets not Normal is normal and should be catered to. I do know, however, that from a practical standpoint more indigestion and ill health is caused among children by eating sweets than by any other one article of diet. A moderate amount of candy usually does io harm, but moderation is difficult to achieve. Friends and relatives always see to it that the supply is not lacking, and it is far easier to lay down rules than it is to carry them out. Candy may, however, be allowed after the second year, once or twice a week, one or two pieces after dinner, provided the dessert has not been a sweet one. Sugar takes away the appetite because it is a very concentrated form of nourishment. For the same reason it harms the digestion. Children who have poor appetites should have no sweets nor desserts whatever.

Cut fruits, berries of all kinds either cooked 
The Eating or uncooked, make good desserts. Bananas of Fruits. are the only fruit I exclude from the dietary. Under two years fruits, such as apples, pears, and peaches, should be scraped with a spoon. Berries should not be allowed, until the latter part of the second year. It is a false idea that children will not digest uncooked fruits. If they are carefully given and not swallowed in great pieces which have not been mashed - or scraped, or well masticated, they are as digestible as cooked fruits. Cooked fruits must not be sweeter $d$ too much. If they are made sirupy with a lot of sugar, they are far worse than when given raw. The eating of fruits between the meals helps the bowels if the latter are inclined to be constipated. It also puts something into the stomach while the child is becoming accustomed to longer intervals between feedings. Once the taste for fruit is acquired, a child is just as well pleased with it as with cake and candy, and it does him no harm. For this reason I encourage the eating of fruits as much as possible. Oranges are best eaten with the spoon until the third year, so that the toughest part of the pulp will not be swallowed. 
Cut the orange in half and dig out the soft part as well as the juice. An apple can be most easily scraped if it is cut in half with the skin on, and the core dug out with a spoon. The skin then makes a cup out of which the rest of the apple is scraped so that there are no hard pieces whatever.

\section{DIET FOR SICK CHILDREN}

As a rule I do not believe that sick children ought to be made to eat things that are distasteful to them. It is no time to teach the child to cultivate a taste for any article of food, when he is ill. Another mistake that is often made, is to try to force sick children to eat. Occasionally, especially during a prolonged illness, this is necessary, but as a rule it is not. Still another error that is apt to occur, is in allowing the child to drink large quantities of milk at irregular intervals during the illness. Especially if there is any fever, the thirst is apt to be excessive and milk is taken in place of water to quench the thirst. It is a very good idea to stop the food altogether at the beginning of almost any sickness, especially where there is fever. 
Broths. Broths and soups are very good invalid's foods, but it must be remembered that, even when well made, they do not contain a great deal of nourishment. This may be a distinct advantage where it is advisable to avoid overtaxing the digestion. Beef, lamb, and chicken may be used. The meat is chopped up and allowed to stand in cold water for an hour or two, when it is put upon the stove and brought to a simmering heat of $160^{\circ} \mathrm{F}$., but never allowed to boil. After simmering in this manner for two or three hours, it should then be strained and set away to cool, so that the fat may harden upon the top, in order to get every particle of it off. It is absolutely impossible to get the grease off while the soup is hot. Bouillon capsules may be temporarily used to make the broth, where it is our purpose to give a weak food.

Gruels. Gruels help to take the place of milk, and are often more easily digested than milk. Especially during attacks of diarrhea, the gruels must be relied upon almost entirely for nourishment. When this is the case, it is best to vary the kinds of gruels, so that the child will not sicken of them. They should 
be made with water only, adding a little salt, but no sugar unless otherwise directed by the physician. Occasionally, however, they may be made with half milk and half water, if it is so ordered. The one essential point is to cook them long enough. If made of the different flours, they should be first mixed up to a thin paste with cold water, and the paste stirred into the proper amount of boiling water to which the salt has been added, and stirring vigorously until brought to an active boil. They should then be put upon the back of the stove, and allowed to boil gently for at least one half hour. Where the double boiler is used, gruels should be cooked for at least two hours. As a rule I do not approve of the double boiler, because this long cooking is apt to be neglected. I may mention as the different kinds of gruels : barley gruel, farina gruel, arrowroot gruel, cornstarch gruel, wheat flour gruel, cracker gruel, browned flour gruel, rice flour gruel, cornmeal gruel, and oatmeal gruel. The browned flour gruel is made by putting ordinary wheat flour into the oven and leaving it until it is browned all through, stirring it 
occasionally so that it will not burn. The browned flour is then made into a gruel. Oatmeal and cornmeal gruels should not be used in cases of diarrhea. Any of these gruels may be dextrinized or partially digested by adding a teaspoonful of Cereo to them after they are cool enough to taste. Dextrinized gruels are often well borne when other foods are rejected.

Bread Bread pap adds another variation to the Pap. sick child's diet. This is made by cutting thin slices of white bread and putting them into the oven until they are thoroughly browned through. They are then put into a saucepan and moistened with enough water to make a thick pap, thoroughly mixed up and put upon the stove and brought to a boil. Neither sugar nor milk should be added unless specially ordered.

Junket. Junket often takes the place of a more solid food, especially for older children. It is also more digestible than milk. It is made in the following manner: Put into a clean saucepan, one half pint of fresh milk, heat lukewarm, and then add one teaspoonful of essence of pepsin, or a junket tablet dis- 
solved in a tablespoonful of cold water. (The junket tablets may be bought at any grocery store.) Stir it just enough to mix the tablet with the milk, then pour it into small cups and allow it to stand until it is firmly jellied. A little flavoring may be added, or often a small amount of sugar, while the milk is heating. Egg junket may be made by stirring in with the milk a thoroughly beaten egg. These eggs add a greater nutrition value to the food.

\section{WATER}

Strange as it may seem, the giving of water to a baby is an important subject and one upon which there have been many false ideas in the past. In some of the leading obstetrical hospitals of the world it is the Water more harmful than bene ficial the first Few Days. custom to administer sweetened water to the new-born babe soon after he is born. This has been done for two reasons: first, to give the baby some liquid to prevent loss in weight during the first two or three days when he is not getting much nourishment from the breast; and second, for the laxative action of the sugar upon the bowels. Now 
the reasons that this procedure is not necessary are also twofold: first, it does not prevent the loss of weight; and second, the newborn babe never has any trouble in having the bowels move if he is let alone. On the other hand, the harm it does is to satisfy the baby so he will not take the breast well, his stomach being filled with sweetened water.

When The small amount of sugar water the Water may be Given. baby gets from the breast is sufficient until he has learned to nurse vigorously. Then, if he cries a good deal, he may be given a small amount of unsweetened water. If he does not cry, give him nothing except what he gets from the breast. After the flow of milk has set in, he will get sufficient water in the milk itself if the milk supply is right. As for the bottle baby, can you imagine a more foolish procedure than giving him a few teaspoonfuls of water when he is already getting a food which is 90 per cent water? A child who is getting a quart of liquids in twenty-four hours has far more water in proportion to his weight than does the adult.

Water for

But there comes a time when it is well to Older Children. 
so that he may learn to take things from the cup and spoon. At six months it is time to begin this training with a few teaspoonfuls. In this way gradually the baby learns to take a considerable quantity so that he is not a stranger to swallowing by any other method than sucking. The weaning is thus made easier. After eighteen months, the child is put upon a drier diet. $\mathrm{He}$ is usually thirsty and drinks a good deal of water of his own accord. If he does not, it should be offered to him at intervals throughout the day. 
9 


\section{PART VI}

\section{LISTS AND TABLES}





\section{LIST FOR EXPECTANT MOTHER}

A fountain syringe.

A bed-pan.

One or two enameled hand basins.

New rubber cloth, one and a half yards wide, two yards long, to protect mattress.

Pilch cloth, five yards (for bed pads).

Unbleached muslin, two yards long, eighteen inches wide (for mother's binders).

Plenty of towels.

Absorbent cotton, one pound package.

Braided silk (for tying the cord).

Large safety pins (two dozen).

Fluid extract of ergot, one ounce (bought one week before confinement).

Brandy, two ounces.

Antiseptic tablets (corrosive sublimate), one bottle.

Boric acid, powdered.

Sterile gauze (1 five-yard package).

\section{FOR THE BABY'S BASKET}

One pound of absorbent cotton.

Safety pins of assorted sizes.

A soft baby's hair brush.

A powder box containing powder and puff. Soap and soap box.

One fourth of a pound of boracic acid.

An old soft blanket in which to receive the child after birth.

A couple of soft towels.

A bath thermometer.

Scales. 


\section{CLOTHES}

Flannel bands

Knitted bands

Diapers

Shirts

Petticoats, flannel

Petticoats, cotton

Slips

Socks

Nightgowns

Jackets

Cloak

Hood

Mittens

Veil

Blankets

\section{TABLE OF HEIGHT}

AGE
1 month
2 months
3 months
4 months
5 months
6 months
7 months
8 months
9 months
10 months
11 months
1 year
2 years
3 years
4 years
5 years
6 years
7 years
8 years

AgE

1 month

2 months

3 months

5 months

6 months

7 months

8 months

9 months

11 months

1 year

2 years

3 years

years

5 years

6 years

7 years

8 years
Height

$20 \frac{1}{2}$ inches

21 inches

22 inches

23 inches

$23 \frac{1}{2}$ inches

24 inches

$24 \frac{1}{2}$ inches

25 inches

$25 \frac{1}{2}$ inches

26 inches

$26 \frac{1}{2}$ inches

27 inches

31 inches

35 inches

$37 \frac{1}{2}$ inches

40 inches

43 inches

45 inches

47 inches 


\section{TABLE OF WEIGHT}

$\begin{array}{cc}\text { AGE } & \text { WEIGHT } \\ 1 \text { month } & 9 \text { pounds } \\ 2 \text { months } & 10 \frac{1}{2} \text { pounds } \\ 3 \text { months } & 12 \text { pounds } \\ 4 \text { months } & 13 \frac{1}{2} \text { pounds } \\ 5 \text { months } & 15 \text { pounds } \\ 6 \text { months } & 16 \text { pounds } \\ 7 \text { months } & 17 \text { pounds } \\ 8 \text { months } & 18 \text { pounds } \\ 9 \text { months } & 19 \text { pounds } \\ 10 \text { months } & 20 \text { pounds } \\ 11 \text { months } & 20 \frac{1}{2} \text { pounds } \\ 1 \text { year } & 21 \text { pounds } \\ 2 \text { years } & 27 \text { pounds } \\ 3 \text { years } & 32 \text { pounds } \\ 4 \text { years } & 36 \text { pounds } \\ 5 \text { years } & 40 \text { pounds } \\ 6 \text { years } & 44 \text { pounds } \\ 7 \text { years } & 48 \text { pounds } \\ 8 \text { years } & 53 \text { pounds }\end{array}$

\section{NUMBER OF PULSE BEATS PER MINUTE}

At birth

At birth . . . . . . . . 130 to 150

First month . . . . . . . . . 120 to 140

1 to 6 months . . . . . . . . . 120 to 130

6 months to 1 year . . . . . . . . . 120

1 to 2 years . . . . . . . . . . . 110 to 120

2 to 4 years . . . . . . . . . . 90 to 110

6 to 10 years . . . . . . . 90 to 100

10 to 14 years . . . . . . . . . 80 to 90

\section{NUMBER OF RESPIRATIONS PER MINUTE}

For the first 2 or 3 weeks . . . . . . . . . 40

During the first year . . . . . . . . . . 30

1 to 2 years . . . . . . . . . . . . about 28

2 to 4 years . . . . . . . . . . about 25

4 to 15 years . . . . . . . 20 to 25 


\section{TABLE OF POISONS AND ANTIDOTES}

Poison

Antidotes

Acid, acetic, hydrochloric, An alkali, such as magsulphuric, nitric.

Acid, carbolic.

nesia, whiting, soda, soap, followed by soothing drinks or sweet oil.

Epsom salts in abundance, soap, no oil; for external burns, alcohol.

Acid, oxalic.

Emetic, followed by lime (as chalk, plaster, whiting) or magnesia, but not by potash or soda; then soothing drinks.

Aconite.

Emetic, followed by digitalis; no pillow under head; free stimulation.

Alcohol (brandy, etc.).

Emetic; cold douche on head; warmth and artificial respiration.

Alkalies (as ammonia, Vinegar or lemon juice, lye, caustic, potash). followed by soothing Ammonia (see Alkalies) drinks or sweet oil.

Arsenic (Fowler's solution, Paris green, "Rough on Rats").

Atropine (see Belladonna).

Belladonna (atropine).

Blue vitriol (see Copper).

Emetic; followed by a fresh mixture of the tincture of chloride of iron with calcined magnesia, or baking soda, or water of ammonia; then white of egg, soothing drinks, or sweet oil ; castor oil to empty bowels.

Emetic; tannic acid freely; cold to head; coffee; stimulants and warmth if needed.

Carbolic (see Acid). 
Caustic (see Alkalies).

Chloral.

Copper (blue stone, blue vitriol, verdigris).

Corrosive sublimate.

Gas (illuminating gas, coal gas).

Hydrochloric acid (see Acid).

Iodine.

Laudanum (see Opium). Lye (see Alkalies).

Matches (see Phosphorus). Morphine (see Opium). Nitric acid (see Acid). Nux vomica (see Strychnine).

Opium (including laudanum, morphine, paregoric, soothing sirups, etc.).

Oxalic acid (see Acid). Paregoric (see Opium). Paris green (see Arsenic).
Treatment as for opium poisoning.

Emetic, followed by white of egg or milk; yellow prussiate of potash; then soothing drinks.

Emetic, followed by white of egg or milk; soothing drinks; tannic acid freely; castor oil to open bowels.

Fresh air ; artificial respiration; ammonia to nostrils; cold douche.

Starch or flour mixed with water, given freely; emetic; soothing drinks.

Emetic (often not effective); permanganate of potash in doses of 4 or 5 grains if case is seen early; strong coffee; atropine; keep awake by cold douche to head and back, walking, and artificial respiration. 
Thosphorus (match- Emetic; then permanheads, some roach and ganate of potash in doses rat poisons). $\quad$ of 4 or 5 grains well diluted; Epsom salts or magnesia to open bowels;

Potash (see Alkalies). no milk or oil of any kind. Rough on Rats (see Arsenic).

Silver nitrate (lunar caustic).

Table salt, followed by emetic; milk or white of eggs.

Strychnine (nux vomica).

Sulphuric acid (see Acid).

Emetic, followed by tannic acid, bromide of potash freely, or chloral. 


\section{Record of Weight the First Year}

Name

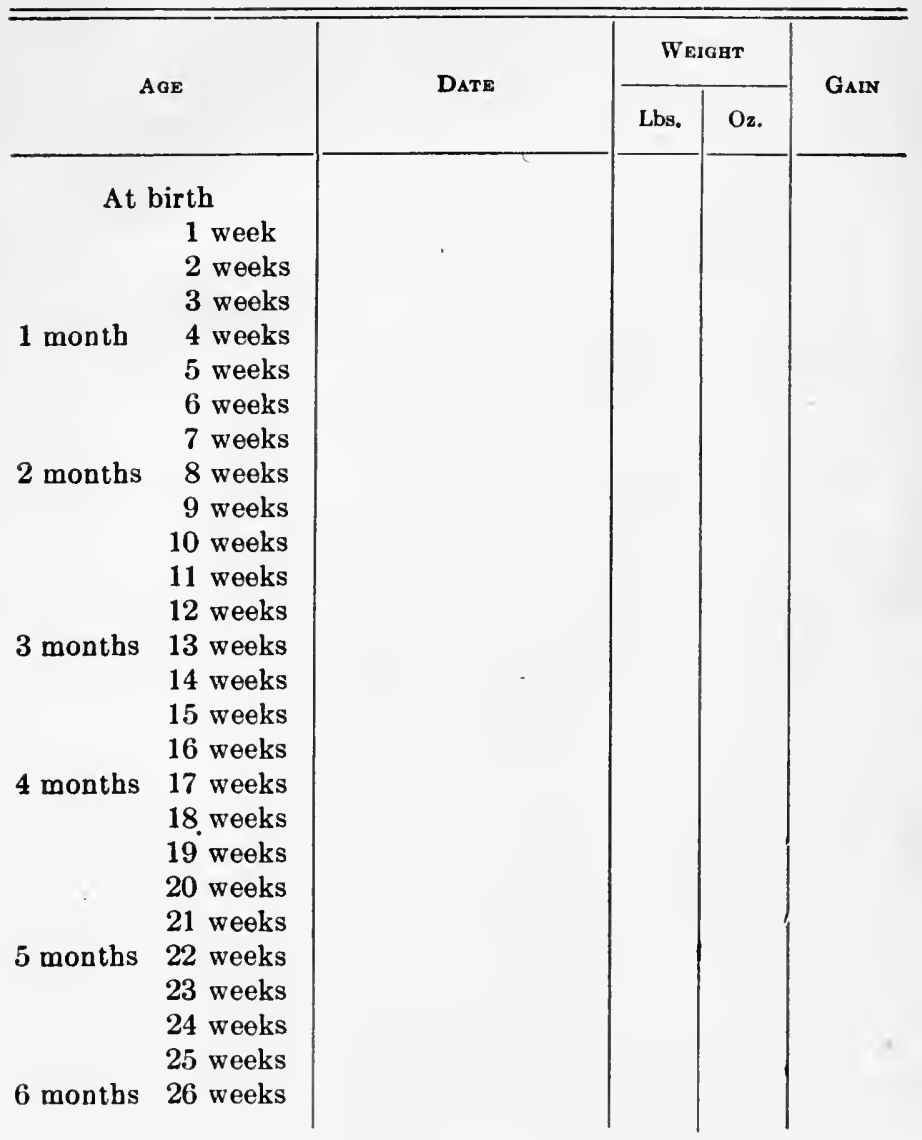


Record of Weight the First Year (Continued)

Name

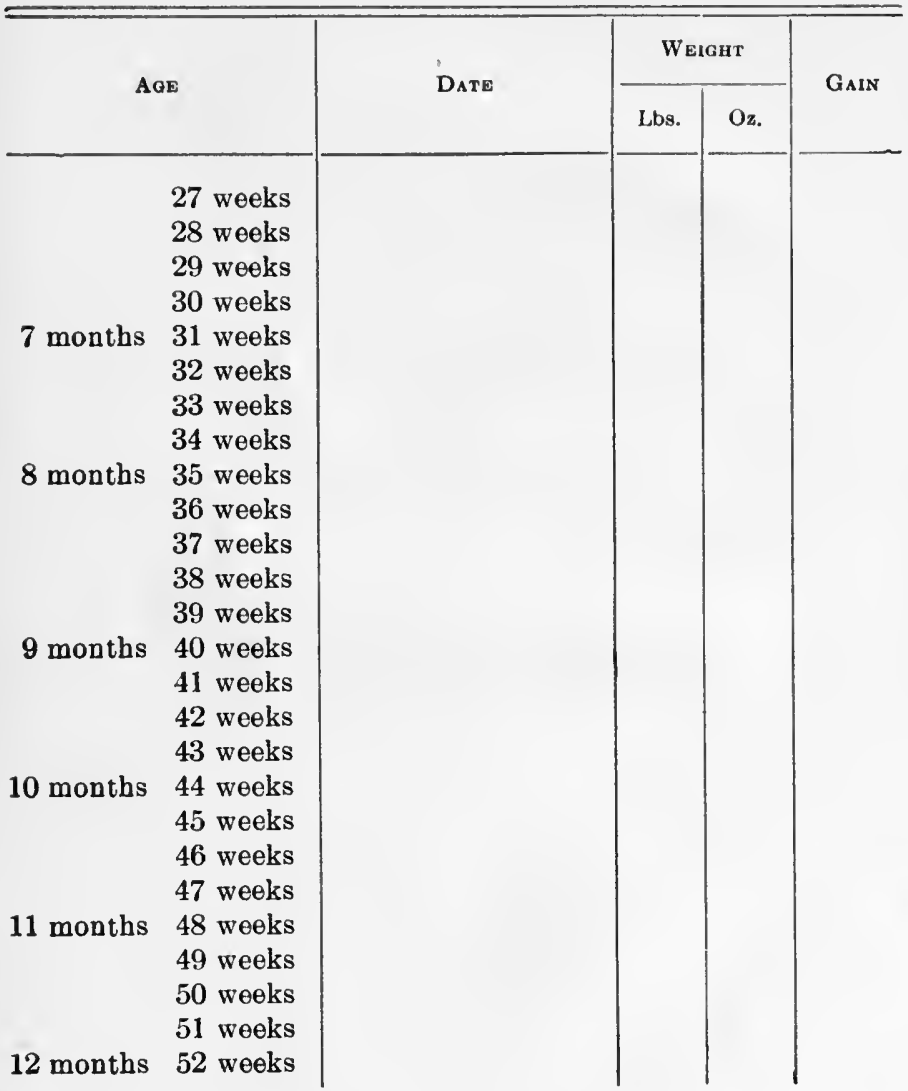


Record of Weight after the First Year

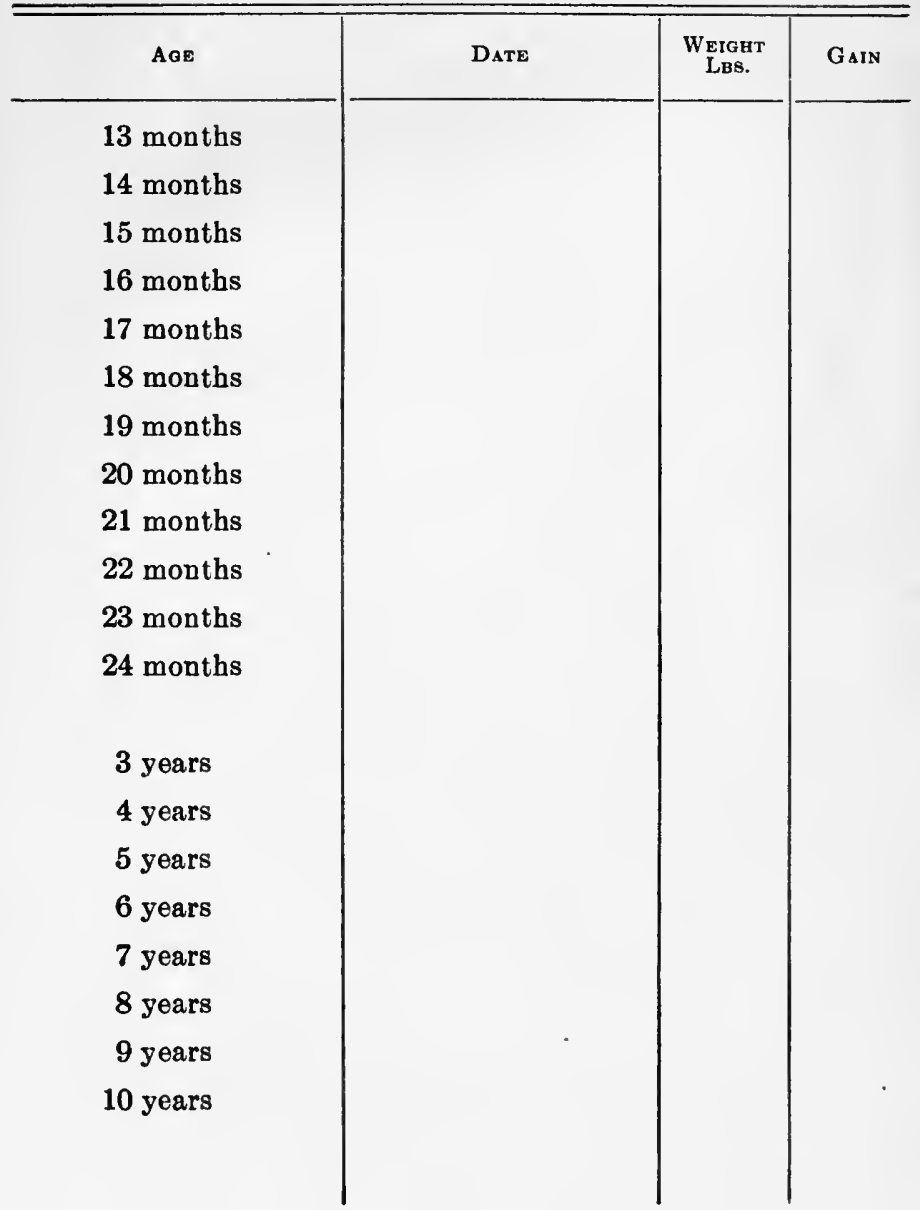




\section{Record of Bottle Baby's Food}

Date

.oz. Milk

oz. Water

_oz. Sugar
Age.

Quantity at Each Feeding _-_..._oz.

Number of Feedings in $24 \mathrm{hrs}$.

Intervals between Feedings..._._.hrs. _oz. Total quantity in $24 \mathrm{hrs}$.

Bowels

Number.

Appetite
Color. Sleep
Consistency Vomiting.-..-..-.
Date.

oz. Milk

oz. Water

oz. Sugar

\begin{abstract}
Age.
Quantity at Each Feeding...--_oz.

Number of Feedings in 24 hrs.......

Intervals between Feedings.......hrs.
\end{abstract}

_oz. Total quantity in $24 \mathrm{hrs}$.

Bowels

Number.

Appetite.
Color

Sleep.
Consistency

Vomiting-........
Date.

........oz. Milk

_..._.oz. Water

....._oz. Sugar
Age

Quantity at Each Feeding.

Number of Feedings in $24 \mathrm{hrs}$.

Intervals between Feedings

hrs.

oz. Total quantity in $24 \mathrm{hrs}$.

Bowels

Number Appetite
Color

Sleep.
Consistency.

Vomiting. 


\section{Record of Bottle Baby's Food}

Date

.oz. Milk

_oz. Water

_oz. Sugar
Age.

Quantity at Each Feeding-_-_-_oz.

Number of Feedings in $24 \mathrm{hrs}$.

Intervals between Feedings hrs. -oz. Total quantity in $24 \mathrm{hrs}$.

Bowels

Number.

Appetite
Color

Sleep.
Consistency Vomiting.
Date.

-._-_oz. Milk

-.._-_oz. Water

_....oz. Sugar

\begin{abstract}
Age.
Quantity at Each Feeding-_._-_oz.

Number of Feedings in 24 hrs.......

Intervals between Feedings...... .hrs.
\end{abstract}

Bowels

Number. Appetite.
Color

Sleep.
Consistency Vomiting-.
Date.

-.....oz. Milk

_..._._oz. Water

--.-_oz. Sugar

\section{Age}

Quantity at Each Feeding -..._oz.

Number of Feedings in $24 \mathrm{hrs}$.

Intervals between Feedings_._._._hrs.

\section{...-_oz. Total quantity in $24 \mathrm{hrs}$.}

Bowels

Number. Appetite
Color

Sleep.
Consistency.......... Vomiting ......-- 
MEMORANDA 
Held Head erect

Sat up Alone

Crept

Walked with Support

Walked Alone
Date....- Age_...

Date...-. Age.

Date.

Date......

Date.....-
Age......

Age.....

Age...... 


\section{Record of Talking}

First word, Notable sayings, eto. 


\section{Health Record}

Date

Duration

Notation

Date

Duration

Notation

Date

Duration

Notation

Date

Duration

Notation
Nature of Illness

Attending Physician
Nature of Illness

Attonding Physician
Nature of Illness

Attending Physician
Nature of Illness

Attending Physician 


\section{Teething Record}

First Tooth

2 Lower Central Teeth

2 Upper Central Teeth

2 Upper Lateral Teeth

2 Lower Lateral Teeth

2 Upper Double Teeth

2 Lower Double Teeth

$2 \frac{1}{2}$ Year-old Double Teeth

\begin{tabular}{|c|c|}
\hline Right._._._- & Left. . . . . \\
\hline Right_-_._- & Left_...... \\
\hline Right__._._. & Left.-. \\
\hline Right_-_._- & Left_-_. \\
\hline Right....... & Left.-. \\
\hline Right__-_... & Left _. \\
\hline
\end{tabular}

$\begin{cases}\text { Upper Right_.....- } & \text { Left....... } \\ \text { Lower Right_.....- } & \text { Left......- }\end{cases}$ 
MEMORANDA 


\section{INDEX}

Abdomen, 9.

Abscess of breast, 152. of ear, 133.

Accidents, 101.

Adenoids, 121. cause of, 122 .

cause of bed-wetting, 109 .

in infancy, 124.

symptoms of, 123.

Airing, 55.

indoors, 56.

of sick room, 79 .

Alcohol bath, 91.

Anger in discipline, 64.

Angry cry, 17.

Antidotes for poison, 108, 210.

Antitoxin, 84.

Anti-vaccinationists, 86 .

Appetite, 20.

excessive, 23.

lack of, 184.

loss of, in infants, 21.

loss of, in older children, 22. Awakening baby for food, 12 .

Baby's basket, 207.

Baby carriage, 57-59.

Baby comfort, 73, 122.

Backward children, ears in, 132.

Backwardness from defective eycs, 131.

Bad air, 53.

Bananas, 196.

Band, 41.

Barley gruel in infant feeding, 172 .

Bath, 49. in fever, 52-91.

temperature of, 51 .

thermometer, 51 .

time of, 52 .

tub, 49.

when omitted, 52 .

Beans in nose, 104.

Bed, the, 16.

Bed-wetting, 73, 109.

eauses of, 109.

- punishment for, 112 . treatment of, 111.

Belly, 9.

Belly-band, 41.

Berries, 195.

Blankets, 41, 45.

Bleeding from nose, 103.

from wounds, 102.

Blindness, cause of, 130 .

Body, development of the, 8 .

Boiled milk, 167. for traveling, 182.

Bones, broken, 103.

Bonnet, 48.

Bottles, 162.

brush, 163.

care of, $162,170$.

cleaning of, 163.

cover, 171.

feeding, 172 .

rack, 163.

selection of, 162 .

Bouillon capsules, 198.

Bowels, 28.

habits of, 30 .

nursing mother, 150.

regular habits of, 28 . 
Bowel troubles, cause of, 166. Bread, 190. pap, 200.

Breast abscess, 152.

Breasts, care of, 152.

Breast feeding, 147. bottles in, 152. duration of, 159,161 . intervals of, 154 . number of, 155.

Breast Milk, 147. and mother's bowels, 150. weaning, 155.

Broths, 198.

Bruises, 103.

Burns, 107.

Calomel in diarrhea, 37. in vomiting, 26 .

Candy, 195. cause of poor appetites, 21 .

Cane sugar, 173.

Castor oil in diarrhea, 37.

Cathartics, abuse of, 32 . in diarrhea, 37.

Celluloid gloves for finger sucking, 74 .

Cereals, 191.

Certified milk, 167.

Chamber for evacuation of bowels, 30 .

Chapping, 135.

Chicken pox, 86 .

Choking, 105.

Circumcision, 140.

Citrate of magnesia, 27.

Clothing, 41, 208 . for older children, 47. in summer, 46. restriction from, 59 .

Coins swallowed, 106.

Colds, 53.

beginning of measles, 84 .

cause of, 87.

treatment of, 94 .
Colic, 18, 152.

Complexion, 135.

Condensed Milk, 183.

Constipation, 31. cause of bed-wetting, 109. fruit in, 33 .

in bottle-fed infants, 31 . in breast-fed infants, 31 . in older children, 32 . massage in, 33. vegetables in, 33 .

Consumption, 88 .

Contagion, 81.

Contagious diseases, 81 .

Convulsions, 98 . causes of, 99 . genitals in, 140. treatment of, 100.

Coughs, 92. cause of, 87 . nervous, 116.

Cracked nipples, 153.

Crackers, 190.

Cream, 172.

Creeping, 4.

Cross-eyed children, 131.

Croup, 95. kettle, 97. treatment of, 96.

Crying, 17.

"Crying it out," 16. normal amount of, 18.

Curds in stools, 29.

Cuts, 102.

Cutting the hair, 137.

Daily routine, 68 .

Deafness from adenoids, 122 .

Decayed teeth, 128.

Defective speech, 7 .

Delayed talking, 6 .

Delayed teething, 125.

Delicate Child, exercise for, 61 . fresh air for, 57.

Dentistry, importance of, 129. 
Desserts, 194, 190.

Development, 3.

Dextri-Maltose, 173.

Dextrinized gruels, 200.

Diapers, 43.

the discarding of, 6 .

wetting of, 72 .

Diarrhea, 34.

from improper feeding, 35 .

from teething, 36 .

treatment of, 37.

Diet after the first year, 183. cause of bed-wetting, 109 . cause of poor appetite, 22. for nursing mother, 149 .

for sick children, 197.

in bed-wetting, 112.

in weaning period, 185 .

of first year, 172 .

one year to 14 months, 186 .

at 14 months, 187.

15 to 18 months, 187.

18 months to 2 years, 188 .

older children, 189.

school age, 190.

the third year, 189 .

Diphtheria, 84.

Discipline, 62.

Draughts, 17, 53. .

Drawers, 45.

Dress, the, 43.

Drinking cups, 87.

Ears, 132.

abscess of, 133.

foreign bodies in, 104 .

laps, 48.

protruding, 132.

washing of, 132.

Earache, 133.

treatment of, 134.

Eczema, 136.

bath in, 52 .

Egg8, 193.

Emergency supplies, 101.
Emetics, 108.

Entertaining the baby, 8.

Epilepsy, 98.

Eruption of teeth, 124.

Eruptions, 82, 135.

Examination of the throat, 121.

Exercise, 58.

for delicate child, 61 .

Expectant mother, list for, 207.

Eyes, 130.

care of, 130.

foreign bodies in, 106.

routine examination of, 181 .

Fat babies, 9.

Feeding, 172.

breast, 147.

formulas, 176.

for newborn baby, 178.

for traveling, 182.

gruel in, 172.

intervals of, 69, 175 .

number of, 155, 174, 175.

of sick babies, 180 .

quantity of, 177.

record of, 216.

sugar in, 173.

tabulated scheme for, 176.

Fever, 90.

bath in, 52 .

treatment of, 91.

Finger sucking, 73.

Fire escape, airing on, 69 .

First teeth, 124.

Fly, the, 88.

Fontanel, 9.

Food for traveling, 182.

monotony of, 23.

Forcing, 3.

Foreign bodies, in ear, 104.

in eye, 106.

in nose, 104.

in throat, 105.

swallowed, 106. 
Foreskin, 140.

Formulas, feeding, 176.

Fractures, 103.

Fresh air, 53. at night, 17. for delicate child, 57 .

Fretful babies, 62, 70 .

Fretful children, 20.

Fretful cry, 17.

Fruits, 188, 195. in constipation, 33. uncooked, 196.

Gain in weight, 10 . Genital organs, 139. German measles, 86 . Gruels, 198. dextrinized, 200. in infant feeding, 172.

Gums, care of, 128 . in teething, 126. lancing of, 127.

Gymnasium work, 61.

Habits, 71. of crying, 19. spasms, 115.

Hair, 137. cutting of, 137.

Handling in babyhood, 62 .

Happiness, 68.

Hardening, 48. process, 92 .

Head, 8.

Headache from eyes, 131.

Health record, 222.

Height, 8. table of, 208.

Hemorrhage, 102.

Hoarse cry, 18.

Hot bath in convulsions, 101.

Hunger, 17, 18. natural, 20.

Hysteria, 116.
Ice cap in convulsions, 100. Imagination, 66 .

Inattention, 123.

Indigestion, 18.

Infant feeding, 172.

Infection from wounds, 102.

Intervals of feeding, 154 .

Jacket, 43.

Jaw, deformed, 122.

Junket, 200.

Kindergarten, 8.

Kissing, 87.

Knitted band, 42 .

Lancing the gums, 127.

Layette, 208.

Leggings, 47.

Length of body, 8 .

Lisping, 7.

List for baby's basket, 207.

List for expectant mother, 207.

Lists, 207.

Lying, 66.

Malaria, 88.

Malt liquors for nursing mother, 151.

Malt sugar, 173.

Massage in constipation, 33 .

Masturbation, 141.

Mattress, 17.

Measles, 83.

Meat, 193.

Medicines, as poison, 108.

Memoranda, of talking, 221. of events, 220 .

of weights, 213.

Menstruation, milk supply during, 160.

Mental development, 7 .

Milk, 165.

Milk, bacteria in, 166 . 
Milk, boiled, 167. boiling of, 179 . breast, 158 . cause of diarrhea, 34 . cau. of tuberculosis, 90 . certified, 167. condensed, 183. crust, 138. for nursing mother, 151 . for sick children, 197. from herd, 168. modification of, 172 . pasteurized, 167. production of, 165 . rule for mixing infants', 174. sugar, 173. temperature of, 171. too much, 23.

Minu, the development of, 7 . Mixing of babies' foods, 168 .

Modified milk, 172.

Moist air, 93.

Mosquitoes, 88.

Mouth breathing, 121.

Mouth, care of, 50 .

Mucus in stools, 29.

Muffins, 191.

Mumps, 86.

Mustard flour $t$ ause vomiting, 109.

Mustard foot bath, 100.

Nail biting, 74 .

Naps, 13.

Navel, 9.

Nervous child, 115. treatment of, 117.

Nervous cough, 116.

Nervous mothers, 149.

Nervousness, 115. genitals in, 140 .

Newborn baby, feeding, 178.

Night clothing, 45, 49.

Night cry, 18.

Nightgown, 43.
Nipples, care of, 152, 162.

selection of, 162 .

shield, 153.

soreness of, 153.

Nose, foreign bodies in, 104.

Nosebleed, 103. from adenoids, 123.

Nursing, 147. in sickness, 80 . intervals of, 154. mother, 148. mother, diet for, 149. mother, exercise for, 148 . mother, illness in, 159.

Orderliness, 72.

Outdoor airing, 55.

Overdressing, 46.

Pain cry, 18.

Pasteurized milk, 167.

Patent foods, 181.

Pebbles in nose, 104.

Permanent teeth, 127.

Petit mal, 99.

Pillow, 17.

Pimples, 135.

Pinning blanket, 42.

Pinworms, 114.

Playing with baby, 62 .

Poisons, 108, 210.

Poor appetites in infants, 20.

Poor sleepers, 15.

Powder, common toilet, 134.

Prepuce, 140.

Prickly heat, 136.

Prominent ears, 132.

Proprietary foods, 181.

Protruding ears, 132.

Protruding navel, 9.

Pulse, table of, 209.

Punishment, for bed-wetting, 112.

of children, 65 . 
Question asking, 67 .

Rainy-day airing, 56.

Record, of feeding, 216.

of health, 222 .

of teething, 223.

of weight, 213.

Rectum, fissures, polypi, prolapses, 33.

Regurgitation, 24.

Respirations, table of, 209.

Restless sleepers, 15, 17.

Restless slceping, adenoids in, 123.

Rickets, cause of delayed teething, 125.

Rocking, 16.

Rompers, 45.

Routine, 68.

Rubber diapers, 44.

Rubbers, 49.

Rupture of the navel, 9.

Safety pins, swallowed, 106.

Scales, 11.

Scalp, 138.

Scarlet fever, 82 .

Schedule for the day, 69 .

School age, diet at, 190 .

School for nervous children, 117.

Schools, inspection of, 88 .

Schoolrooms, ventilation of, 58 .

Scraped apple, 197.

Scurvy, 168.

Second summer, 36.

Second teeth, 127.

Sedentary children, 60 .

Shampoo, the, 137.

Shield for nipples, 153.

Shirt, 42.

Shoes, 48.

Showing off, 5 .

Sick room, 79.

conduct, 80 .
Sitting alone, age of, 4 .

Skin, 134.

Skirt, 42.

Sleep, 12.

for nervous children, 18 .

and adenoids, 123.

Sleeping, out of doors, 14, 57 .

Sleeping room, temperature of, 55 . ventilation of, 55 .

Sleeplessness, 13, 15 .

Slip, the, 43.

Smallpox, 86.

Soap for bathing, 134.

Socks, 43, 48.

Sore nipples, 153.

Sore throats, 95.

Soups, 194, 198.

Sour milk, 166.

Speech, 6.

defective, 123.

Spoiled children, 20.

Spoiling the baby, 62 .

Sponge, 51.

Sprays for throat, 121.

Sterilizing wounds, 102.

Stockinette nightgown, 43.

Stomach, attacks, 26.

worms, 11'

Stools, 28.

number of, 28 .

of bottle-fed baby, 29 .

of breast-fed baby, 28 .

Story telling, 66 .

Stuttering, 7.

Sucking, 73.

Sugar, cane, 173.

for older children, 195.

in bottle feeding, 173 .

malt, 173.

Summer complaint, 35 .

Summer teething, 126.

Supplies for accidents, 101.

Swallowing of foreign bodies, 105-106. 
Sweets, 195.

cause of a poor appetite, 21 .

Table, of height, 208.

of poisons and antidotes, 210 . of respirations, 209.

of weight, 209.

Talking, 6 .

memoranda of, 221.

Tapeworms, 114.

Teasing, 66.

Teeth, 124. care of, 128.

number of, 125 .

protruding, 130.

second, 127.

Teething, 126.

and diarrhea, 36.

cause of convulsions, 99 .

record, 223.

Temperature of bottle feedings, 171.

of living rooms, 54 .

Testicles, undescended, 142.

Thermometers, 90, 51 .

Thirst in sick infants, 21 .

Threats, 64.

Throat, 121.

foreign bodies in, 105 .

Tics, 115.

Toothbrush, 128.

Top milks, 172.

Tonsillitis, cause of, 123.

Tonsils, 121.

cause of enlarged, 122.

Trained nurse, 80.

Training, 62.

lack of in bed-wetting, 110 .

Truthfulness, 66.

Tubcrculosis, 88.

Twitching, 115.

Underclothes, 42.

Underfed babies, 19.

Urine, retention of, 142.

Vaccination, 86.

Vegetables, 192.

in constipation, 33.

Ventilation, 53,54 .

of schoolrooms, 58.

of sick room, 79 .

of sleeping room, 55 .

Visiting, 5.

Vomiting, 24

from poisons, 108

habitual in infants, 25.

of infants, 24.

sudden or acute, 25.

Vomitus, green or yellow, 27.

Walking, 5, 59.

Walker-Gordon Milk, 182.

Water, 147.

in diarrhea, 37.

in fever, 91.

in older children, 202.

in vomiting, 37 .

Weaning, 155.

diet in, 185.

from bottle, 162 .

reasons for, 156 .

Weight, 10.

guide to weaning, 156 .

record, 213.

table of, 209.

Wetting, drawers, 113.

the bed, 109.

Whooping cough, 85 .

Windows, 17.

Wine for nursing mother, 151.

Worms, 113.

cause of bed-wetting, 109 . common cause of convulsions, 99.

Wounds, open, 102. 


University of California

SOUTHERN REGIONAL LIBRARY FACILITY

305 De Nev Drive - Parking Lot 17 - Box 951388

LOS ANGELES, CALIFORNIA 90095-1388

Return this material to the library from which it was borrowed. 
UC SOUTHERN REGIONAL LIBRARY FACIIITY

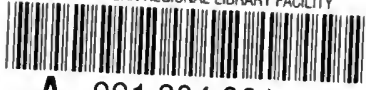

A 0013843610

SOUTHERN BRANGIM, U. TVERSITY OF CALIFORNI,

IBRARY,

GELES, CALIF. 
